Portland State University

PDXScholar

Summer 8-12-2013

\title{
Improving Assessment Practice at the Course and Programmatic-Levels in Community Colleges: Developing The Guidebook For Student Learning Outcomes \& The Assessment Loop
}

Steven George Beining

Portland State University

Follow this and additional works at: https://pdxscholar.library.pdx.edu/open_access_etds

Part of the Community College Leadership Commons, and the Educational Assessment, Evaluation, and Research Commons

Let us know how access to this document benefits you.

\section{Recommended Citation}

Beining, Steven George, "Improving Assessment Practice at the Course and Programmatic-Levels in Community Colleges: Developing The Guidebook For Student Learning Outcomes \& The Assessment Loop" (2013). Dissertations and Theses. Paper 1105.

https://doi.org/10.15760/etd.1105

This Dissertation is brought to you for free and open access. It has been accepted for inclusion in Dissertations and Theses by an authorized administrator of PDXScholar. Please contact us if we can make this document more accessible: pdxscholar@pdx.edu. 
Improving Assessment Practice at the Course and Programmatic-Levels in Community Colleges: Developing The

Guidebook For Student Learning Outcomes \& The Assessment Loop

by

Steven George Beining

A dissertation submitted in partial fulfillment of the requirements for the degree of

Doctor of Education

in

Educational Leadership: Administration

Dissertation Committee:

Thomas Chenoweth, Chair

Michael J. Smith

Gary Brown

Shawn Smallman

Portland State University

2013 


\begin{abstract}
This project-based dissertation described, in detail, a seven-step research and development $(\mathrm{R} \& \mathrm{D})$ process used to create, and bring to operational use, an educational tool that supported the academic use of the assessment loop: the Guidebook For Student Learning Outcomes \& The Assessment Loop. The dissertation established the problem that this product solved, provided relevant research, including a literature review, and the process and methods that led to the development of this useful product. It described the purpose of this specific guidebook and for guidebooks in general.

This project was informed by research of instructional design of text-based teaching materials, R\&D-focused field-testing procedures, assessment theory and practice, programmatic and online course assessment needs and practices, and use of Moodle as an assessment tool and evidence repository.

About the product: The guidebook is designed for use by Community College department chairs (DCs) and faculty members. It describes, from the viewpoint of a practitioner, each step in the process of assessment: from creating and measuring student learning outcomes (SLOs) to using assessment for improvement. It is hoped that use of the Guidebook by its intended audience will lead to more comprehensive assessment practices at the colleges where it is used.
\end{abstract}




\section{Dedication}

This project is primarily dedicated to my loving spouse, Jacqueline Elliott, who has supported my efforts over the past seven years by offering emotional and intellectual support. She listens to my long-winded explanations of educational and technical problems with patience and offers thoughtful responses. Thank you, Jackie, for helping me achieve this dream.

Secondarily, I owe a debt of gratitude to many of my colleagues at Clackamas Community College, who have provided practical advice as I work through the logistics of completing the work described herein. 


\section{Acknowledgements}

I offer thanks and owe a special debt of gratitude to Dr. Tom Chenoweth, Ph.D., my advisor and Dissertation Committee Chair. Dr. Chenoweth is the optimal guide, supporter, and academic advisor. Thank you, Dr. Chenoweth, for always being willing to entertain my countless questions, your unbelievable patience, your feedback, your supportive words at just the right moment, and your prompt responses to everything I have needed over the past few years. Thank you! 
TABLE OF CONTENTS
Abstract .. $\mathrm{i}$

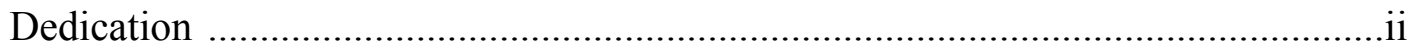
Acknowledgements ..................................................................................ii

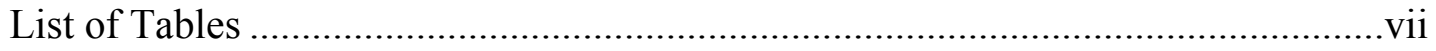

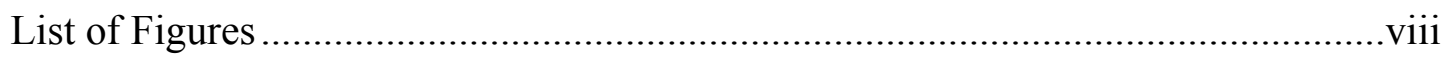

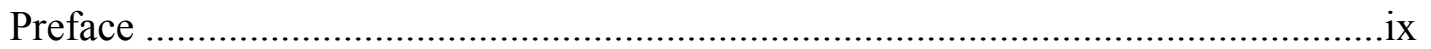

\section{CHAPTER}

1 STATEMENT OF THE PROBLEM ...............................................................

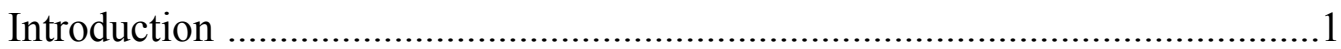

Statement of the Problem ...........................................................................

Purpose and Significance of the Problem ....................................................5

Significance of Supporting Assessment Reform .................................... 7

Significance of Supporting the Development of Direct, Course-Embedded,

Outcomes-based Assessment Practices ......................................................10

Significance of Support for Using the LMS More Effectively ....................12

Significance of Supporting Accreditation Efforts ......................................13

Research Methodology ....................................................................... 13

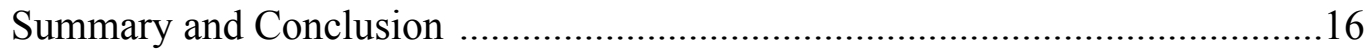

2 REVIEW OF RELATED LITERATURE ..................................................... 18

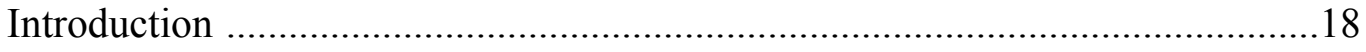

Knowledge Domains that Bear on these Problems .........................................19

Identification and Review of the Knowledge Domains Relevant to this

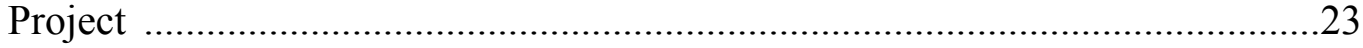

Practical And Scholarly Significance of the Problems and Rationales .............28

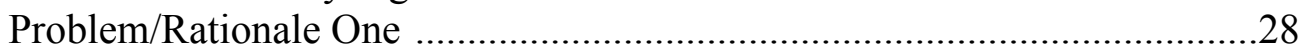

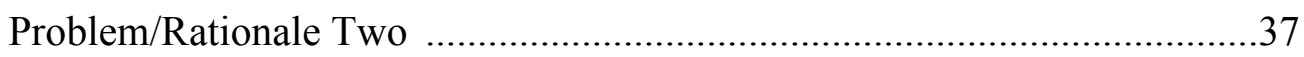

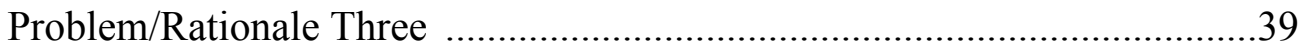




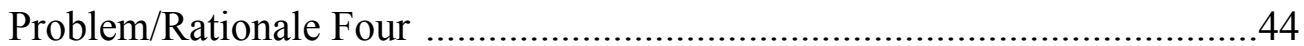

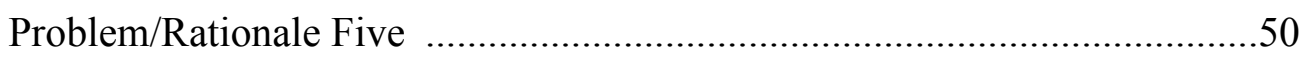

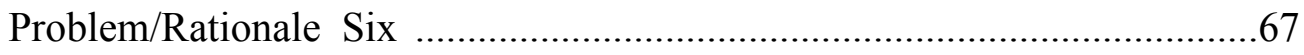

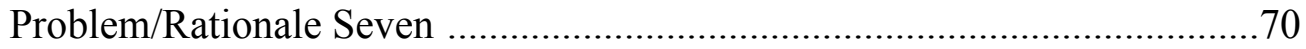

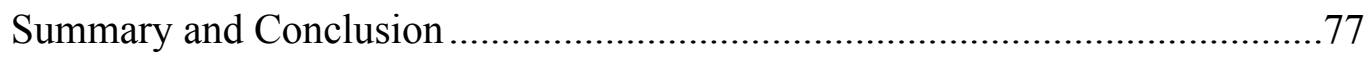

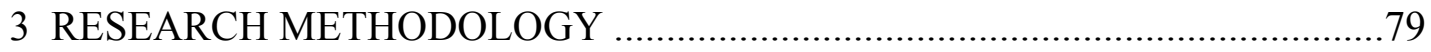

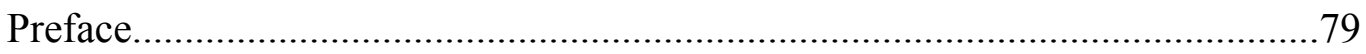

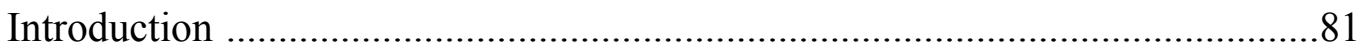

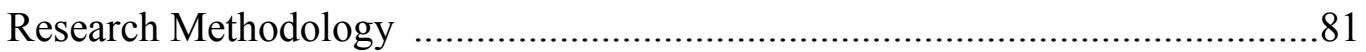

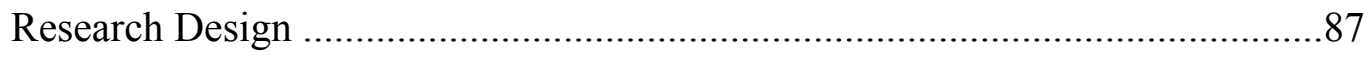

Step 1: Research And Information Collecting ...............................................8

Step 2: Planning Objectives, Learning Activities, And Small-Scale

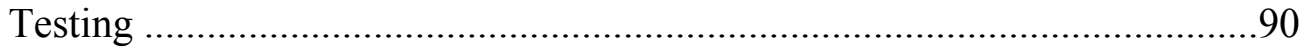

Step 3: Develop Preliminary Form Of The Product ......................................98

Step 4: Preliminary Field Testing ………………......................................99

Step 5: Main Product Revision ………………………...........................101

Step 6: Main Field Testing ......................................................................102

Step 7: Operational Product Revision ...........................................................104

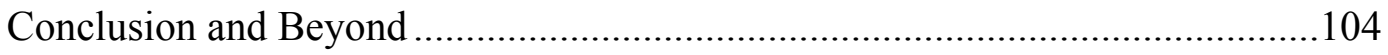

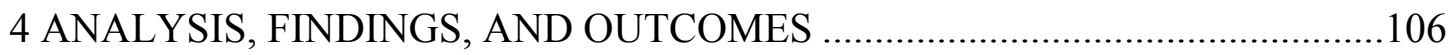

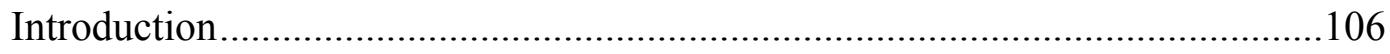

General Design of the Project and Review of Research Goals/ Questions.................106

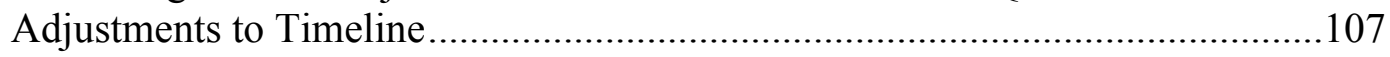

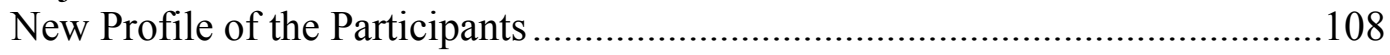

Re-development of the Surveys .................................................................108

A Refocused Product ………………………….........................................108

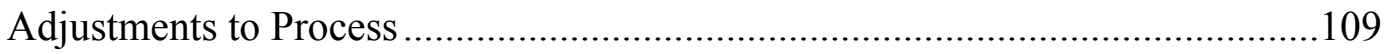

Steps of R\&D Process and Incremental Data Analysis .............................................110

Research and Development Process .............................................................111

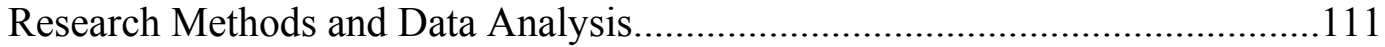

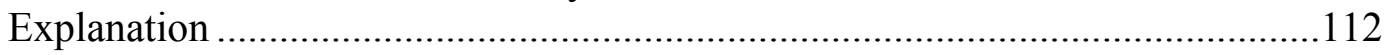


Step 1: Research And Information Collecting …………........................................113

Step 2: Planning Objectives, Learning Activities, And Small-Scale Testing ...........119

Step 3: Develop Preliminary Form Of The Product …………………....................132

Step 4: Preliminary Field Testing ……………………...................................137

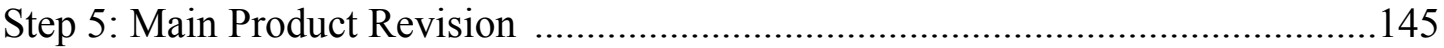

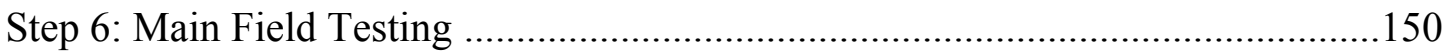

Step 7: Operational Product Revision ................................................................158

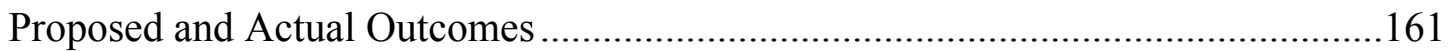

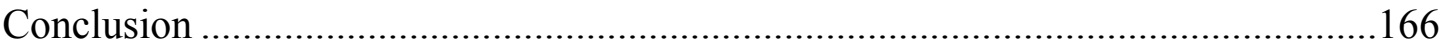

5 CONCLUSIONS, SPECULATIONS AND RECOMMENDATIONS ……..........168

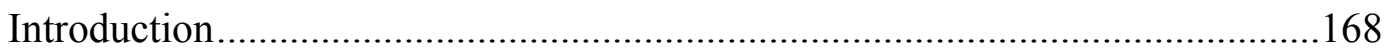

Overall conclusions and assessment of the experience......................................169

Professional growth of myself and others...................................................172

Role of Assessment Designer ....................................................................176

Speculation about future research, development, and use of the product.............178

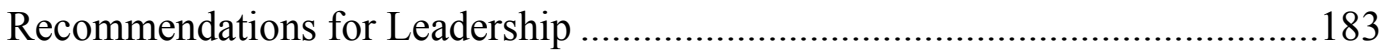

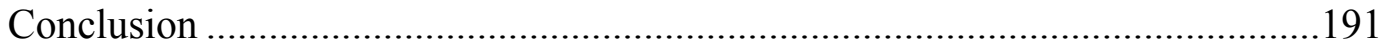

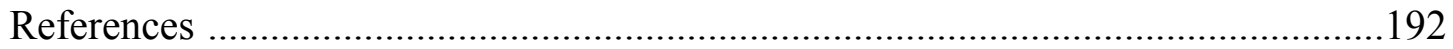

Appendices

A Adjusted Survey Questions ........................................................................201

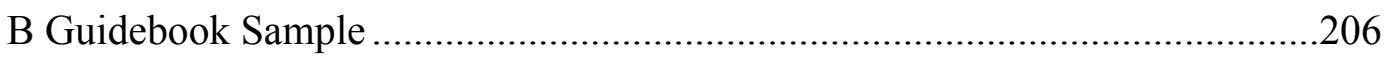


List of Tables

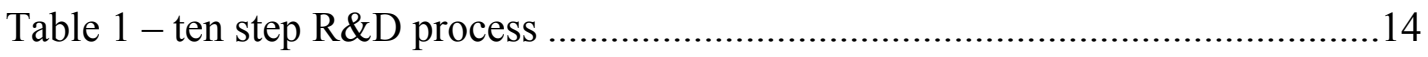




\section{List of Figures}

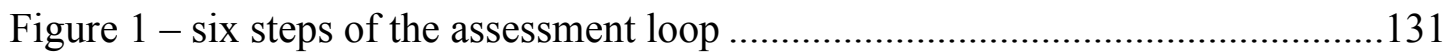




\section{Preface}

A role I fulfill at Clackamas Community College (CCC), as Department Chair (DC), is oversight of the Distance Learning (DL) Department and the Learning Management System (LMS). My work as the DL DC is focused on the resolution of technical issues related to systems management, online instructional design, management of designer/technologists, conversion of content from paper- to computer-based formats, and technology-related professional development activities. However, my ambition pushes me to strive beyond the role typical of a DL Coordinator; I strive to be a DL leader, who interacted closely with online educators, their content, and who wanted to help others to improve online pedagogy. I was eager to improve the DL program at my college. Since I was a Doctoral student in Education as well as a DL leader, I was uniquely situated to play a larger role within the institution and profession. My dissertation project led to the development of a resource that would help me, and other DCs, become more effective.

While I oversee the DL department, I do not oversee the DL program as a whole. Oversight of the program was distributed across the college with instructional DCs being tasked with ensuring quality of courses offered within their areas. As the DL DC, I reach out to engage instructional DCs in addressing problems that prevent optimal online teaching and learning from taking place, but participation by others is problematic. The expertise and levels of engagement of DCs with distance learning instruction and assessment varied widely, and their willingness and ability to gather and analyze data about student attainment of their particular program outcomes was mixed. I felt that as a 
DL and faculty leader that I should play a greater role in helping my colleagues do a more effective job in this area. I came to understand online pedagogy better than most higher education administrators (including, ironically, those tasked with faculty evaluation of online instructors.) By teaching others what I knew about online teaching/learning and focusing attention on assessment practice using Moodle through development of the Guidebook, I hoped to build awareness of best practices among DCs and, thus, to impact the program on a wider basis. This dissertation told the story of my efforts to accomplish this.

As I dove deeply into this project, I discovered more and more that assessment practice, in online and on-ground environments, could be problematic. As a member of the CCC Assessment Committee, I was engaged with college executives and faculty leaders in understanding current assessment practice and where we can improve. The committee examined our strengths to discern possible solutions and weaknesses to discern problems within the institution and, based on accreditation requirements, worked to develop plans and to implement institutional changes. Improving assessment practice was a priority for $\mathrm{CCC}$; the $\mathrm{CCC}$ Assessment Committee was tasked with making change within this domain happen. This was difficult work and it was acknowledged that achieving this aim would require shifting the way faculty viewed their work and significant training in new practices. Through my dissertation project, I attempted to provide solutions for particular problems faced by $\mathrm{CCC}$ in its efforts to change assessment practice. 
Two other aspects of assessment leadership emerged as I worked through this project. I discovered that the college had gaps in process and technical leadership. Therefore, in the context of developing the Guidebook, I took on increased leadership in providing training, consulting, and general support for effective assessment and technical support in assessment methodology and data analysis (Allen, 2005).

While we laid the groundwork for improvement, the committee struggled to move to the next level; i.e., getting widespread buy-in towards significant change in assessment practice and moving faculty to evidence-based assessment. The committee aimed to develop a culture that highly valued assessment, but had to also build awareness of and overcome resistance on the part of faculty in order to make the changes needed to achieve success.

It was here that the story of Instructor Mary Smith (Mary is not a real person; she is, rather, a fictional amalgam of several instructors at CCC) began. Mary was a faculty member at CCC. She earned her Masters Degree in Geology and began teaching introductory 100-level geology courses the next year. She had been teaching geology at CCC for ten years. As a graduate student, Mary was trained in the discipline of Geology. While she was a very knowledgeable subject matter expert, she admits that she was not a highly creative teacher. She teaches like she was taught. Mary was eager to better understand teaching and learning, but she was a busy person and did not have much time to attend the training sessions offered by the college's faculty leadership. She did not understand how to design and develop her own instructional materials. She compensated for this lack of instructional design prowess by taking the time to select well-written and 
comprehensive textbooks and relied on the textbook design to organize her courses. She was an engaging speaker and tended to lecture frequently. She used the assessments that were provided to her through Examview software to craft her assessments. At the college, Mary was hearing more and more about assessment and her awareness slowly built about this topic.

Early in 2007, Mary and her colleagues discussed a national report during a departmental meeting. Her DC talked about $A$ Test of Leadership: Charting the Future of Higher Education (2006), which discussed moving from a culture of teaching to a culture of learning. She was interested in the concept of improving student learning, but was unsure of what this meant.

Later in 2007 , her DC told her that college accreditation efforts would require that she articulate the student learning outcomes (SLOs) for her courses and include these in course outlines and syllabi. She was not sure what this meant, but attended a training session where she learned how to complete this task. She wrote up a list of the objectives she had for her courses and created a course outline; she added the outcomes to her syllabi and went on teaching her courses exactly as she had done before. She relied on student grades to indicate how students did in meeting the objectives she taught.

In 2008, her DC told her that college accreditation efforts would require that she work with her colleagues to identify the general education outcomes for science that the university could expect of students taking the science courses offered by the college. Her DC took the lead in this effort and brought back lists of outcomes that Mary and her faculty colleagues debated, adjusted, and finally agreed to support in their courses. She 
did not really understand how these broadly envisioned goals related to her courses. She viewed these efforts as intrusive and disruptive to her work as an instructor.

In 2009 and 2010, she learned that would need to align or "map" her course outcomes to those general education outcomes from the previous year and to show that her students were meeting the outcomes that the science department had agreed to. She would be asked to assess the learning outcomes that she had for her course and identify how many students in her courses had attained each outcome, which would be entered in a database along with her grades. Again, she relied on student grades to indicate how students did in meeting the objectives she was teaching. She determined the number of successful students by looking at how many passed her exams and coursework. Since she taught the outcomes in her courses, she figured that passing the courses meant that the outcomes were attained. Based on this, she tracked the numbers as the college expected.

In 2011, the DC began to ask Mary and her colleagues how they could be certain that students were learning the course outcomes. Mary explained that since she taught the outcomes in her course that she knew students who passed had attained the skills and knowledge she expected. The DC asked Mary to think about her teaching on a deeper level and if she were asked about a specific outcome if she could show students had learned the skill. She thought about it a while and realized that the skills and knowledge that pertained to particular outcomes were combined and were assessed all together through her exams. She also realized that sometimes she passed students who worked very hard, but who shallowly attained the outcomes. Some students attained some outcomes deeply, while not attaining others, but they had done well enough on her exams 
to pass. She realized that she probably could not show that each student had or had not attained a particular outcome. She began to understand what it meant to work in a culture of learning.

In 2012, the college embarked on a three-year project to require all course outlines to be revised and approved by the curriculum committee. The review panels charged with approval tasks scrutinized all course SLOs to ensure that they were measurable. Preliminary research for the R\&D of the Guidebooks described herein began with this project. A preliminary Guidebook for Course Outline Revision (also called Guidebook \#0) was created to support these efforts. The preliminary research that went into this product was described in chapters 3 and 4 of this dissertation.

As Mary worked on revising her course outlines to ensure the SLOs were measurable, she strove to learn more about assessment and how to measure each outcome more clearly and discretely. She asked her DC for more information about assessment. Her DC struggled to help Mary as she exhausted her own knowledge about assessment. In addition the college increasingly used technology to support learning. The DC knew that there were wonderful tools that could help with this work, but was unsure how to harness their power. The DC and Mary were using the Guidebookfor Course Outline Revision for guidance, but the process described therein was not complete. They asked the college for another Guidebook on Student Learning Outcomes \& the Assessment Loop to help. They relied on help from faculty leaders to support these efforts.

Many DCs struggled trying to help their faculty members keep up with the changes in assessment and accreditation. These Guidebooks were directed to them. 


\section{CHAPTER 1 \\ STATEMENT OF THE PROBLEM}

\section{Introduction}

This dissertation was focused on the research, development, and evaluation of a learning project that solved an instructional problem. Chapter 1 described this problem in depth. I described the purpose and significance of a project aimed at researching, developing, creating and refining a product, in this case, a guidebook for assessment practice reform: the Guidebook For Student Learning Outcomes \& the Assessment Loop aimed to address the problem. In the process of outlining this R\&D project, I itemized the outcomes and the rationale for the outcomes that I hoped to achieve in developing this project, along with methods that I attempted to use to understand, development and refine the product. I explored other noteworthy problems that I hoped to solve, at least partially, by engaging in a process of participating in this study at my institution. Key concepts and terms were defined, as well as the purpose and significance of this work.

I also attempted to situate the problems and the project within the larger context of the institution in hopes of helping the reader to understand why the particular solution I propose made sense and had a high probability of being successful.

\section{Statement of the Problem}

In the rapidly changing environment of higher education and instructional technology, Department Chairs (DCs) must play a role in shaping the future of their 
departments. Yet many DCs lacked a clear understanding of their role in leading institutional change (Lucus \& Assoc., 2000). Many chairs need better understanding of the practices of effective assessment leadership within their departments, particularly in the domains of distance learning and integration of technology (Lucus et al., 2000). Some DCs resisted engaging in this role due to the difficulty of achieving meaningful reform, lack of knowledge and/or confidence, and in limitations in available resources, such as time and funding. Yet, as DL continued to grow as a delivery method of instruction, this perception needed to change and an attendant emphasis on building the capacity of the DC to be successful in this role needed to occur.

In conjunction with this, institutional executives, such as presidents and deans, may not perceive or expect DCs to be assessment leaders at the institutional level or in helping the college meet accreditation goals; they may under-value and under-utilize the DC within this role. DCs needed to successfully demonstrate leadership in order to change these perceptions. DCs, especially inexperienced ones, needed help in building the skills of leadership required for assessment leadership.

Within the milieu of competing interests, there were factors internal to the institution that impacted the ability of DCs to lead reform efforts in the domain of distance learning assessment and the use of technology to support assessment reform. DCs lacked understanding of technology and its role in teaching, learning and assessment (Lucus et al., 2000); they lacked understanding in the theoretical foundations of assessment and nuances of assessment practice (Black \& Wiliam, 1998). 
Lucus et al., (2000) cited the costs of maintaining technology and the need for constant updating of skills as a barrier in effectively embracing technology within a department. The complexity of using advanced technology for non-instructional purposes, like collecting and analyzing large collections of evidence, were beyond the skill sets cultivated by most academics.

One of the recognized problems in effectively utilizing outcomes assessment was "having the needed expertise and skills on campus" (Serban, 2004, p. 23). Black and Wiliam (1998) had found problems and shortcomings in everyday assessment practice; practitioner understanding of and the underutilization of assessment were among the shortcomings they mention. Faculty members, including DCs, viewed their assessment role inconsistently; traditional faculty worldviews justified minimal participation in assessment activities (Murphy, 2006). Banta, Jones, and Black (2009) stated that faculty engaged in assessing SLOs in community colleges faced unique challenges, including understanding how assessment fits into broadly conceived institutional missions (for example, faculty needed to better understand the role of assessment in basic skills, career/technical and/or community education) and complexities of assessing a highly diverse student body. Gibbs and Simpson (2004) and Gibbs (2006) reported that resource constraints in higher education (reduced public funding, increased faculty/student ratios, etc) and the responses to these constraints (bundling sections together, increasing seat loads, etc.) led to decreasing quantity and quality of feedback that students receive in face-to-face and distance courses; these constraints impacted the quality of assessment 
more than the quality of other components of the institution, such as class contact and library facilities.

Within the milieu of competing interests, there were factors external to the institution that impacted reform efforts. Employers and parents demanded more highly educated and trained graduates. Governments were tasked with providing more nimble workers. Accreditation bodies and legislators were focusing greater attention on higher education assessment practices as they sought higher levels of institutional accountability. In efforts to define educational quality, accreditation demanded that institutions expand the scope of assessment practice from the classroom to the program or institutional level and use the results obtained for continuous improvement (Banta et al., 2009).

The tensions between these internal and external factors play out at the local level, in places like Clackamas Community College (CCC), where educators in real-world contexts grappled with these problems. These educators worked on the front lines where resources and constraints must be balanced in order to maintain the institution, and, ideally, move it forward. DCs were the leaders tasked with interpreting and translating these changing contexts into ideas and practices that could be adopted within their academic departments and the faculty members therein, and once this was accomplished, change could then move into the classroom. DCs were well placed to support the reform of assessment practices, not only at the course level, but also at the program level. Program review efforts often began with self-study and provided DCs opportunities to (re)engage faculty in discussion of departmental priorities (Ferren \& Mussell, 2000), 
including accreditation efforts. DCs must have quality data, which could be made available through technology-supported evidence collection, to conduct program reviews.

\section{Purpose and Significance of the Problem}

When viewed at the micro level, this project, through greater collaboration between me and instructional DCs, sought to solve problems related to DC understanding of the theory and practice of direct, course-embedded, outcomes-based summative and formative assessment in both face-to-face and online environments, use of computerbased tools that support assessment in online instruction, and use of methods to improve the collection and analysis of evidence through more extensive use of the Learning Management System (LMS).

When viewed more broadly, the project had the potential to solve other problems related to institutional change / improvement in the face of increased accountability and meeting stakeholder / policy-maker expectations for student achievement. These involved providing evidence and supports for persuasive arguments in favor of change.

More specifically, the Guidebooks helped DCs at my community college to take a larger, more mindful, role in supporting the reform of assessment practice. Not all members of the faculty understood the principles or ramifications of outcomes-based assessment, how to design curriculum that facilitated outcomes-based assessment, articulated the criteria for successful attainment of SLOs, or how to align instructional activities in order to create the conditions that allow valid and reliable measurements of SLOs. Ideally, the faculty collected evidence that validly measures that students have learned what we say our courses teach. The Guidebooks provided instructional materials 
that DCs used to a) address deficits in faculty understanding of outcomes-based assessment theory and practice and the role of evidence in program and course improvement, b) develop systems and methods to collect and store useful evidence, connect evidence to learning outcomes, extract and analyze assessment data, and to report the findings, and c) address deficits in skill sets needed to use computer-based assessment tools more effectively and efficiently. As Banta and Blaich (2011) found,

Assessment leaders should avoid doing presentations in which the data and conclusions are simply handed out to faculty. If faculty do not participate in making sense of and interpreting assessment evidence, they are much more likely to focus solely on finding fault with the conclusions than on considering ways that the evidence might be related to their teaching (p. 24).

Getting the DCs and faculty working jointly to understand and change assessment practices is a great way to support institution-wide change efforts.

The Guidebook d) taught strategies useful to help the faculty communicate the criteria for successfully attaining the SLOs of their courses and help students better understand what they must do to succeed. This communication formed the foundation for effective formative assessment practice. In addition, the use of the LMS made managing formative assessment easier to do.

Creating the conditions for students to successfully demonstrate their learning was key to the collection of valid assessment evidence. While there were many useful tools in Moodle that could be used to create assessment conditions, faculty had difficulty in matching the available tools to practical assessment needs; this problem was compounded by variations in assessment practices across the different disciplines. The Guidebook e) showcased the function of specific tools and connected these functions to assessment 
practices unique to a discipline and across the curriculum. At CCC, there were inadequate models and examples of how the gamut of tools could be used for specific assessment purposes across the disciplines. The Guidebook provided ideas for examining and correcting these problems.

Work at the departmental level was necessary for the institution to demonstrate that it was working toward meeting accreditation goals, therefore, development of the Guidebook f) supported institutional change / improvement in the face of increased accountability and meeting stakeholder / policy maker expectations for student achievement. This evidence was incorporated into upcoming accreditation reporting efforts.

This project introduced new models for the design and creation of instructional materials that increased learning through improvements in course quality. The processes of R\&D that were being modeled in the creation of the Guidebook, such as g) collaborative content identification and instructional design, use of research for making instructional design decisions, and prototyping and field-testing of materials to ensure their efficacy, provided new models for the faculty in support of their instructional design efforts.

\section{Significance of Supporting Assessment Reform}

Consistency of outcomes-based assessment practice, in online and on-ground environments, was found to be problematic and improving assessment practice was a priority for CCC. This project is concerned with, among other things, improving practices of assessment of learning, known as summative assessment, which refers to methods that 
assess the outcomes of learning after learning has occurred; and with practices of assessment for learning, known as formative assessment, which referred to methods that assess the learning process rather than the learning outcome (Kim, Smith, \& Maeng, 2008), was used to adapt teaching to meet student need (Black \& Wiliam, 1998), and was increasingly used to provide evidence useful for program and school improvement (Stiggins, 2001, 2005). A component of formative assessment, known as formative feedback - defined as "information communicated to the learner that is intended to modify his or her thinking or behavior for the purpose of improving learning" (Shute, 2008, p. 154) — was also a focus of attention. Summative and formative assessment practice and improving the collection and analysis of evidence was the central focus of the Guidebook because these elements were integral to the core teaching and learning mission of the college, and also central to accountability and accreditation. Faculty needed to better understand summative assessment and its connections to student production, educational evaluation, and grading. Faculty needed to better understand formative assessment, its connections to pedagogy, instructional and curriculum design, educational processes and in fostering student learning. Assessment had impacts on student learning and motivation that faculty needed to better understand.

There were differences between grading and outcomes-based assessment that needed to be disambiguated in the minds of faculty. Because grades fulfill an important role in higher education (for example, they are used to rank and classify students and to award diplomas), record-keeping and tradition demand that faculty post grades after each term of school; faculty understand their role in providing grades as evaluations of student 
performance. This task takes substantial amounts of faculty time (Heywood, 1989; Walvoord \& Anderson, 2010). However, accreditation bodies are quick to point out that, due to differences in the application of grading systems, subjective assessment of student work, and abuses, use of grades as an indicator of course or program quality is not necessarily reliable or valid, is not an absolute indicator of student learning, and their acceptance as such is problematic (Heywood, 1989). Grades, especially those derived from a small number of summative examinations, measure particular aspects of academic performance deemed worthy by the teacher (or exam creators); their correlation to the whole spectrum of student learning or the larger aims of the institution is often unknown. This is also the case with grades awarded by faculty from different disciplines; their equivalency is easily brought into question (Heywood, 1989). Faculty grading systems are idiosyncratic and may or may not be useful, in the same way as a formative assessment process may be, to students who are trying to learn the subject.

Assessment, as it is practiced in most classrooms and online, is problematic in that it is focused on grading rather than on constructive diagnosis of student deficits and improving instruction (Black \& Wiliam, 1998). Researchers have established that high quality formative assessment and feedback provided by teachers has dramatic positive impacts on student learning (Black \& Wiliam, 1998; Shute, 2008).

Improved formative assessment and feedback practice has the potential to increase the quality of student-instructor and student-content interactions, student active participation in online courses, student motivation and achievement, provide the help 
needed to move students from low to high achievement levels and encourage greater levels of student help-seeking behavior (Black \& Wiliam, 1998).

\section{Significance of Supporting the Development of Direct, Course-embedded, Outcomes-Based Assessment Practices}

I learned that teaching and learning are social activities, and the fact that interaction, even if it may be teacher-centered, takes place between teachers and learners is obvious; but the nuances of these interactions were not obvious. Research in formative assessment practice studies the interactions that take place between the instructor, the students, the curriculum, and tools used to support learning, categorizes and analyzes these interactions, and develops and studies theories that help practitioners improve. Assessment practice is inextricable from instruction; instructors assess student characteristics, scaffold instruction by continuously checking for understanding, assess and provide feedback to students about their performance, incorporate tools to support interaction, and design curriculum wherein these interactions are maximized. While scaffolding is easily practiced within the face-to-face classroom, faculty generally find it somewhat more difficult to practice within distance education or online courses; this project attempted to provide an approach to increase this. In addition, not all teachers practice direct, course-embedded, outcomes-based assessment, and one aim of this project was to encourage those that do not to understand their reasoning behind this decision, and to convince them to take steps to change their approaches.

Educational researchers have identified three conditions necessary for students to benefit from the formative aspects of direct, course-embedded, outcomes-based assessment. Sadler (1989b) argued that students must know: 1) what good performance 
is, i.e. "the student must possess a concept of the goal or standard being aimed for" (Sadler, 1989b, p. 121); 2) how current performance relates to good performance, for this, the student must be able to "compare the actual (or current) level of performance with the standard" (Sadler, 1989b, p. 121); and 3) "engage in some appropriate action which leads to some closure of the gap" (Sadler, 1989b, p. 121). Assessment research studies these three conditions and provides insight into how to best accomplish these goals. An essential, initial starting point is the creation of measurable SLOs.

Not all teachers are clear about their criteria for good performance. Granted, some skill sets deriving from tacit knowledge are difficult to describe, causing some faculty to assert that they are "connoisseurs" (Price \& O'Donovan, 2010, p. 103) and know good performance when they see it, a claim often made without having made a concerted effort to attempt description of measurable outcomes. Still, accreditation will require SLOs to be made explicit to all involved. This project provided support to the faculty of CCC in understanding how to enact measureable SLOs in their curriculum, how they can better articulate criteria for student performance, create the conditions for successful performance, and collect and provide evidence of their efforts useful to accreditation. Improved feedback loops created through assessment have the potential to improve communication between the teacher and student when there is misunderstanding about the clarity of face-to-face and online course materials and instruction. Instructors can use feedback loops to initiate interaction with students who do not otherwise seek help. If a student indicates confusion, but takes no action to seek help, the instructor can intervene and begin to inquire about problems and scaffold instruction with that student. 
Feedback loops can be used to collect data about student response to curriculum; this data can be used for identifying problem areas in the curriculum and for improving design. However, many faculty members do not use assessment data to improve their course designs (Black \& Wiliam, 1998).

The research and development process, with its focus on incorporating end-user, or learner, feedback into the design of instructional materials, had the potential to help faculty better meet the demands of their instructional design role. This project, and the iterative design processes it empowered, helped faculty to better understand how to improve curriculum, instruction, and assessment through frequent field-testing of new materials.

Field-testing, in the short term, and scholarship of teaching and learning practices, longitudinally, can empower faculty to create and continuously improve their instructional materials. While beyond the scope of this project, the collection and analysis of assessment data could help faculty and instructional designers build new distributed knowledge tools or adaptive scaffolds into course materials so as to provide immediate answers for students who seek help in subsequent iterations of the course. When many students fail an assessment, instructors are likely to revise the materials, but usually this does not occur before the next iteration of the course. Using summative assessment data to guide course design is useful and commonly done, but this data is gathered after the fact of learning and it eliminates the possibility of immediately enacting interventions for confused learners. Other, more formative, methods of assessment were needed.

\section{Significance of Support for Using the Learning Management System (LMS) More Effectively}


Modern LMSs, like Moodle, are incorporating numerous tools that support directcourse-embedded, outcomes-based, assessment approaches, and these approaches can be used without adding to the workload of practitioners (Davies, 2010). Based on my work at $\mathrm{CCC}$, it was apparent that many faculty are not aware how to use them or even that they exist. This lack of awareness prevents faculty from leveraging these tools to automate their assessment work, thus technology is not utilized to work smarter or to redistribute workload.

There is a growing need for summative and formative Computer-Based Assessments (CBAs) in post-secondary education (Miller, 2008). The use of Moodle at CCC afforded us the possibility of enacting new tools for assessment.

\section{Significance of Supporting Accreditation Efforts}

Educational executives, policy makers, and accreditation bodies have targeted improvements in assessment practice as a high priority for colleges and increasingly recognize this as the most important improvement strategy that can be implemented by higher education institutions. Improving assessment practice is a regional, national and international priority (University Leadership Council, 2008).

\section{Research Methodology}

This dissertation has documented the research and development (R\&D) / problem-based learning (PBL) approaches that were used to develop and refine the product. Bridges and Hallinger recommended an R\&D cycle developed initially by Borg and Gall (1989), and it consisted of ten steps (p. 120), the first seven of which are relevant to dissertation research. 
Table 1 - Ten-step $R \& D$ process

\begin{tabular}{l|cl|} 
The Ten- & 1. & Research and information collecting \\
\cline { 2 - 3 } $\begin{array}{l}\text { Step } \\
\text { Research and }\end{array}$ & 2. & Planning objectives, learning activities, and small- \\
Development & & scale testing \\
\cline { 2 - 3 } (R\&D) & 3. & Develop preliminary form of the product \\
\cline { 2 - 3 } Process & 4. & Preliminary field testing \\
\cline { 2 - 3 } developed by & 5. & Main product revision \\
\cline { 2 - 3 } $\begin{array}{l}\text { Borg and } \\
\text { Gall (1989) }\end{array}$ & 6. & Main field testing \\
\cline { 2 - 3 } & 7. & Operational product revision \\
\cline { 2 - 3 } & 8. & Operational field testing \\
\cline { 2 - 3 } & 9. & Final product revision \\
\cline { 2 - 3 } & 10. & Dissemination and implementation \\
\end{tabular}

The project conducted for this dissertation followed steps one through seven of this cycle. Descriptions of each step will follow in chapter 3. In that chapter, I have overlaid this multi-step process with a timeline, project implementation plan, and methodological contexts so as to provide a comprehensive picture of how this project rolled out over time.

In overview, the research and development approach required that the author begin with initial research and information collecting in order to identify a problem in the field and develop a product that solves the problem. Once a problem was established and a solution, in the form of a product, was proposed, the author conducted an iterative cycle of refinement by developing a preliminary form of the product, which is then field-tested and feedback gathered from the participants. This feedback is used to refine and improve the product, which is again field-tested and feedback gathered. Ultimately, a useful, highquality product emerges. The author situated his project in a real world context where product design, product content, and target audience were sensitively considered as part of the context for the dissertation (Bridges et al., 1995). This real world context was CCC 
and the audience for the project was the instructional DC. The problem was inconsistency in DC understanding of assessment practices and assessment leadership. The proposed product was the Guidebook For Student Learning Outcomes \& the Assessment Loop. I understood my problem well enough to solve it; understanding, in this case, involved researching outcomes-based assessment reform pertinent to accreditation at multiple levels: researching what the typical instructional DC at CCC knows about the quality of programs and courses offered by his/her department and discerning what he/she may want to know; collaboratively creating a guidebook to meet specific college needs and researching the process; and researching high-quality text-based instructional design that supported the DCs in teaching faculty to make sense of and implement assessment reform. In addition, I believed that inconsistency in the level of engagement of DCs in assessment leadership was remedied by providing high quality, research-based materials that improved the consistency of instruction, standardized language, and provided a myriad of practical strategies, and that built DC confidence in taking a leadership role. This process took place as part of the development of the Guidebooks. Their confidence was benefited by offering them high-quality, research-informed materials to use as they lead professional development activities with faculty.

This dissertation documented the process used to create the product (i.e., the Guidebook) that aimed to close the gap between what is needed at the various levels and what we have currently in place. I believed the gap was closed by providing to the chairs a set of guidebooks that a) established a set of principles and useable frameworks to help them better understand assessment theory and outcomes-based assessment practices, 
including how to effectively measure SLOs and increase the integrity and validity of evidence; b) provided strategies and materials which can be used to establish a department-based training program designed for teaching department faculty about these concepts and skills and c) provided training materials that show how chairs and faculty can use technology and the LMS more effectively to manage and use evidence.

Because the project outcomes needed to fit within the existing constraints of a working institution with its attendant personalities and idiosyncratic procedures and policies, the practitioner was forced to reckon with these elements up front, thus this mitigated many of the translation problems that may emerge when research is conducted in a vacuum. The outcome was built specifically to work within this institution, so it was eminently applicable and of immediate value to CCC. The ultimate goal was to provide a product that aimed to solve problems encountered by all of the instruction departments at CCC. This could lead to issues of generalizability to other community colleges in Oregon and beyond. Still, since community college environments in Oregon are similar, there are opportunities for this product to be useful throughout the state.

\section{Summary and Conclusion}

This chapter described, in detail, aspects of the problem of inconsistency in CCC DC understanding of direct, course-embedded, outcomes-based assessment theory / practice and haphazard engagement in assessment leadership activities. The significance

of aspects of this problem was explored. To address this problem, the author proposed focusing more attention on building knowledge of how to write and assess measurable SLOs, including descriptions of assessment methods/ tools that support assessment 
practice. The author suggested that production of the Guidebook could be used to improve the DC's capacity to reform assessment practice as it would provide him/her practical instructional materials for building the capacity of faculty to understand the assessment loop, communications technology in managing assessment activities and collecting evidence, and how course-level assessment creates a foundation for program-, and institutional-level reforms. The proposed research methodology is based on Bridges et al., (1995) R\&D PBL model. 
CHAPTER 2

\section{REVIEW OF RELATED LITERATURE}

\section{Introduction}

Department Chairs (DCs) are well placed at Clackamas Community College (CCC) to support faculty development of the skills and attitudes necessary to help the college meet its accreditation goals. Yet, despite their influence, department chair willingness to participate in leadership roles can be problematic. As a DC and member of the Assessment Committee, I learned about and examined our strengths to discern possible solutions and weaknesses to discern problems within the institution and, informed with knowledge of accreditation requirements, I worked to develop plans in support of institutional changes.

Chapter 1 examined the problem of inconsistency of DC understanding and varied responses of their role in leading institutional change. Again, departmental instructional leadership, particularly in the domains of assessment practice, distance learning and integration of technology, varies widely across the college. DCs may avoid leadership roles because they perceive achieving meaningful reform as difficult or because they lack knowledge and/or confidence, or available resources, such as time to attend training to become instructional leaders. DCs, especially inexperienced ones, may not understand assessment, teaching and learning and instructional technology systems well enough to lead others in their adoption and use. 
As stated in chapter 1, improving assessment practice was a priority for CCC. This was difficult work and it was acknowledged that achieving this aim required shifting the way faculty view their work and significant training in new practices. Through my dissertation project, I attempted to provide solutions for particular problems, but not all problems, faced by $\mathrm{CCC}$ in its efforts to change assessment practice. We value high levels of professionalism on the part of faculty and support their efforts to engage faculty in professional development. We envision all faculty using effective teaching and learning strategies, including using assessment data to guide practice. This project supported the vision and mission of CCC.

As described earlier, the college has a system in place that can be used to support widespread assessment reform, teaching and learning activities, and accreditation efforts. Moodle is a powerful learning management system (LMS), evidence repository, analytic and reporting tool that is currently in widespread use by practitioners and students at CCC. This system was the centerpiece of a professional development program that built DC assessment leadership capacity.

\section{Knowledge Domains that Bear on These Problems}

Consistent with Bridges et al., (1995), the literature review for this Ed.D. project deviated from commonly accepted formats for Ph.D. documents. This literature review drew from "a combination of literatures" (p. 125) and was problem-focused. This research and development project was multidimensional and drew ideas from many related domains of knowledge and theory. This project drew from instructional design research for text-based teaching materials, R\&D-focused field-testing procedures, 
formative and summative assessment, feedback, social constructivism (scaffolding and self-regulated learning (SRL)), online instructional design theory concepts (distributed cognition and computer interface design), motivational theory, and the scholarship of teaching and learning.

The outcomes of this project, the development of a faculty resource entitled the Guidebook For Student Learning Outcomes \& the Assessment Loop, were aimed at solving corresponding institutional problems in our assessment practices:

Outcome 1. Address deficits in faculty understanding of outcomes-based assessment theory and practice and the role of evidence in program and course improvement.

The Guidebook presented and explained underlying principles that guide faculty work in articulating and measuring student learning outcomes (SLOs) and that help them to validate that students are successfully meeting these claims, and show how these principles connect and fit into larger institutional priorities/goals related to instructional program improvement. In addition, the Guidebook helped instructors write measurable SLOs, align and incorporate learning activities into their curriculum that lead to successful attainment of the SLOs, allow teacher expectations to be communicated more effectively through more explicitly-stated criteria, and create the conditions wherein assessment of student performance of learning can take place. The Guidebook shared high quality, practical, discipline-specific examples of measurable SLOs, including observable factors, conditions for performance, and explicit criteria, that became models for the faculty to emulate. 
Outcome 2. Develop systems and methods to collect and store useful evidence, connect evidence to learning outcomes, extract and analyze assessment data, and to report the findings.

As faculty increasingly validate their claims of student learning with evidence, evidence management becomes essential for effective assessment practice. Technologybased systems are commonly used for evidence management. These systems and methods were developed as part of this project and described via the Guidebook, which provided practical examples that demonstrated systems use (with Moodle) and effective methodology to complete needed tasks that maximized the functionality of the available tools to collect actionable data. This provided DCs the needed information and analysis to be more effective in data-informed decision-making.

Outcome 3. Address deficits in skill sets needed to use computer-based assessment tools more effectively and efficiently.

Faculty members need training in the use of computer-based assessment tools. The Guidebook provided step-by-step training guides that DCs use to train faculty how to implement the methods and tools that are available. Also, shifting to computer-based assessment tools also allows assessment work to be redistributed to the computer and can lessen the workload for faculty. When assessment entails less work, more assessments can be developed and used within courses.

Outcome 4. Help faculty better understand and design curriculum in a way that promotes more effective use of formative assessment practices. 
Effective direct, outcomes-based, course-embedded assessment practices require that teacher expectations be articulated via explicitly stated criteria of performance. This requirement establishes the foundations for better use of formative assessment strategies. Faculty need help articulating, communicating, tracking, and assessing student performance based on these criteria.

Outcome 5. Showcase the function of specific tools and connect tools/functions to assessment practices unique to a discipline and across the curriculum.

Each department has assessment needs that can be better met by incorporating the right tool useful to the task; the Guidebook examined these needs, identified and showcased appropriate tools.

Outcome 6. Support institutional change / improvement in the face of increased accountability and meeting stakeholder / policy maker expectations for student achievement.

As stated above, when enacted as part of a strategically planned improvement initiative, the Guidebook provided a focal point for articulating working principles, evidence, in the form of practical examples, of how these principles work in practice, and support persuasive arguments in favor of change. The intended outcome of improved assessment practice benefited the institution by providing evidence that educational and teaching activities result in learning.

Outcome 7. Model collaborative content identification, joint instructional design, use of research for making instructional design decisions, and prototyping and field- 
testing of materials to ensure their efficacy, for the faculty in support of their instructional design efforts.

R\&D processes, by actively soliciting and incorporating the viewpoints of others to guide content selection and instructional design, provide new models that can improve curriculum. This project modeled the use of these processes and encouraged their adoption by others.

An aim of this literature review was to show that these tools and methods are capable of meeting the outcomes and will have the desired effect. Where possible, other studies were reviewed that showed how others studied this aspect of the problem and their findings.

\section{Identification and Review of the Knowledge Domains Relevant to this Project}

Angelo (1995) defines "assessment" as "an ongoing process aimed at understanding and improving student learning. It involves making our expectations explicit and public; setting appropriate criteria and high standards for learning quality; systematically gathering, analyzing, and interpreting evidence to determine how well performance matches those expectations and standards; and using the resulting information to document, explain, and improve performance. When it is embedded effectively within larger institutional systems, assessment can help us focus our collective attention, examine our assumptions, and create a shared academic culture dedicated to assuring and improving the quality of higher education." This definition incorporates the processes and rationales that formed the "assessment loop" (see figure 1 for more information about the assessment loop) and the foundation for direct- outcomes-based 
course embedded assessment. The Guidebook made this definition practical and real for CCC.

In addition, the following definitions for formative and summative assessment from Bakersfield College (n.d.) will guide this work.

Summative assessment is a final determination of knowledge, skills, and abilities. This could be exemplified by exit or licensing exams, senior recitals, or any final evaluation that is not created to provide feedback for improvement, but is used for final judgments. Some midterm exams may fit in this category if it is the last time the student has an opportunity to be evaluated on specific material. Formative assessment generates useful feedback for development and improvement. The purpose is to provide an opportunity to perform and receive guidance (such as in class assignments, quizzes, discussion, lab activities, etc.) that will improve or shape a final performance. This stands in contrast to summative assessment where the final result is a verdict and the participant may never receive feedback for improvement such as on a standardized test or licensing exam or a final exam (Bakersfield College, n.d., no page).

Much of the literature on formative assessment and feedback came from universities and scholars working in the UK. It seems that differences in the historical practice of assessment and policy development over time has led higher education in the UK to focus on assessment for learning (formative assessment) while higher education in the U.S. seems to focus on assessment of learning (summative assessment), however certain American authors (Rick Stiggins (2001, 2005) comes to mind) buck this trend. There is evidence that, historically and now, student learning in the UK is assessed primary by written exams with feedback provided via ample dialogue between faculty and students. The quality of that feedback has been scrutinized more thoroughly within the literature, resulting in a richer body of knowledge about formative assessment theory and practice. Conversely, there is much influence of policy (i.e., standards-driven accountability) in the U.S. along with a reliance on standardized multiple-choice exams 
to assess student achievement. I believe this partially explains the difference. I believe there is much to learn from U.K. researchers and I drew much material from the deeper pool of formative assessment literature produced abroad.

In part because the knowledge domains that provide input into this project were broad, I chose to organize the literature review below around the problems I was attempting to solve. In the paragraphs that follow, I list the problems and rationales for why the problems are significant (shown in italics); following those, I review the literature specific to the problem:

Problem 1. There are deficits in understanding of outcomes-based assessment theory and practice among faculty at CCC. There is insufficient expertise and skills with assessment methods at CCC. Faculty members need training in this. DC understanding of the role of evidence in program and course improvement is inconsistent. Localized efforts are inconsistently connected to institutional efforts.

Rationale 1. Using the Guidebook will be useful for DCs in their efforts to become assessment leaders and factors can be incorporated into their development that will maximize departmental and faculty adoption of the ideas they teach. A Guidebook can connect localized change efforts to institutional priorities.

Problem 2. The institution lacks systems and methods to collect and store useful evidence, connect evidence to learning outcomes, extract and analyze assessment data, and to report the findings. These systems need to be developed and the methods to use them documented and disseminated so that DCs and faculty can use these systems. 
Rationale 2. Technology-based systems must be in place so that high quality evidence and the assessment data that is derived from it are available to the people who need to use it. Such systems are essential for continuous programmatic improvement plans to take root and flourish.

Problem 3. There are deficits in skill sets needed to use computer-based assessment tools more effectively to ease assessment workload among faculty at CCC. Many members of the faculty at CCC are not aware how to use computer-based assessment tools or even that they exist. This lack of awareness prevents faculty from leveraging these tools to automate their assessment work, thus technology is not utilized to work smarter or to redistribute workload.

Rationale 3. Using computer-based assessment tools will not increase and may lessen faculty workload.

Problem 4. There are inconsistent and inadequate levels of instructor understanding of formative assessment practices at CCC. Not all teachers are clear about their standards of good performance. One important merit of outcomes-based assessment is an increased emphasis on communicating expectations to students via articulated criteria. This lays the groundwork for improved formative assessment practices.

Rationale 4. The faculty want to effectively communicate their expectations to students and close feedback loops with students. Both will mutually benefit from formative assessment and the dialogic feedback it enables. There are principles and practices of assessment and feedback that many faculty have not fully considered, that 
may be counter-intuitive to most faculty, and faculty need to be exposed to these ideas as a preliminary step toward their adoption.

Problem 5. While there are many useful tools in Moodle that can be used to support assessment activities (i.e. used to create conditions wherein students can successfully demonstrate learning), faculty have difficulty in matching the available assessment tools to SLOs (Walvoord \& Anderson, 2010); this problem is compounded by variations in assessment practices across the different disciplines. There are inadequate models and examples of how the gamut of Moodle tools can be used for specific assessment purposes across the disciplines.

Rationale 5. The faculty needs help matching the right tools to SLOs/evidence. Moodle's assessment tools (Rubrics Scoring, Adaptive Mode Quiz, Checklist, Survey, Poll, Feedback, Notifications, Outcomes and others) can provide useful and effective solutions for specific assessment needs within the different disciplines. Moodle's capacity for content management provides a useful mechanism for collection and analysis of high quality evidence.

Problem 6. Accreditation reports reveal that assessment practice at $\mathrm{CCC}$ needs improvement. It was recommended that the college better clarify SLOs, how they are assessed, show evidence that our students have attained the outcomes, and that evidence is used to improve. The college continues to struggle with implementation of new and reformed assessment practices. This project aimed to help the college improve faculty assessment practice in our overall efforts to maintain compliance with standards set by the North West Commission Colleges \& Universities. 
Rationale 6. The efforts for accreditation bodies in promoting institutional change through improved application of assessment practices are worthwhile and will accelerate both institutional improvement and student learning in both traditional and online courses.

Problem 7. Improving curriculum and course quality is difficult to do. There is inconsistent understanding of effective instructional design strategies, use of research in the instructional design efforts of the faculty, and applied scholarship of one's own teaching and learning among the faculty.

Rationale 7. I learned from processes of $R \& D$ that were modeled in the creation of the Guidebook, such as collaborative content identification, joint instructional design, use of research for making instructional design decisions, and prototyping and fieldtesting of materials to ensure their efficacy. Exposing faculty to these processes / new models helped them to improve their instructional design efforts. My research into textbased instructional design used for the guidebook development did benefit others.

\section{Practical and Scholarly Significance of the Problems and Rationales}

The literature review now turns to researching the practical and scholarly significance of the problems and rationales for examining the problem. Through this process, I hoped to, and did, uncover aspect of the domain that led to research questions that provided direction to the research design and methods I used to create the Guidebooks.

Rationale 1. Using the Guidebooks will be useful for DCs in their efforts to become assessment leaders and factors can be incorporated into their development that 
will maximize departmental and faculty adoption of the ideas they teach. A Guidebook can connect localized change efforts to institutional priorities.

The project I proposed provided supports for a comprehensive change effort, and as such, it was important that the project met its intended goals: the creation of the Guidebook must be useful for DCs and faculty and must motivate them to adopt new practices. Faculty buy-in was key to this effort (Banta et al., 2012). The research suggested that there are factors/elements that can be incorporated into its development that will maximize its effectiveness.

External change forces are driving colleges to become more accountable for proving that they do for students what they say that are doing. Outcomes are direct measures of student learning and, when validly measured, provide evidence of learning. Outcomes-based education is at the heart of this accountability movement (University Leadership Council, 2008). Colleges today are undergoing comprehensive change as they act to implement a shift away from a paradigm of instruction (an input-based system) and toward a paradigm of learning (an outcomes-based system). Institutions need to provide support for these change efforts; faculty training and professional development opportunities are the result (University Leadership Council, 2008). The Guidebook supported this change effort by focusing faculty attention and engagement on professional development around direct, outcomes-based, classroom-embedded assessment methods.

Faculty members, for a variety of reasons, when tasked with learning, want practical, easy-to-learn-from materials. Learning audiences tend to be "impatient, task- 
oriented, unforgiving, and disdainful of anything they perceive to be condescending, jargon-ridden, or overly technical in nature" (Mehlenbacher, 2010, p. 204). This is a truism of busy faculty members, who are tasked with learning new procedures to complete administrative tasks they perceive as indirectly related to their work. Walvoord and Anderson (2010) describe how assessment and grading can be combined into the same faculty work, accomplish both grading and assessment tasks, and faculty save time. For these reasons, the Guidebook focused on the most useful and directly applicable information for faculty, i.e., accomplishing grading and outcomes-based assessment via direct, course-embedded assessment.

According to Allen (2008), student learning can be assessed via 1) direct or 2) indirect methods. Direct assessment is "based on an analysis of student behaviors or products in which they demonstrate how well they have mastered learning outcomes (p. 1)." Indirect assessment is "based on an analysis of reported perceptions about student mastery of learning outcomes (p. 1)." Direct methods that are used to assess learning within courses as part of the learning activities students are expected to do are called "course-embedded" assessments. Direct, course-embedded assessment methods can include, but are not limited to, published tests, locally developed tests, course-embedded assignments and course activities. Assessments that take place as part of the course are easiest for faculty to administer and use because they are things that faculty are doing anyway (Walvoord \& Anderson, 2010).

As mentioned above, $\mathrm{CCC}$ has initiated a large-scale institution-wide change effort by requiring all for-credit course outlines to be revised to include measurable 
SLOs. This project has motivated the CCC curriculum committee to provide the faculty concise and accurate materials, in the form of a Guidebook (Guidebook $\# 0$ ), about how to successfully complete these course outline revisions. As part of this dissertation, this preliminary work was expanded.

This institutional effort will have far-reaching impact on assessment practice. It will help instructors align assessments to outcomes including identifying criteria for performance, thus laying the groundwork for improved formative assessment. As mentioned above, Guidebook $\# 0$ was developed as part of preliminary research for this dissertation. Guidebook \#0 provided practical instruction in how to write measurable SLOs, however, it does not describe how identification of observable behaviors, assessment methods/tools, and criteria flow from the process of writing the SLOs. It does not describe how course-embedded activities lead to the conditions wherein the demonstration of student learning can take place. In this way, Guidebook \#0 was incomplete. The Guidebook expanded and completed the initial processes described in Guidebook \#0. This set of Guidebooks can be used as a professional development resource to establish the foundation for college-wide assessment reform.

Part of the expansion of materials will teach faculty about measurability of SLOs. A measurable learning outcome has three major components. In order to measure the SLO, instructors must consider and should identify the components that derive from and make the outcome measurable: A) the observable behavior(s), B) selection of assessment method/tool, and C) criteria for measurement and assessment and performance levels that 
determine successful attainment of the outcome (Arreola, 1998; Gagne, Briggs and Wager, 1992).

The development of guidebooks to support professional development is a sound decision. According to Bredin (2002), guidebooks that support self-study for professional development (at least in the domain of computer training) are inexpensive, flexible, and comprehensive and are an effective means of supporting professional development. Bredin added that their use is more effective when combined with face-to-face classes, human interaction and social learning. The lesson I learned from Bredin was that the value in producing the Guidebook lies as much in the process of its production and in the supporting dissemination activities, awareness building, follow-up training, etc. as it does as a self-study resource for faculty. The process of getting faculty actively discussing the issues of assessment is as valuable as the product (Borko, 2004) that emerges to teach others. These are all considerations I made when developing the Guidebook.

Change management is most effective (indeed, some would say only possible) when it involves all levels of the institution and its constituencies (Nicol \& Draper, 2009; Wenger, McDermott, \& Snyder, 2002). But inclusion may mean walking a fine line between strongly held beliefs and research findings that contradicts those beliefs. Morgan (2006) warns that "favored ways of thinking and acting" (p. 211) can become traps that confine individuals within socially constructed worldviews and prevent the emergence of other worldviews. This can be the case with mid-career faculty members who have practiced specific techniques for a long time and for whom these practices have seemingly always worked. Following this idea, the development of the Guidebook, 
because it is intended as an aid to faculty practice, was inclusive and incorporated the viewpoints of faculty, but, because their viewpoints were sometimes based on intuition rather than reason, discussions wherein principles are articulated were informed by research.

Based on an idea posited by Black and Wiliam (1998), "teachers face difficulties reconciling their formative and summative roles and this confusion can impede the improvement of practice"; I deduced that one element that the Guidebook must include is clarification of the differences between formative and summative assessment. Most faculty understand summative assessment and the managerial role of assessment in grading, record keeping and transcriptions of learning, because they are required to enter grades at the end of each term. Some may also understand that their role is to provide feedback to students about their progress, but they may misunderstand how best to give and receive feedback to maximize learning. When faculty do provide a wide range of assessment, they may not differentiate their uses of formative or summative, causing them to be excessively intertwined in the minds of faculty or they might be held mutually exclusive of each other, preventing their useful interplay. The Guidebook needed to define, clarify, and qualify for faculty the differences and the similarities of these practices, where they can overlap or where they are best used exclusively. Some examples were provided below.

Based on ideas posited by Black and Wiliam (1998)

teachers will not take up ideas that sound attractive, no matter how extensive the research base, if the ideas are presented as general principles that leave the task of translating them into everyday practice entirely up to the teachers (p. 11) 
and

what teachers need is a variety of living examples of implementation, as practiced by teachers with whom they can identify and from whom they can derive the confidence that they can do better[; t]hey need to see examples of what doing better means in practice (p. 12),

I deduced that the Guidebook must contain practical examples of formative assessment that derive from and model the departmental and instructors own assessment preferences, but that were developed by experts in conjunction with faculty. MacDonald (2008) extended this by saying that "to effect lasting educational change, teachers must come together around common interests, which must also be based in authentic teacher contexts. Teachers' experiences must be acknowledged and valued" (p. 431). This gave shape to the methods that were employed in developing aspects of the Guidebook; gathering groups of teachers around common interests, such as developing a Guidebook, discipline/department interest in using particular computer-based tools, particular assessment practices, or other unifying context to share their experiences, with a skilled facilitator, and working toward the articulation of working principles. These natural cohort groups exist at CCC, the group of DCs is a good example; as a faculty leader, I did gain access to these groups by establishing relationships with departmental or committee chairs. Such inclusivity was productive, mutually satisfactory, and led to higher levels of faculty buy-in.

Borko (2004) cites use of classroom artifacts to inform the professional development process as a successful strategy; Delin, Bateman, and Allen, (2003) concur. Their comments about "access structure" (defined as: "those features that serve to make the document usable by readers and the status of its components clear" (p. 56)), point to 
the necessity of incorporating artifacts into text-based instructional materials. Therefore, the Guidebook contained illustrative examples of classroom artifacts drawn from the classrooms of those who potentially benefit from using the Guidebook. Artifacts such as “instructional plans and assignments, videotapes of lessons, and samples of student work to bring teachers' classrooms into the professional development setting $[. .$.$] enable$ teachers to examine one another's instructional strategies and student learning, and to discuss ideas for improvement" (Borko, 2004, p. 7). The value of this theory was borne out in practice. For example, in my ongoing faculty development practice, faculty designers of online courseware often ask to view the courses of other teachers. Viewing real-life examples, along with discussion of the supporting teaching methods, helps them to learn how other teachers adopt and adapt certain tools to meet their teaching needs; my office has responded by integrating exemplars of online course design into our sessions and this has continued after development of the Guidebook.

To ensure stakeholder buy-in, Nicol and Draper (2009) posited the necessity of engaging impacted stakeholders in discussing and mutually developing the principles upon which improved practice will be based. This can be problematic if strongly held beliefs are in opposition to research findings. For example, a principle held by many faculty is the idea, drawn from transmission-based learning models, that, for students, simply reading an article or textbook implies that learning is taking place; this belief is counter-intuitive to active learning theories, which state that students must engage with reading in order to comprehend it. Reading, when done mindlessly (not "mindfully," which is "a reflective process in which the learner explores situational cues and 
underlying meanings relevant to the task involved" (Dempsey as cited in Shute, 2008)), is not cognitively processed, easily forgotten, and is equivalent to studying nothing. It is not until students are actively engaged through some sort of mindful processing activity, such as reading for meaning, guided reading, or active dialogue, does cognitive processing engage and learning occur (Graesser, McNamara \& VanLehn, 2005). In other words, the learning task must be predicated upon assessment, i.e., setting clear expectations for the learning goal, in order for students to direct their engagement to attain the learning task: instruction and assessment is inextricable.

Soliciting strongly held, but counter-productive, beliefs, from faculty, and then eliminating them from the end product, could offend faculty and prevent their buy-in toward improving assessment practice. Conversely, the incorporation of assessment methods whose effectiveness is called into question by the research could have confounded the effectiveness of the Guidebook for those who did adopt it. Creation of the Guidebook balanced these concerns; the methods that provided balance are discussed next.

The significance of this problem/rationale was that the Guidebook needed to define and describe types of assessment and feedback, reveal what the research says about best practice, clarify how some commonly accepted practices may not be optimally effective, and encourage the adoption of practices that are shown to be optimally effective, it did this within the context of beliefs, values, and practices already established within the institution. 
Rationale 2. Technology-based systems must be in place so that high quality evidence and the assessment data that is derived from it are available to the people who need to use it. Such systems are essential for continuous programmatic improvement plans to take root and flourish.

Since regional accreditation bodies are insisting that community colleges complement traditional indirect measures of student learning (such as grades and surveys), with direct evaluations of student competency, preferably from classroom artifacts (such as real assignments submitted in actual courses for a grade), course design and system development is increasingly concerned with evidence collection (University Leadership Council, 2008).

A commonly used design strategy, "evidence-centered design," connects SLOs, evidence, and assessment tools and activities (Millett, Payne \& Dwyer, 2008).

Evidence-centered design (ECD) is an assessment framework intended to ensure validity by aligning the assessment products and processes with the goals of assessment. Put another way, assessment program designers (i.e., DCs) can use evidence-centered design to link their decisions about the students being assessed to the information institutions need to have to support those decisions (Millett et al., 2008, p. 5).

ECD promotes design that aligns outcomes, activities and assessment, and highlights the importance of alignment in ensuring valid evidence is collected to support institutional needs. CCC has already adopted a model of ECD for its online courses; the Quality Matters ${ }^{\mathrm{tm}}$ program for course design and peer review has been in use at CCC for several years and over a dozen practitioners have been trained in its use.

Since the amount of evidence that can be collected within a course, program and institution is extensive and can exist in various mediums (text, video, sound etc), 
computer-based automated tools, such as databases, are needed to manage it. These tools are indispensible to contemporary assessment programs. Moodle has the capacity to manage large amounts of multimedia evidence.

Moodle gives practitioners and students direct access to the database and assessment tools needed to develop and maintain a robust assessment program. Faculty can establish SLOs at the course level, collect evidence and evaluate student performance from their desks. DCs can establish programmatic goals and these flow through to the teachers of the pertinent courses.

Moodle is an evidence repository. Students can upload their work (which becomes evidence) directly into the management system where it can be evaluated by faculty. The collected evidence is tied directly to the pertinent SLO and teacher evaluation of the evidence (in the form of a grade or performance indicator). Because it collects evidence from the point of origin (i.e., the student who creates it) and delivers it seamlessly to the point of evaluation (i.e., the instructor who assesses it), Moodle reduces the labor-intensity of direct assessment methods that involve evidence.

Moodle has built-in data reporting tools, such as a gradebook and outcomes module. Moodle's built-in reporting tools are certainly adequate for course-level assessment tasks and adequate for most programmatic review tasks, so it supports faculty and department assessment leadership activities. However, conducting large-scale institutional assessment tasks required use of value-added products, such as reporting and analytical tools that integrate with the Moodle evidence repository; such complementary 
integration work was beyond the scope of this dissertation, but will occur at CCC as a result of this project.

The significance of this problem/rationale was that CCC was already heavily invested in a tool that met its assessment needs for accreditation. Moodle was already extensively used by many faculty and DCs who rely on it for instruction and technology integration into their courses. Students found the tool easy to use. To innovate this tool in the ways needed to meet larger institutional goals, CCC needs only to continue on a path it has already embarked upon. Granted, CCC may need to complement Moodle with other tools to meet larger institutional needs, but it already has laid a strong foundation for success. Active assessment of these larger contexts does point to increased faculty workload. The issue must be addressed before any movement will be made to adopt new practices. Any practice that is perceived to increase workload for faculty will be shunned unless suitable compensation is provided; this idea was addressed in the next section.

Rationale 3. Using computer-based assessment tools will not increase and may lessen faculty workload.

Gibbs (2006) made a connection between class sizes and the amount of assessment and feedback provided by faculty; these are inversely proportional. With time for instruction and curriculum development being held constant, increased student enrollments logically lead to a decrease in the remaining component that can give way, i.e., assessment. In large classes, faculty have less time to provide quality assessment and feedback to each student; because students are not assessed as often or with decreased rigor, students might not work as hard at their studies; student learning suffers as a result. 
The approach taken by faculty is all-too-often a pragmatic one, where time constraints dictate the assessment choices that are made by time-starved faculty who choose assessment methods, not because they produce the best information about student learning, but because they easy to administer and mark.

At worst, assessment can be designed on the basis of being something easy to assess, which will perform the function of producing student results or grades with no real regard as to whether the things being assessed adequately reflect the major learning goals of the course or module (Murphy, 2006, p. 44).

The antidote, Gibbs suggested, is unwavering institutional investment in consistent levels of rigorous assessment, through, say, decreasing the credit load for faculty so they have time to devote to assessment tasks. This antidote was highly unlikely to happen at CCC.

Black and Wiliam (1996) identified an important barrier to adoption of formative assessment practices within systems where summative assessments are required, i.e., there is a perception that, since the use of summative assessments do not serve formative purposes very well, that an inordinate increase in workload will result if faculty are required to provide both types of assessments. The literature is inconclusive on this point, but if this unfunded project is to be successful, it must effectively make the case that the methods it espouses will not increase faculty workload. Fortunately, several thinkers assert that institutions can implement assessment reform without increasing overall faculty workload by using course-embedded assessment, using technology more effectively, increasing self-regulation of learners, using peer assessment more effectively, and re-designing curriculum. Certifying this fact was key for DCs to even consider 
moving in this direction, much less to adopt them, as they had to defend their choices with faculty, who challenged any change that requires more work to be done.

Davies (2010) was one such thinker, asserting that, in environments where computers, appropriate software and systems, and the Internet are available, the potential, additional assessment workload will be borne by technology. She cited a few examples. One is that computer-scored multiple choice testing reduces the workload of administrators and practitioners by eliminating the chore of marking exams. Another is use of internet-based plagiarism checking tools, like Turnitin, that eliminate the need for faculty to check for plagiarism. She and others (e.g., MacDonald, 2001) extended this thinking by anticipating emerging tools that will increasingly use data and artificial intelligence more effectively to assist with assessment chores. Faculty who teach a course over time have the benefit of streamlining their own assessment practice by tracking their own assessment inputs longitudinally and building a database of them, which can be drawn from term-by-term. Faculty can develop their own assessment databases using productivity tools like Excel or Word.

Nicol and Macfarlane-Dick (2006) and others pursued another line of thinking regarding workload by pointing out that the student him/herself can also provide feedback, and thus share the workload. This research posited that an inevitable outcome of formative assessment is an increased ability for students to self-assess their own work (Espasa \& Meneses, 2010). Practicing self-assessment builds a student's ability to selfregulate his or her own learning. Pintrich and Zusho (2002) provided the following working definition of self-regulation: 
self-regulated learning is an active constructive process whereby learners set goals for their learning and monitor, regulate, and control their cognition, motivation, and behaviour, guided and constrained by their goals and the contextual features of the environment (p. 64).

Such learners are capable of better interpreting and using the feedback they do get, thus making the output of teachers more productive. Such learners can also benefit from rubrics and other articulated expectations of student performance that are provided by faculty within online courseware, allowing them to master learning outcomes the first time. Since such learners more readily meet learning goals, less feedback overall is needed in order for them to excel.

Another approach to maintaining or decreasing faculty workload is to enlist students in mutually assessing each other through peer mentoring and assessment strategies (Nicol \& Macfarlane-Dick, 2006). The adoption of peer assessment strategies requires developing somewhat sophisticated curriculum in order to implement effectively and there are computer-based tools that can help with the process (Davies, 2010; Nicol \& Macfarlane-Dick, 2006). Many faculty members do not have the expertise to develop effective peer mentoring environments, and many students need practice and guidance in order to provide useful assessments (MacDonald, 2001). However, when the practice is effective, students find the experience valuable in "improving self-judgment and seeing alternative approaches”(MacDonald, 2001, p, 186) to meeting educational goals.

Student / faculty collaboration can lead to redistribution of workloads. This process can work like it does at Brigham Young University (BYU) where students are central to the development of expected learning outcomes for courses (Banta, Jones \& Black, 2009). BYU uses a wiki system to encourage faculty/student involvement in the 
articulation of outcomes; this has led to a deepening of the culture of assessment where faculty and student "have an emerging vocabulary and conceptual framework to improve learning and teaching and fine-tune curriculum" (Banta et al., 2009, p. 35).

In efforts to better target faculty production of feedback, curriculum redesign efforts can include asking students to target the sorts of feedback they wish to receive. For example, there are examples of faculty surveying students to find out if they would prefer or use feedback when receiving grades. Other techniques to control faculty workload could include limiting assessments on a given submission to a single criterion, doing random sampling of student work to discover common problems and then provide group-based feedback, doing joint review of student work, or collaborative scoring of common assessments across groups of teachers. Whatever methods are chosen, "the trick," as Gibbs and Simpson (2004) pointed out "when designing assessment regimes is to generate engagement with learning without generating piles of marking” (p. 8).

The significance of this problem/rationale is that Davies (2010) and MacDonald et al., (2001) posited that emerging tools, online environments, social networking, and data systems are improving and will ultimately make assessment easier for faculty (indeed, this premise was central to my project here) but, I needed to be sensitive to the fact that there is an investment in curriculum (re)development and training that must be made before this payoff is likely. This investment could increase workload, albeit, temporarily. Faculty needed to be persuaded to make this investment if they are to benefit from the Guidebook. They need to be supported in these efforts. In addition, I learned there are assessments methods that are underutilized that can help faculty work smarter; 
the Guidebook needed to provide models and examples of these methods across the disciplines.

Rationale 4. The faculty want to effectively communicate their expectations to students and close feedback loops with students. Both will mutually benefit from formative assessment and the dialogic feedback it enables. There are principles and practices of formative assessment and feedback that many faculty have not fully considered, that may be counter-intuitive to most faculty, and faculty need to be exposed to these ideas as a preliminary step toward their adoption.

As described above, a goal of the CCC course outline revision initiative was to ensure that all courses have measurable SLOs. Increasing the measurability of SLOs within all courses at CCC provided the foundation for the better use of formative assessment. The purpose of formative assessment "is to provide an opportunity to perform and receive guidance (such as in class assignments, quizzes, discussion, lab activities, etc.) that will improve or shape a final performance. This stands in contrast to summative assessment where the final result is a verdict and the participant may never receive feedback for improvement such as on a standardized test or licensing exam or a final exam" (Bakersfield College, n.d.).

Basing instruction on measurable SLOs demands faculty to clarify what good performance is, and when combined with clear communication about what is expected of students, can empower students to enact metacognition to self-correct, self-direct, and achieve at higher levels. Faculty members need to clarify, at the start of instruction, what the criteria are for successful learning in the course, i.e., the specific level of performance 
that students must attain to show mastery of the SLO. These clarifications are called by various names in the literature, including criteria, competencies, standards, or expectations. For the Guidebook, I selected "criteria" to describe this concept because the term "criteria" conveys the idea of objective measures that all students can meet; this differentiates it from subjective or normative measures, the latter being used as a means to rank students as a basis of grading.

The literature is clear that faculty members are likely to not fully understand the nuances of formative assessment and feedback types and when to use each type. This was problematic and a barrier to adoption of new practices that improve learning and that meet accreditation standards. Understanding can be improved by education; the Guidebook provided a context within which the faculty could learn. By fostering a process and codifying the results, faculty were exposed to new ideas, unlearned counterproductive methods, and adopted new practices.

One value of the Guidebook, then, was in determining what, precisely, is a best practice for the CCC faculty. This proved controversial, especially since some of the research is inconclusive or contradictory.

For example, best practice in praise-based feedback is inconclusive and needs to be examined. Sadler (1989a) pointed out that behaviorist research examining stimulus/response theory validates praise-based feedback for student effort as leading to higher self-esteem, more effort, and finally higher achievement, while, from a cognitivist paradigm, the value of praise-based feedback is confounded by variables related to the nature of the assessment task, the learners response to that task, the learner's level of 
conscious appreciation of high-quality production, and understanding how to attain high standards. Shute (2008) brought up concerns that, while this practice may motivate students in the short-term, the "attenuating effect of praise of learning and performance" ultimately distracts learners when used for longer periods. "Kluger and DeNisi (1996), Butler (1987), and others have noted that use of praise as feedback directs the learner's attention to "self," [emphasis in original] which distracts from the task and consequently from learning” (Shute, 2008). On the other hand, Nicol and Macfarlane-Dick (2006), in defining the characteristics of high quality feedback, found that some researchers (e.g., Freeman \& Lewis, 1998, is cited) encourage the provision of praise, as long as it is integrated into feedback offering corrective advice or constructive criticism. The takeaway from this debate about praise-based feedback is that it should be used sparingly unless informed by understanding of the larger context of learner attributes and objectives. The Guidebook sought to explore this controversy with practitioners at CCC to arrive at a consensus about the use of praise in this particular context.

Related to this, educating faculty about best practice will require them to unlearn practices that are counter-intuitive. For example, many faculty members believe that providing feedback, regardless of content, is always valuable to students and that feedback should always be provided immediately. But, Bangert-Drowns et al., (1991 as cited in Shute 2008) reported a counter-intuitive aspect of feedback; they state that "feedback can inhibit learning if it encourages mindlessness, as when the answers are made available before learners begin their memory search, or if the feedback message does not match students' cognitive needs (e.g., too easy, too complex, too vague)" (p. 
20). This contradicts commonly accepted practices, such as providing answers to to-beworked problems, as in the back of a mathematics textbook, and brings into focus, during large group teacher-led discussion sessions or within online courses, for the need for adequate wait times before answers are revealed.

Similar conversations can be had about interaction within online courses. Simonson et al., (2011) stated that "although interaction seems intuitively important to the learning experience, interaction should not be added without real purpose" (p. 139). As distance education and new information/communication technologies have expanded, some online educators adopted the mistaken belief that if interaction is important, " the more interaction there is in a distance education class, the better'' (Simonson, 2000, p. 278). As Simonson (2000) noted, early research in the field had "demonstrated clearly that the provision for interaction was critical"' (p. 278), but later research indicated as clearly that "interaction is not a magic potion that miraculously improves distance learning"' (p. 278). Indeed, "the forcing of interaction can be as strong a detriment to effective learning [as is] its absence'” (p. 278). This makes clear that interaction, like any assessment activity, should be linked to learning outcomes.

Another practice that appears to be counter-intuitive and that needs to be examined is the use of normative feedback. Feedback is considered normative when it is "provided to students in a norm-referenced manner that compares the individual's performance with that of others" (Shute, 2008, p. 15). Feedback that is normative in nature can impede learning, especially among low-achieving students, because its use leads students "to attribute their failures to lack of ability, expect to perform poorly in the 
future, and demonstrate decreased motivation on subsequent tasks" (Shute, 2008, p. 15). Black and Wiliam (2009) reviewed findings from Ruth Butler that show that "giving marks or grades, or otherwise focusing on judgment or competition, as part of feedback can inhibit the learner's attention to any substantive advice on improvement” (p. 23). Such feedback can negatively impact the learning mastery orientation of the learner, promoting instead a performance orientation. "Other features of feedback that tend to impede learning include: providing grades or overall scores indicating the student's standing relative to peers, and coupling such normative feedback with low levels of specificity (i.e., vagueness) (Butler, 1987; Kluger \& DeNisi, 1998; McColskey \& Leary, 1985; Wiliam, 2007; Williams, 1997 as cited in Shute 2008).

Changing normative feedback practices will be difficult, even with greater understanding of the counter-intuitive outcomes of this practice, because norming is, in the minds of faculty members, closely coupled to required educational grading systems. Faculty members extensively use normative feedback because they feel that they are expected to grade and rank students by their ability to learn the assigned content and meet the course outcomes. Sadler (1989a) reminded us that "giving grades" need not be explicitly linked to "normative feedback," rather self- or criterion-referenced models can be used for grading; this tenet informed the process of Guidebook development.

Faculty need to better understand the interaction and "significant tensions" of using feedback that simultaneously serves both summative and formative purposes (Black \& Wiliam, 1996). Sadler (1989b) pointed out that summative feedback "can have the effect of making the student unwilling to repeat work in order to improve it" (p. 540). 
This reality may limit the value the providing summative feedback in conjunction with formative feedback because, in the student's mind (especially if the student is performance-oriented), summative feedback signals an end to a cycle of learning; because the student has no opportunity to apply the feedback to his/her immediate performance --and have it count with an improved grade-- the formative feedback is ignored and neglected. An example would be tests that are administered formatively. Tests are important learning tools, but are often structured in ways that limit their effectiveness as learning aids. Tests used as summative evaluations lose their ability to teach, tests should be administered formatively first. "For formative purposes, a test at the end of a unit or teaching module is pointless; it is too late to work with the results" (Black \& Wiliam, 1998, p. 9). A way this problem can be explored is "by separating the elicitation of the evidence from the interpretation of the evidence" (Black \& Wiliam, 1998, p. 545). Another way would be to use summative assessment as a feed-forward mechanism wherein summative information is fed into subsequent learning tasks. This would allow the interlinking of functions without confounding them.

The significance of this problem/rationale is that the research findings indicate that formative assessment and feedback can never be applied with a blanket approach, rather best practice is more nuanced than most faculty appreciate; the most effective practice involves actively assessing not only student work, but also this work in the context of the learner's characteristics and learning environment. These sorts of questions will need to be grappled with if faculty members are to fully realize the benefits of outcomes-based assessment. 
Rationale 5. The faculty need help matching the right tools to SLOs/evidence. Moodle's assessment tools (Rubrics Scoring, Adaptive Mode Quiz, Checklist, Survey, Poll, Feedback, Notifications, Outcomes and others) can provide useful and effective conditions for specific assessment needs within the different disciplines. Moodle's capacity for content management provides a useful mechanism that aids collection and analysis of high quality evidence.

An important component of assessment and of measuring SLOs is creating the conditions wherein student performances that show learning has occurred can take place. Doing this successfully entails matching the assessment tool, or media, to the expected performance.

Media should be selected based on different criteria such as learning outcome, instructional strategy, learner characteristics, and instructional setting. Hence, aligning the media used based on the other instructional elements is important. The purpose in media/technology selection should not be to show the mastery of the technology, but to select media that best magnify learning (Martin, 2011, p. 962).

Selecting media is initiated through the creation of SLOs. The appropriate assessment procedures emerge from the action verb that describes the performance and is informed by the level of complexity of the cognitive, affective, or psychomotor behavior(s) to be demonstrated. Levels of complexity based on Bloom's (or other theorists') taxonomy help instructors determine the sorts of assessments that can apply (Bloom, 1956). For example, simpler cognitive tasks, like recalling a fact, can be assessed with a multiple-choice exam; more complex tasks, like evaluating a professional situation, can be assessed with a written essay or case study. 
In addition, assessment connects to classroom instruction via the instructional strategies, or learning tasks, that lead up to the performance. These strategies / learning tasks are not part of the SLO, but provide the prerequisite knowledge and skills that students need to demonstrate learning. These learning tasks might include graded or nongraded assignments, such as reading, watching, discussion, role-playing, drilling, practicing, etc. The instructional designer needs to determine what sorts of prerequisite skills or knowledge that student would have attained prior to enrolling in the course and which need to be developed as part of coursework, so that the SLO can be attained.

Gagne (1985) and Gagne, et al., (1992) presented a useful classificatory system for determining and sequencing instructional and assessment tasks. They described five types of learning. Each different type of learning requires different types of instruction: intellectual skills, verbal information, motor skills, cognitive strategies, and attitudes. Instructors must provide the internal and external conditions appropriate for each type of learning, e.g., for cognitive strategies to be learned, instructors must provide conditions where learners can practice developing new solutions to problems; to learn attitudes, instructors must provide to the learner a credible role model and persuasive arguments. Gagne, like Bloom (1956), also created a taxonomy of learning behaviors. According to Gagne (1985), learning tasks that develop intellectual skills are classified in a hierarchy going from simple to more complex: stimulus recognition, response generation, procedure following, use of terminology, discriminations, concept formation, rule application, and problem solving. The less-complex behaviors might be assessed within the classroom via scaffolding; the more complex might require a specific action. 
The usefulness of Gagne's taxonomy to instructional design is that it provides a logical ordering of learning conditions that should be completed to facilitate learning at each level. By using Gagne's taxonomy for task analysis of a SLO and prerequisite knowledge and skills, instructors can more effective sequence instruction. Gagne identified nine instructional events and (corresponding thinking process): gaining attention (reception), informing learners of the objective (expectancy), stimulating recall of prior learning (retrieval), presenting the stimulus (selective perception), providing learning guidance (semantic encoding), eliciting performance (responding), providing feedback (reinforcement), assessing performance (retrieval), enhancing retention and transfer (generalization). This taxonomy can help instructors sequence learning activities and can serve as a framework for designing instruction and selecting appropriate assessment instruments, including media or tools (Gagne et al., 1992).

Through the use of Bloom's and Gagne's taxonomies, an assessment instrument that matches the conditions and levels of work can be found and applied. A detailed list of assessment possibilities follows below (Allen, n.d.).

Providing conditions that allow factors of student performance to be observed is essential to measuring SLOs. Because "faculty may not achieve a good fit between the learning they say they want and tests and assignments they actually give" (Walvoord \& Anderson, 2010, p. 10), the Guidebook provided guidance on how to select tools and construct assignments that align with SLOs. Research is ongoing into how to use computerized tools and systems to create the conditions necessary for valid and reliable assessment to occur. A major design goal of the Guidebook was to teach faculty currently 
unaware of this and how to use tools built into Moodle to better support the assessment conditions described above.

As the process of Guidebook development unfolded, participants revealed a variety of assessment needs and practices, which were then explored and analyzed; As pertinent needs and practices emerged, these underutilized practices were revisited and new practices demonstrated. Since this domain was well defined, needs and practices fell within knowable parameters, e.g., research described commonly used assessments, CCC had collected data on assessment types being used to measure general education outcomes which, in turn, helped define the parameters, and there was a wealth of literature that connects assessment principles and practices to specific web-based pedagogical tools (WBPTs). The next section examined this literature to reveal categories of tools. By better understanding these categories via the drafting of the Guidebook, I successfully made connections to assessment method/tools to tools available in Moodle within a compendium of assessment methods/tools.

There are good examples within the literature that classify assessment tools based on the needs of outcomes-based assessment. Allen (n.d.) has created a list of assessment tools that identifies appropriate uses for a large list of assessment tools and sorts them by: method $(\mathrm{d}=$ direct, $\mathrm{i}=$ indirect $)$; domain $(\mathrm{c}=$ cognitive, $\mathrm{p}=$ psychomotor, $\mathrm{a}=$ affective $)$; usage type ( $\mathrm{f}=$ formative, $\mathrm{s}=$ summative $)$; bloom's level $(\mathrm{k}=$ knowledge, $\mathrm{c}=$ comprehension, $\mathrm{a}=$ application, ase $=$ analysis or synthesis or evaluation); pros; and cons. This example was useful and, once reformatted, was included in the first draft of the Guidebook. While this example provided a starting point for the matching of SLO to 
assessment method / tool, it did not provide specific examples of how to apply the tool, which tool in Moodle corresponds to the methods, nor were discipline-specific examples given. Since instruction and assessment are inextricable, the table was enhanced with such references. These additions enhanced and extended the Allen effort and was included in Guidebook design.

CCC upgraded to a newer version of the Moodle LMS in Fall 2012 [the period during which this project took place]; the following lists Moodle 2.x tools. Methods/ tools for direct assessment were listed; indirect assessment tools were not listed. Assessment methods / tools were categorized according to four functional aspects of assessment: a) formative assessment of task performance (scaffolding-focused methods/tools), b) cooperative, c) objective assessment, and d) authentic performance.

The literature cited tools that allow question prompts and feedback to work as a dialog are useful for scaffolding and formative assessment tasks; in Moodle, this would include survey, poll, and feedback. Tools that encourage cooperative learning (social learning) via student-to-student and student-to-instructor interaction, and group processes are useful tools for assessment; in Moodle, this included discussion I, wikis, and group assignments. Providing criteria for performance and examples of high and low quality examples can be done with use of the Moodle Rubrics Scoring tool. Objective tests useful for encouraging memorization and for drill and practice include the questions/quiz tool in Moodle. Authentic/Performance assessments allow students to emulate the real-world tasks that they might be asked to do in the workplace 
Tools that allow question prompts and feedback to work as a dialog are useful for formative assessment tasks; in Moodle, this would include survey, poll, and feedback. The use of Moodle formative assessment tools can lead to improved personalization via student-to-instructor interaction and active teaching. Using terms from scaffolding theory, this use of Moodle tools has the potential to increase the dialogic and interactive aspects of instruction (Puntambekar \& Hübscher, 2005) because instructors who engage in formative assessment are potentially more aware of problems with student understanding of materials and instruction. The Guidebook, through building awareness of new assessment tools and strategies, encouraged greater faculty engagement in polling as a scaffolding activity. Polling geared toward helping individual students understand the materials and used to solicit student questions about misunderstood ideas, those in need of more elaboration, or restatements of unclear ideas could be a real benefit to instructors using internet-based resources. A benefit of obtaining student data on curriculum clarity is that it allows faculty to better understand how their selection and enactment of curriculum and related design work impacts student learning. Student feedback can focus the faculty member's attention on problem areas within the curriculum, encourage revision of those materials, and can lead to improvements in curriculum quality. This is especially important if the instructional designer does not teach the course (as is increasingly the case in distance learning programs) because he/she might not otherwise learn about these issues. When this process is iterative over time, it can lead to continuous improvement of the curriculum, and thus closes the assessment loop. If this process is informed through peer review and collaboration, it 
opens the doors of the classroom and improves faculty acceptance of and participation in a teaching commons (Huber \& Hutchings, 2006). Participation of adjunct faculty in this commons could improve morale, feelings of being respected, and loyalty to the college of this often-marginalized group (Chism, 1999).

The use of Moodle assessment tools can lead to improved meaningful engagement with the curriculum via student-to-content interaction - Dunlap, Sobel, and Iceman-Sands (2007) showed that incorporating the use of guided activities, such as a short answer survey that is filled out as students interact with content can focus students on their own understanding and helps students to pay more attention to content. Research shows that students tend to quickly skim and scan Web sites to locate the "right answer" to their questions instead of reading for comprehension (Quintana, Zhang \& Krajik, 2005). Dabbagh and Kitsantas (2005) showed that students strive to understand materials more fully if they are asked to rate their clarity. The intended outcome is that students will slow down, read more mindfully and, in turn, lead to more active reading / watching of materials leading to higher comprehension of materials. An indicator that this is happening will be improved summative grades.

More extensive use of assessment tools and feedback should establish new processes for data collection useful to support course design and redesign efforts and provide evidence for accreditation. The evaluation of formative data will be used to support individual instructor-designer's curriculum (re)design processes. This evidence will be used to both revise unclear curriculum-making it easier to understand and learnand to expand the curriculum in ways that support the learning needs of diverse learners, 
for example, through differentiation of the materials and development of scaffolding and cognitive tools, which are then added to the whole collection. This process, if continued longitudinally, could lead to a continuous curriculum improvement process wherein the individual practitioner can gather, analyze, and reflect upon a collection of evidence about the quality of the curriculum (Tucker, Jones, Straker \& Cole, 2003). The collection of artifacts concerned with a common curriculum can establish a foundation for a teaching commons or collaborative curriculum development / improvement efforts - Bass and Bernstein (2008) believe faculty would be willing to open their practices to the review of others if proper supports were enacted. This project has helped identify such criteria that can be acceptable to faculty at CCC.

The Guidebook provided practical descriptions of and advice on how assessment needs can be met by Moodle and provided a framework for developing online training materials for Moodle. Note: Moodle training materials development was beyond the scope of this dissertation, but will be pursued as part of overall DL goals for CCC. Moodle's rubrics scoring, survey/poll/feedback, adaptive mode quiz, checklist, notifications, and outcomes tools can be collectively referred to as web-based pedagogical tools (WBPTs). The WBPTs were classified by assessment functionality and tied to online training resources.

Rubrics Scoring Tool. Reddy (2007) studied the theory of rubrics and their practice and has assembled from the literature this definition of "rubrics":

rubrics are guidelines that enable the assessment process of communicating expectations; providing focused ongoing feedback; and grading. A rubric is defined as a document that articulates the expectations for an assignment by listing the criteria, or what counts, and describing levels of quality from excellent 
to poor. [Rubrics are] considered an effective tool for measuring, evaluating and reporting student achievement. [R]ubrics are also designed to guide students' learning, teachers' instruction, course development and administrators program observations (Andrade and Du, 2005; Glickman-Bond and Rose, 2006, as cited in Reddy 2007, p. 4).

Rubrics are especially useful for formative assessment and make it possible to communicate to students: 1) what good performance is (i.e. the student must possess a concept of the goal or standard being aimed for); 2) how current performance relates to good performance (for this, the student must be able to compare current and good performance); and 3) how to act to close the gap between current and good performance" (Sadler, 1989b). Rubrics provide the impetus for clarifying learning goals beyond the level taken by many faculty members.

Moodle 2.x incorporates a rubric-scoring tool into the suite of assessment tools available to faculty. This tool has made it easy to incorporate the use of rubrics into the assessment practice of faculty across a broad range of subjects. Because the use of the rubrics scoring tool required faculty to be more explicit about what they are really trying to teach, i.e., more clearly articulate evaluation criteria, use of the tool should help students to understand what good performance is. The use of the rubrics scoring tool will also require faculty to translate course outcomes into specific actions for student performance and "provide a detailed explanation of what a student must do to demonstrate a skill/ proficiency or criteria in order to attain a particular level of achievement or performance" (Reddy, 2007, p. 5). Rubrics provide a multidimensional mechanism for scoring student work that allows students to understand how their performance measures up to the standard. The articulation of quality definitions will 
greatly benefit students as they try to understand how to guide their activities toward good performance, the second condition by which students benefit from formative assessment. Because the scoring mechanism is not necessarily a summative one (i.e., it is not necessarily a grade), students are more likely to use the feedback to guide improvements as they continue to work on their performance. In this way, the rubrics scoring tool meets Sadler's (1989b) third condition of understanding how to close the gap between current and expected performance.

A benefit of increased use of the rubrics scoring tool could be increased intersubjectivity and interactivity in online courses. Puntambekar and Hubscher (2005) described a component of instructional scaffolding called intersubjectivity, which involves defining (and negotiating) the joint ownership of the task between the student(s) and teacher so that both begin to understand the task from the perspective of the other. Increasing information to the instructor will improve intersubjectivity. The instructor (esp. if he or she is a novice) may still be learning ways to do this, thus, the rubric scoring system may be helpful to instructors in discovering alternate ways to define and design learning tasks and expectations and apply these new definitions and designs to diverse learners. This may be very useful information for improving task definition within the curriculum. Also, in instances where the instructional designer and instructor are not the same person, this information can be fed back to the designer so as to inform improvement processes.

Survey/Poll/Feedback Tools. According to Lee (2006), the "primary way to assess whether learning has occurred is to ask students questions" (p. 223). When 
students answer questions, they reveal not only the knowledge that they have acquired, but also how new knowledge fits together with previous knowledge (Lee, 2006). One rationale of using frequent surveys or polls in instruction is to increase the number and frequency of times students are asked to self-assess their understanding of curriculum, instruction, and/or assessment within an online course with the answers being used to help the instructor more effectively monitor and support student progress and to adjust their teaching practice. Their use of online questioning activities/ tools should theoretically encourage students to increase their feedback to instruction. "Choi et al., found that on-line guidance seems to affect the frequency of questions students generate over time. Specifically, students generated significantly more clarification and elaboration questions [...]" (Azevedo \& Hadwin, 2005, p. 375). Based on this finding, the polling system should produce adequate artifacts for individual instructor-designers and the design community to use for curriculum improvement efforts. Informing faculty about the best practices with Moodle survey/poll/feedback tools was a goal of the Guidebook.

By providing opportunities for students to provide feedback on curriculum quality, their performance in comparison to the expectations, and their overall learning, I hoped to validate motivational theories that show that increasing opportunities for student metacognitive processing of their learning of course materials results in improvements in self-regulation and higher levels of course completion. Since a frequently used measure of quality is clarity of materials and instruction, surveys/polls could focus student's attention toward this important aspect of curriculum. These criteria should be effective in 
improving achievement because, based on studies of low-inference teaching behaviors, these aspects are shown to be one of the strongest influencers of student performance in a face-to-face course (Marsh, 2007; Murray, 2007). In Murray's 1983 study, clarity, at .29, was near the top of factors that correlated into the amount learned rating, the only other factor that showed a higher correlation value was task orientation (.39); informality tied at .29. In addition, selecting clarity makes sense because it is a teaching behavior that carries over to online environments, as opposed to other behaviors, such as informality, expressiveness and disclosure. There is a caveat here about the differing contexts. Murray's (2007) research is based on studies on teaching behaviors in face-to-face courses; this study also included the online environment. There were questions as to the generalizability of findings from one context to the other.

There are ways to promote student acceptance of survey/polling/feedback systems. Better response rates occur when faculty actively promote the survey/polling system (Ballantyne, 2003); assessment-tool-using faculty will be encouraged to endorse student use. Ballantyne (2003) reported that student response rates increase when survey/polling systems are convenient and easy to operate; Moodle's design of surveys are easy-to-use (one click) operation and are conveniently placed within the courseware: survey prompts will appear on pages that students are already using.

Moodle surveys/polls/feedback can be administered either anonymously (without personally identifiable student information) or onymously (with personally identifiable student information). More needs to be learned about the use of onymous surveys to collect student feedback. Moodle surveys/polls/feedback are generally built into the 
courseware and student answers are tracked by name and time. This goes against conventional wisdom that respondents will not be honest in their responses if they can be personally identified. The use of onymous surveys might be a concern if students fear that negative feedback will be used against them somehow by the instructor. Still, I believe that the benefits of onymous surveys outweigh the possibilities for confounding data with dishonest responses, which is likely to be minimal, once the reasons for collecting and use of the data are explained to students. An unrealized goal of the Guidebook was to encourage faculty to affirm that their students will benefit from providing honest answers, that the use of the polling data is solely to improve course and instructional quality, not punish students who have difficulty with the course materials. Plus, if it is made clear to students that the survey results will be used to provide help or info to the student, they will realize that this process is not possible if students remain anonymous. This mitigates, and hopefully offsets, a finding by Tucker et al., (2003) that information about changes that have occurred as a result of sharing their concerns are infrequently reported back to students; the use on onymous surveys will make such reporting much easier.

An unrealized aspect of the project was based upon an assumption that studentprovided feedback can be successfully collected using web-based pedagogical tools (WBPTs) such as the built-in Moodle survey tool. Research shows that the data collected in this way is valid for formative assessment, easier to collect and analyze, and leads to more input by students (Bain \& Swan, 2011). Online survey/rating systems have been shown useful for acquiring reliable and valid data from students. Surveys are commonly 
used to research student cognitive processing and emotional responses to stimuli encountered in online courses. Online instruments, such as the Online Learning Interactivity Inventory (OLII), which has been used to determine student wishes and expectations for interactivity within online courses (Northrup, 2002) or the Learning And Study Skills Inventory (LASSI), which is used to assess student metacognitive processing during learning and studying events, are shown to be a valid research methodology for gathering data relating to student cognitive and emotive processing (Northrup, 2002).

Quiz tool, including Adaptive Mode Quizzes. Multiple-choice quizzes have limitations as assessment tools. They are often cited as being effective for measuring cognition only at lower levels and, thus, orient students to take a rote approach to their studies; they often do not validly measure student learning, in particular when used to measure higher order thinking skills. They are perceived to be easy to cheat at and this may encourage cheating. They provide few opportunities for useful feedback. Despite their limitations, Hatzipanagos and Warburton (2009) found that multiple choice quizzes are the most commonly used format of electronic quiz. They are widely popular with faculty because they are often bundled with course packs from textbook publishers, easy to administer, are time effective because they are computer-marked and scores are transferred directly to the gradebook. Multiple choice tests are used by most of the faculty at CCC.

Moodle supports use of computer-marked multiple-choice question tests. Instructors can choose to use the scores summatively or formatively by administering them via adaptive mode. 


\section{Navigation/Learner Control Modules: Completion Tracking, Personalized}

Learning Designer, and Notifications. LMSs, like Moodle, are incorporating

navigation/learner control features that allow instructors to better scaffold and sequence instruction. The use of three WBPTs are notable here: completion tracking, that can act as an aid for monitoring progress; students use it to check off items they have completed and teacher review student lists to monitor overall class progress toward learning goals; personalized learning designer, an adaptive control feature, allows instructors to limit learner controls based on learner performance; and a notification module, that automates the sending of canned messages to students or instructors when certain criteria are met. "The Moodle Completion Tracking module allows teachers to create a "to do" list for students to work through and provides an easy visual representation of what has been accomplished so far. With a Checklist, teachers can monitor progress as students complete items on the list, and students can see a progress bar showing the percentage of the items they have completed" (OIT support, 2011).

While, technically, the Moodle checklist and notification modules are web-based cognitive tools (Pea, 2004), and not a scaffold, they are closely related to fixed scaffolding concepts, which were shown by Dabbagh (2003) to have the potential to prompt metacognitive responses from students and foster increases in SRL.

Formative assessment tools like this use can help students "learn how to learn." A goal here is to encourage students to do their best at comprehending the curriculum and then rate their understanding. Metacognition is 'thinking about thinking,' but metacognition also involves knowing how to reflect and analyze thought, how to draw 
conclusions from that analysis, and how to put what has been learned into practice (Downing, Kwong, Chan, Lam \& Downing, 2009); metacognition is needed for students to learn how to learn. The completion tracker will check items that students complete, the notification tool will send a notice about student progress to the student's email account; these tools will trigger a metacognitive response in the students. As part of the triggering event, individuals will be cued to self-regulate by "engaging in metacognitive monitoring, which can lead to attempts to control the learning process through changes within any of the four foci of self-regulation. For example, an individual may notice that a particular learning strategy (e.g., outlining) does not seem to be leading to retention of the material, and switch to another strategy (e.g., self-questioning)" (Winters, Greene \& Costich, 2008). These adaptations, once learned, may then influence future learning activities. It is also possible that individuals, knowing a check will be required on an asyet-uncompleted assignment or that a notification will be forthcoming if an assignment is not turned in, may recycle back through previous learning, particularly when monitoring reveals that the strategies being used are not resulting in understanding or retention. However, this recycling is not likely unless the student has well-developed regulatory skills.

Winters et al., (2008) confirmed that individuals in online courses are capable of monitoring and controlling the cognitive, motivational, behavioral, and contextual aspects of learning, but that novice online learners need to learn to do this. Based on operant conditioning theory and research into web-based pedagogical tools (WBPTs), once students are taught how the rubrics scoring, completion tracking, notifications, and other 
tools operate, and the use of them is repeated and reinforced, students should be able to carry on SRL behaviors without frequent reminders. The checklist and notification tools, by virtue of their ability to prompt metacognitive responses and SRL, should help learners actively construct their own meanings and increase the capability of individuals to set goals for their learning using the various activities in the course and from their own internal cognitive systems.

Cooperative Tools. A recent review by Johnson, Johnson, and Smith (2007 as cited by Clark, 2010) concluded that

Cooperation, compared with competitive and individualistic efforts, tends to result in higher achievement, greater long-term retention of what is learned, more frequent use of higher-level reasoning and meta-cognitive thought, more accurate and creative problem solving, more willingness to take on difficult tasks and persist in working toward goal accomplishment (p. 19).

Among 138 influences on learning, Hattie (2009 as cited in Clark, 2010) ranked the benefits of cooperative versus individual learning twenty-fourth, with an overall effect size of .59 (Clark, 2010).

Because cooperative, social learning is growing in prominence, the Guidebook included all examples of online methods/ tools for cooperative, social learning, such as blogs and mini-blogs (such as Twitter), breakout rooms, chats, e-mail, message boards, online conferencing, social networks, and wikis.

Outcomes and Reporting tools. The outcomes and reporting tools are part of a new tool set being introduced by LMS publishers related to "learning analytics." Learning analytics provides evidence for accreditation by connecting course outcomes to 
programmatic and institution outcomes, and then linking those with actual assignments managed inside of the LMS.

The significance of this problem/rationale is that Moodle, and related electronic tools, provides a set of tools and methods to conduct and manage the work of assessment and record-keeping tasks that faculty engage in. These tools are extremely versatile and can be adapted in many ways to align with the assessment practices of faculty. Moodle acts an evidence repository that can allow examples of student performance and work to be organized by outcomes and be stored longitudinally in either a portfolio format or assignment databases, and that can be drawn from when programmatic or institutional program review takes place.

Rationale 6. The efforts for accreditation bodies in promoting institutional change through applying assessment practice are worthwhile and will accelerate both institutional improvement and student learning in both traditional and online courses.

Based on research that confirms the effectiveness of assessment practices in improvement efforts at the macro and micro levels, the efforts for accreditation bodies in focusing institutional change through applying assessment practice are worthwhile and will accelerate both institutional improvement and student learning in both traditional and online courses. Assessment of educational quality has always been central to the accreditation process but the recent emphasis stems from external constituencies (public institutions and their peers) wanting to be held more directly accountable for the results of their efforts (Baker, 2002). As such, according to Baker (2002), each "accredited institution is expected to formulate a plan which provides for a comprehensive 
assessment of outcomes and further to incorporate the results of assessment to improve planning that leads to successful achievement of mission and goals" (p. 5). In other words, accreditation requires institutions to assess, and use the data collected through assessment formatively to continuously improve. Assessment, and in particular formative assessment, of institutional missions and goals is explicitly believed to be the factor that most influences institutional improvement.

Many colleges primarily work to improve assessment practice, not because it accelerates learning, but because accreditation requires it. The case is also made that reform should be primarily made because it meets the core learning and teaching mission of the institution. Whatever the emphasis, this is a worthwhile activity for institutional engagement.

Constituencies at $\mathrm{CCC}$ want the college to improve and believe that the college will be successful in implementing assessment reform. College leaders recognize that assessment reform will provide increased rigor and accountability and are working to build a "culture of assessment" at CCC. A "culture of assessment" is defined as "an environment in which continuous improvement of student learning is influenced by thoughtful assessment is expected and valued." A survey of student satisfaction conducted in 2006 by CCC revealed that students want increased rigor. A subset of faculty members is engaged in building a culture of student-centered learning and wants faculty to adopt more formative assessment practices that support this culture.

According to Weiner (2009), "there are 15 major elements contributing to the attitudes and behaviors of a true culture of assessment. The fifteen elements needed to 
achieve a culture of assessment are the following: clear general education goals, common use of assessment-related terms*, faculty ownership of assessment programs*, ongoing professional development*, administrative encouragement of assessment, practical assessment plans*, systematic assessment*, the setting of SLOs for all courses and programs*, comprehensive program review, assessment of co-curricular activities, assessment of overall institutional effectiveness, informational forums about assessment, inclusion of assessment in plans and budgets, celebration of successes, and, finally, responsiveness to proposals for new endeavors related to assessment" (Weiner, 2009). The creation of the Guidebooks supported no less than six of the elements (supported elements are marked with *) leading to a culture of assessment at CCC.

Barriers to assessment reform put up by faculty are based in institutional and professional traditions, which, at CCC, are haphazardly upheld, and faculty fears that are based on emotion and intuition. Faculty autonomy is a cherished tradition and executive efforts to change any part of any teacher's work is met, by some, with suspicion and distrust. The professionalism of faculty is held in high regard, this regard is derived from disciplinary training; there is not as strong a tradition of professionalism in teaching and adherence to collective professional teaching performance standards; Elton (2010) cited this as a problem throughout higher education within the western world. CCC faculty are quick to support the principle of academic freedom, but tend to apply this principle only partially; they want freedom to make curriculum decisions but many are unwilling to critically examine the results of those decisions. While these decisions support disciplinary studies, such examination could reveal weaknesses in their choices in terms 
of effectiveness for learning. In some faculty circles, summative programmatic assessment is a pejorative idea. "Being assessed in undoubtedly an emotional business. Having a judgment made about the quality of your work is a potential humiliating experience" (Clegg \& Bryan, 2010, p. 218), particularly when evaluation of faculty performance is involved, that conjures up possibilities of assessment data being socially misused and shrill calls to stop "the negative and destructive side effect of assessment which devalues personal worth and future prospects" (Taras, 2008, p. 174). Antidotes are to promote the neutrality of all assessment, endorse feedback that encourages positive motivation beliefs and self-esteem (Nicol, 2010), and to promote formative assessment as an alternative. The process of creating the Guidebook did provide opportunities to critically examine these assumptions and CCC made headway in seeing how they can fit into a culture of assessment.

The significance of this problem/rationale is that the faculty does not understand accreditation's focus on assessment reform as well as they should and they may perceive reform efforts as intrusive and disruptive; consequently, they erect barriers that hinder reform. A research goal, then, was to explore faculty understanding and perceptions of accreditation and its focus on assessment reform and how associated perceptions are grounded in traditions of faculty autonomy, professionalism, and academic freedom.

Rationale 7. There was much to be learned from processes of $R \& D$ that were modeled in the creation the Guidebooks, such as collaborative content identification, joint instructional design, use of research for making instructional design decisions, and prototyping and field-testing of materials to ensure their efficacy. Exposing faculty to 
these processes / new models helped them to improve their instructional design efforts. My research into text-based instructional design used for the guidebook development did benefit others.

As stated earlier in the literature review, published guidebooks are useful in lots of ways. Finished products are great, but there is educational value in demonstrating the procedures leading to their creation as well. For example, guidebook creation can provide opportunities for situated, i.e., workplace-based, learning of instructional design techniques; such situated learning can be especially useful to novice designers. Since instructors are subject-matter experts, and not always well skilled in instructional design, they can benefit from seeing how others create guidebooks. Faculty members have long produced their own text-based instructional materials, and this remains true today as more internet-facilitated, multimedia enhanced instruction occurs. They generally design multimedia materials "mostly based on the[ir] intuitive beliefs [...], rather than on empirical research, and as a consequence some of the potential benefits of e-learning may not be fully realized or implemented" (Thompson \& McGill, 2008, p. 144). An antidote to this over-reliance on intuition was the use of research-based techniques learned and demonstrated as part of this project. Having an expert instructional designer model the step-by-step processes used in guidebook design taught the faculty better design processes. Instructional materials that were successfully jointly designed using group processes exemplified production techniques that benefitted other group design processes. The procedures involved in field-testing of materials served as a useful model for others who were interested in testing materials before using them with learners. 
One goal of this dissertation was to test and model procedures of instructional design as it applied to guidebook development. Instructional design is a system of developing well-structured instructional materials using objectives, related teaching strategies, systematic feedback, and evaluation (Moore \& Kearsley, 1996). It can also be defined as the science of creating detailed specifications for the design, development, evaluation, and maintenance of instructional material that facilitates learning and performance (Sweller, Merriënboer \& Paas, 1998). A prominent aspect of the science of instructional design includes cognitive load theory; "Cognitive load theory has been designed to provide guidelines intended to assist in the presentation of information in a manner that encourages learner activities that optimize intellectual performance" (Sweller et al., 1998).

Cognitive load is the capacity of the learner to process items in working memory, make sense of them, and convert them into long-term memory. Human cognitive processing capacity is limited and each element contained within an instructional design adds cognitive load for learners. Cognitive load theory has broad implications for instructional design. "The cognitive load imposed by instructional designers should be the pre-eminent consideration when determining design structures" (Sweller et al., 1998, p. 262). Cognitive Load Theory provides a general framework for instructional designers that help them understand how to control the conditions of learning through the design of their instructional materials. The theory differentiates between three types of cognitive load: intrinsic cognitive load (defined as "load intrinsic to the material being presented and that can not be altered"), germane cognitive load, and extraneous cognitive load. 
Specifically, Sweller et al., described guidelines that help instructional designers to decrease "extraneous cognitive load" (defined as "the manner in which material is presented or the activities required by students" (p. 259)) during learning, and refocus that learner's attention toward germane presentations; i.e, those that "contributes to the construction of schemas" (p. 259). The guideline that was drawn from Sweller et al., (1998) is that instructional designers need to avoid extraneous cognitive load by designing their materials well; this means being aware of all of the modes in which cognition is being tapped, and avoiding ones that are not essential.

The application of cognitive load guidelines requires a deep understanding of modality. Experts in document layout remind us "all texts are multimodal" (Delin et al., 2003, p. 54). In Delin's et al., (2003) view, “every communicative act, spoken or written, takes place over more than one 'mode' or channel of communication: [...] for example, written language always involves other visual elements, such as even the most basic choices of typeface, margins, and headings. We take the view that language, layout, image, and typography are all purposive forms of communication” (p. 55). An expert in the science of instructional design for e-learning, Ruth Clark (2011) elaborated on multimodal design and provided many principles of design that I considered as I designed these guidebooks. While Clark's principles pertain to e-learning design, those that follow here also pertain to text-based instructional materials.

Clark (2011) recommended that instructional materials "include words and graphics rather than words alone" (p. 70). In her definition of "graphics," Clark included "illustrations such as drawings, charts, graphs, maps, or photos" (p. 70). Graphics (with 
the possible exception of decorative visuals added for aesthetic appeal or for humor) should not be added to the materials after the words are written, rather, instructional designers "should consider how words and pictures work together to create meaning for the learner" (p. 71). Including both text and graphics readily engages the learner in active learning, where learners engage in "relevant cognitive processing such as attending to the relevant material in the lesson, mentally organizing the material into a coherent cognitive representation, and mentally integrating the material with their existing knowledge" (p.

71). Based on Clark's (2011) recommendations, the guidebooks included text and also relevant graphics. These graphics included some of the following examples:

representational visuals to illustrate the appearance of an object (e.g., screen capture of software application or a photograph of equipment); organizational visuals to show qualitative relationships among content (i.e., concept map); relational visuals to summarize quantitative relationships (e.g., bar graph or pie chart or a map with circles of different sizes representing location and strength of earthquakes); transformational visuals to illustrate changes in time or over space (e.g., photos that demonstrate a computer procedure or stages of how volcanoes erupt); interpretive visuals that make intangible phenomena visible and concrete (e.g., drawings of molecular structures or bacteria) (Clark, 2011). These graphics can be used in different ways to teach various content types, such as facts, concepts, process (defined as "a description of how something works") procedures (defined as "a series of steps resulting in completion of a task"), or principles (defined as "guidelines that result in completion of a task) (p. 75). The use of graphic images can teach, but if not pertinent to the learning task, can also 
confuse the learner. Since the guidebook dealt largely with all of these content types, I incorporated as many graphics as possible, but avoided those that were extraneous.

The use of graphical representations within guidebooks is also endorsed by Mehlenbacher (2010), who stated that the use of graphical representations in the form of diagrams in combination with textual descriptions often facilitate the understanding of complex hierarchical and sequential relationships and are more easily remembered than textual descriptions. Designers should replace textual representations with visual ones, if the inter-object relationships are complex, multidimensional and/or easily misunderstood. I did use graphical representations where greater understanding about the relationships between ideas and objects was sought.

Clark (2011) spoke to the style of writing that should be used when authoring a guidebook for faculty. Her findings showed that, when discourse processing, people work harder to understand material when they feel they are in a conversation with a partner, rather than simply receiving information. [...] In short, expressing information in conversational style can be a way to prime appropriate cognitive processing in the learner (p. 184).

Since these materials are being designed by a DC for DCs, and since my colleagues will pay more attention to a colleague rather than a formally written guidebook, I wrote in a style that I would normally use in a collegial conversation.

A lesson learned from cognitive load theory was that learners could be overwhelmed if too much information is presented at one time. One solution to this dilemma is to break the lesson into manageable parts, using a technique called "segmenting," which allows the learner to "better manage essential processing" (p. 210). Thus, the rationale for using segmenting is that it allows the learner to engage essential 
processing without overloading the learner's cognitive system. Since creating and aligning curriculum with SLOs is a complex procedure with many steps, including working with high levels of abstraction, I carefully segmented the lessons within the guidebooks.

Clark (2011) described another principle that supports effective cognitive loading; she recommended activating prior knowledge by using the "pretraining principle". This principle should be used in learning situations involving complex material. Learners can learn more easily if some of the processing can be done in advance of the presentation. An example would be to present separately the definitions of instructional design terms from graphics of pertinent procedures within the guidebook. If they already understand what the "assessment loop" is, they can

devote their cognitive processing to building a mental model of how that component relates to others in the causal chain. Thus, the rationale for the pretraining principle is that it helps manage the learner's essential processing by redistributing some of it to a pre-training portion of the lesson (p. 215).

Clark (2011) wrote about adding "step-by-step demonstrations of how to perform a task or solve a problem" (p. 224) by including "worked examples" in materials. Examples can help learners understand procedural skills such as how to measure SLOs. Examples are popular with learners, who often bypass verbal descriptions in favor of examples. Time-strapped faculty will use the learning strategy that is most respectful of their time, so ample use of examples was a good idea for the Guidebooks. Moreno and Valdez (2007) showed that worked examples have proven beneficial for learning new applications of teaching principles. When worked examples are pulled from a wide range of differing contexts, and displayed with varying levels of completeness, learners can 
apply those examples to a wider range of situations. This is called "far transfer learning" (Clark, 2010, p. 240) and these techniques can be incorporated into guidebooks by providing SLOs from a wide -range of disciplines and by showing examples of how SLOs fit into larger assessment and curricular planning efforts. This was an unrealized goal of the guidebook.

Folmer, Moynihan, and Schothorst (1992) described the three basic types of manuals. Reference manuals store information that is too detailed to remember, reminds users of things that might be forgotten, and sums up what is known about a subject. Instruction manuals teach new knowledge and skills, show how to do something, and introduce new ways of looking at a task. Teaching manuals teach you something you will pass onto others, teach you how to teach others and to teach yourself. The Guidebook that was created for this project had aspects of all three types.

The previous literature in applied research in text-based instructional design helped me to produce the best possible Guidebooks.

\section{Summary and Conclusion}

The literature review examines key rationales that impacted the creation of the Guidebook. These rationales can be groups into four categories: a) they support assessment reform, b) they support the development of active teaching and clarity, c) they explore the array of assessment tools available in Moodle and d) they support accreditation efforts. The analysis and application of the findings described herein formed the foundation from which the development of the Guidebook proceeded. The next 
chapter describes the research methods that I used to further research and refine the intended product. 


\section{CHAPTER 3}

\section{RESEARCH METHODOLOGY}

\section{Preface}

Note: I have made changes to the project and research plan that were described in and defended during my proposal. The following preface describes what has changed.

I had originally intended to research and develop one guidebook, entitled Guidebook To Moodle Assessment Tools For Instructional Department Chairs. The dissertation describes two guidebooks. I informed the committee of how this change came about and how it fit into my research plan.

Two guidebooks were created. To meet accreditation needs, the Clackamas Community College (CCC) curriculum committee decided that it needed a Guidebook for Course Outline Revision, which I principally authored. This project emerged simultaneously to the defense of my proposal and was needed as soon as possible. I decided that this would fit into my preliminary research plan. It did indeed help me to prepare more effectively for my dissertation project. In completing this preliminary project, I learned that the DCs (and college) needed support at a more fundamental level. They needed a reference manual for writing measurable SLOs and that identified practical tools for assessment more than a guidebook on Moodle resources. To accommodate their needs, I decided to focus my research and development on a book that guided more fundamental aspects of assessment; this guidebook is entitled Guidebook 
For Student Learning Outcomes \& The Assessment Loop. While I had envisioned the proposed Guidebook as a comprehensive training manual for Moodle assessment tools, it ended up being more focused on direct outcomes-based assessment. I describe what I learned during this preliminary project in chapter 4 . I edited the dissertation throughout, with the exception of large parts of chapter 3, to reflect this change.

I made other changes to the manuscript since the proposal defense. I updated my list of outcomes to better reflect edits made to the problem statement in chapter 1 . I added additional research to the literature review (chapter 2) to include literature of pertinent instructional design literature for text-based guidebooks. I annotated chapter 3 in the sections where I made edits since the proposal defense. I described what the preliminary project and outcomes of this work were in chapter 4.

After successfully defending my proposal, I moved forward with my human subjects review application. The HSRRC required that I make changes to the proposed research methods. In essence, the changes entailed eliminating interviews and focus groups from the research protocols. It was feared that confidentiality could not be maintained with interviews or group interviews. I obtained an exception to the HSRRC rules near the end of the process, so that I could more openly discuss the new curriculum throughout my institution. I revised chapter 3 to reflect the changes requested by the HSRRC. In addition, some language in chapter 3 described studying CCC faculty attitudes was incorrectly stated as I, in actuality, studied the instructional design of the Guidebooks. This language has been edited. 
At the request of the Committee, I removed references to ethnographic research. I also eliminated some research steps that I had proposed, but that were thought to be beyond what was necessary to successfully complete the dissertation. Notes indicating these changes are included in text.

\section{Introduction}

This chapter describes the methodology and design that I will use to conduct the research for this dissertation. I plan to use a multi-step process focused mainly on qualitative surveys. I have overlaid this multi-step process with a timeline, project implementation plan, and methodological contexts so as to provide a comprehensive picture of how this project would roll out over time.

\section{Research Methodology}

In an attempt "to provide a demonstration of the [Ed.D candidates] ability to apply knowledge in a professionally productive and academically sound manner," (p. 113) and "to develop more productive linkages among research, theory, and practice in the context of our professional students' doctoral research" (p, 114), Bridges et al., (1995) proposed an alternative to the traditionally structured research-based dissertation. Bridges and Hallinger promoted a problem-based learning approach to doctoral study. I prefer this approach to traditional approaches because it provides an opportunity for me, as a practitioner, "to develop the capacity to apply knowledge from theory and research to problems of policy or practice" (p. 116) as they exist at my institution. It is an opportunity for me to deeply assess problems of practice and offer solutions for them based on my particular perspective and within the framework of my department and 
unique skill set. In overview, the research and development approach requires that the author begin with initial research and information collecting in order to identify a problem in the field and develop a product that solves the problem. Once a problem is established and a solution, in the form of a product, is proposed, the author conducts an iterative cycle of refinement by developing a preliminary form of the product, which is then field-tested and feedback gathered from the participants. This feedback is used to refine and improve the product, which is again field-tested and feedback gathered. Ultimately, a useful high-quality product emerges. The author must situate his project in a real world context where product design, product content, and target audience are sensitively considered as part of the context for the dissertation (Bridges et al., 1995). For this project, the real world context is CCC and the audience for the project is the instructional Department Chair (DC). The problem is inconsistency in DC understanding of assessment theory and practices and engagement in assessment leadership activities. The proposed product is a set of teaching/reference guidebooks for assessment practices and technology-enhanced assessment; they are entitled Guidebook For Writing and Assessing Measurable Student Learning Outcomes and Guidebook For New Course and Outline Revision Approval, the latter Guidebook was created as I conducted a preliminary research and development cycle. Together, this set of materials should support faculty in better understanding the assessment process in how to write measurable SLOs, establish an assessment plan, incorporate formative assessment strategies, identify and align prerequisite knowledge/learning tasks to meet SLOs. 
The Guidebooks will attempt to build understanding of assessment theory and practice and provide resources to empower DCs to play a role in leading colleagues to new understanding about assessment practices.

I must understand my problem well enough to solve it; understanding, in this case, will involve researching evidence-based assessment reform pertinent to accreditation at multiple levels: researching what the institution can and needs to do to meet its accreditation goals in this area; researching what the typical instructional DC at CCC knows about the quality of programs and online courses offered by his/her department and discerning what he/she may want to know; and researching how to help the faculty to make sense of and implement assessment reform. In addition, I believe that inconsistency in the level of engagement of DCs in assessment leadership can be remedied by engaging them in a process focused on better understanding assessment leadership, which may include conversations that are research-informed and focused on practical strategies, and that build DC confidence in taking a leadership role. This process will take place as part of the development of the Guidebook. Their confidence will benefit by offering them high-quality, research-informed materials to use as they lead professional development activities with faculty.

This dissertation will document the process used to create the product (i.e., the Guidebook) that aims to close the gap between what is needed at the various levels and what we have currently in place. I believe the gap can be closed by providing to the chairs a guidebook that 1) establish a set of principles and useable frameworks to help them better understand assessment theory and evidence-based assessment practices, 
including how to increase the integrity and validity of evidence; 2) provides strategies and materials which can be used to establish a department-based training program designed for teaching department faculty about these concepts and skills and 3) provides training materials that show how chairs and faculty can use technology and the LMS more effectively to manage and use evidence. In addition, the following outcomes of this project can be used to solve corresponding institutional problems in our assessment practices:

Outcome 1. Address deficits in faculty understanding of outcomes-based assessment theory and practice and the role of evidence in program and course improvement. The Guidebook will provide theory that underlies the principles that guide this work and related practical discipline-specific examples that will provide models for them to emulate.

Outcome 2. Develop systems and methods to collect and store useful evidence, connect evidence to learning outcomes, extract and analyze assessment data, and to report the findings. The Guidebook will provide practical examples that show effective methodology to complete needed tasks and that maximizes the functionality of the available tools.

Outcome 3. Address deficits in skill sets needed to use computer-based assessment tools more effectively and efficiently. The Guidebook will provide step-bystep training guides that show DCs can use to show faculty how to implement the methods and tools that are available. Also, shifting to computer-based assessment tools also allows assessment work to be redistributed to the computer and can lessen the 
workload for faculty. When assessment entails less work, more assessments can be developed and used within courses.

Outcome 4. Help faculty better understand and design curriculum in a way that promotes more effective use of formative assessment practices. Use of formative assessment tools in Moodle and the increased feedback they enable can improve interaction and dialogue that engage students to achieve more. Formative assessment tools, such as completion tracking, personalized learning designer, and notifications can act as cognitive tools that trigger metacognitive processing that empowers students. By focusing student attention on his or her own comprehension of course materials, these tools support the development of student self-regulatory learning behavior in competent self-regulators and/or help seeking behaviors in novice students. Based on constructivist learning theory, cognitive tools are mechanisms that help people remember, think, learn or solve problems. Students who self-regulate develop behaviors that help them direct their own learning activities; for example, use of different strategies to improve comprehension of difficult-to-learn concepts.

Outcome 5. Showcase the function of specific tools and connect tools/functions to assessment practices unique to a discipline and across the curriculum. The guidebook will help improve communication of expectations by helping faculty better understand the value of clarity and to use formative assessment tools built into the LMS, such as the rubrics grading tool, that allow expectation to be communicated more comprehensively. Each department has assessment needs that can be better met by incorporating tools 
useful to the task; the Guidebook will examine these needs, identify and showcase appropriate tools.

Outcome 6. Support institutional change / improvement in the face of increased accountability and meeting stakeholder / policy maker expectations for student achievement. As stated above, when enacted as part of a strategically planned improvement initiative, the Guidebook could provide a focal point for articulating working principles, evidence, in the form of practical examples, of how these principles work in practice, and support persuasive arguments in favor of change. The intended outcome of improved assessment practice would benefit the institution by providing evidence that educational and teaching activities result in learning.

Outcome 7. Model collaborative content identification, joint instructional design, use of research for making instructional design decisions, and prototyping and fieldtesting of materials to ensure their efficacy, for the faculty in support of their instructional design efforts. R\&D processes, by actively soliciting and incorporating the viewpoints of others to guide content selection and instructional design, provide new models that can improve curriculum. This project will model the use of these processes and encourage their adoption by others.

Because the project outcomes must fit within the existing constraints of a working institution with its attendant personalities and idiosyncratic procedures and policies, the practitioner is forced to reckon with these elements up front, thus mitigating many of the translation problems that may emerge when research is conducted in a vacuum. The outcome will be built specifically to work within this institution, so it is eminently 
applicable and of immediate value to CCC. While the ultimate goal is to provide a product that aims to solve problems encountered by all of the instruction departments at CCC (and perhaps, at other community colleges in Oregon and beyond), the preliminary format will address the unique needs of small subset of departments. This may lead to issues of generalizability to other departments. Still, since departmental environments at CCC are similar, there are opportunities for this project to be replicated with fidelity throughout the college.

\section{Research Design}

The research and development project-based dissertation is the approach that will be used for this project. Bridges and Hallinger recommended an R\&D cycle developed initially by Borg and Gall (1989), and it consists of ten steps (p. 120), the first seven of which are relevant to dissertation research (see table 1).

The project planned for this dissertation will follow steps one through seven of this cycle. Descriptions of each step will follow. The R\&D model is a good one for this project because it is not a rigid formula, but can be modified according to need (Lorenz \& Pichert, 1989). I have overlaid this multi-step process with a timeline, project implementation plan, and methodological contexts so as to provide a comprehensive picture of how this project would roll out over time.

General timeline: I plan to take three academic terms (once the proposal is successfully defended in Spring 2012) to complete the project (likely, SU 2012 to WI 2013) and one additional term (SP 13) to complete the dissertation, conduct analysis and 
final research, and write up of the dissertation. I plan to defend the dissertation and complete my degree in Spring 2013.

\section{Step 1: Research And Information Collecting}

Timeline: Ongoing work of preliminary research and information collection should be completed before the late summer (2012) work prior to the preliminary fieldtest.

The initial step of research and information collecting defines the problem and educational need; methods used have included review of the published literature, informal surveys of potential users, and field observations, with the result, in this case, being the production of a prototype guidebook that will be more fully developed through "small-scale research." This idea has emerged from and has been informed through extensive participant observation in the activities and cultural norms of my institution. As a faculty leader, I have access to many historical and current institutional documents, participate in many committees and discussions with key administrative and faculty leaders and have learned their perspectives on many issues facing the college. I have an insider's view of my college. Through participation in many institutional activities and reviewing the literature in related areas (as you can read in chapter 2), I have developed an extensive knowledge of institutional needs and the articulation of a problem set that I feel can be solved with the proposed project.

Since September of 2009, I have served on the college's Assessment Committee. During this service, I have been exposed to an immense collection of information generated by administration, faculty, and outsiders, such as accreditation bodies and 
policy-makers concerning assessment. From this collection, the committee has identified problems we face in meeting the expectations of outside agencies, and is attempting to articulate solutions that can be implemented in light of CCC's unique needs and culture. Toward this end, in February 2012, I was invited to participate in a national AAC\&U assessment conference with several colleagues. Based on observations made at the conference, this group is formulating a set of activities that will support college-wide change. I have confirmed with college administrators that the activities of this dissertation will dovetail with, or even set the pace for, the work of this group. I have presented initial planning with key administrative leaders, including the Vice President of Instruction, two Deans, an Associate Dean, and many DCs and faculty members. Their responses will be included in the analysis sections of the dissertation.

In addition, we have a state-of-the art LMS that, through its powerful assessment tools and evidence repository, can serve as the impetus for a new initiative related to departmental assessment leadership and assessment reform. Through the timeline described later in this chapter, it is shown that this product can be researched and further developed in the immediate future and can meet the timeline imposed by our accreditation processes.

Through this timeline of the project, I have determined, and have shown in chapter 1 , that this proposed product will serve valuable and important educational needs at my college by providing supports that improve teaching, learning, and that meet accreditation goals. 
Through my learning and research efforts, I have attained the theoretical and practical knowledge to outline a curriculum to deliver training that addresses the problem. These efforts show that the faculty needs training to:

1. connect principles and theories of learning to their instructional practice

2. write measurable SLOs for their courses and enter these outcomes into Moodle

3. articulate clear expectations for student performance and communicate these expectations to students using Moodle

4. use a variety of assessment activities in Moodle that align with their outcomes and content

5. collect valid evidence of student performance in Moodle

6. use Moodle as a content repository to enable programmatic and general education assessment

These efforts show that DCs need to training to:

1. feel confident in teaching other faculty about assessment theory and practice

2. write measurable goals for the programs they oversee

3. train faculty to collect evidence within Moodle, a content repository

4. organize evidence-based programmatic reviews

In order to develop broader and deeper understanding of the problem, I am in the process now of doing "small-scale research," which will entail meeting with practitioners and a researcher who are knowledgeable about the problem. The three-pronged preliminary research plan is described below.

\section{Step 2: Planning Objectives, Learning Activities, and Small-Scale Testing.}

Timeline: Ongoing work of planning objectives, learning activities and smallscale testing should be completed before the late summer (2012) work prior to the preliminary field-test. 
The second step of the R\&D process involves planning objectives, learning activities, and small-scale testing. This includes stating specific learning objectives, defining the skills, developing a curriculum and timeline (Lorenz \& Pichert, 1989).

To establish the components needed to successfully refine the Guidebook with its aim of impacting a larger institutional culture, I plan to ask, through online surveys, the intended audience what they need and want a Guidebook to do for them; I'll interpret their feedback. The intended audience that I intend to ask is the faculty of CCC. To research the problems and solution sets, I plan to act as a participant observer. This unique perspective will allow me an insider's view of the processes and personalities in place and afford me opportunities to enact solutions that serve this exact population's needs. According to Nicol (2010), faculty buy-in will be key to the effort to reform assessment practice. I extracted information from this group about how it approaches the use of text-based instructional materials. Instructional design was informed by this data.

As stated earlier, the Guidebook supported aspects of a larger initiative, i.e., accreditation activities, taking place a CCC. A project taking place in the UK influences this project: Re-engineering Assessment Practices in Higher Education (Nicol, 2010) project (www.reap.ac.uk ). Indeed, the outline for the proposed dissertation project stated herein has been influenced by ideas articulated by REAP. I reviewed the REAP program and used it as model for some aspects for my project.

REAP's principal author, David Nicol (2010), examined the improvement of assessment practices systemically and systematically; he acknowledges that in order for assessment practice to improve, efforts must be made at all levels of institutional 
operations, i.e., from the top-down and from the bottom-up. Practitioners are central to the process described by Nicol; they must better understand and provide high quality summative and formative assessment and feedback as part of everyday practice with students in order to accelerate their learning, and students must participate in the dialogue enabled by feedback loops and change behavior based on assessments of their performance (Nicol \& Draper, 2009). It is assumed that other aspects will form part of the context around project development. As such, they are not part of the dissertation, but will inform the processes.

Objective: At this step, I hope to better understand the instructional needs related specifically to assessment literacy and leadership practice of CCC DCs and more broadly, to understand how this group interacts with other constituent groups, i.e., administration and faculty, in order to establish what these groups value and need / wish to know regarding assessment practice. In addition to surveying colleagues, I plan to gather data from outside the institution from knowledgeable others to examine whether the experiences of $\mathrm{CCC}$ constituents regarding the processes of accreditation-based reform is unique or typical.

How will this be evaluated? This step will be evaluated by determining how well the prototype Guidebook meets the needs of DCs in terms of providing materials that strengthen their assessment literacy and capacity for leading assessment reform (i.e., increases confidence, builds knowledge of assessment theory and balanced practice within the classroom and department, provides practical examples for taking action with faculty). The success of this step will be revealed via analysis of participants feedback 
data collected as part of the preliminary field test of the Guidebook and afterwards, once they have used the developed Guidebook . It should be noted that specific evaluation methods will change with the development of the program (Lorenz \& Pichert, 1989). What follows is a conceptual framework that will guide the R\&D process, but actual procedures may be adjusted based on emergent needs and circumstances.

Preliminary Research Plan for Step 2

\section{DC Surveys}

Population: I plan to conduct online surveys of three DCs that are involved in or have expressed in interest in programmatic and/or online courseware assessment. The survey responses will be recorded and transcribed for the purpose of analyzing the answers to look for common themes and repeated elements.

The online survey will consist of the following questions (these were generated in conjunction with Buller (2011) and Chappius, Commodore, and Stiggins (2010). To be answered before reviewing the Guidebook:

- Has your department as a group engaged in discussions about assessment and accreditation? If yes, describe the number of times this has happened and topics that have been discussed.

- Has your department ever conducted an assessment audit?

- Are there commonly accepted or agreed upon theories or principles of assessment that guide the work of the faculty in this department? If yes, what are the principles?

- Does your department have a mission statement? If yes, what is it? 
- Do you oversee programs that have articulated goals? If yes, which program(s) and what are the goals?

- What sorts of "indicators of quality" do you use to measure program or course quality?

- How do you assess whether the stated goals at the program-level are being met?

- What sorts of assessment activities do faculty in this department tend to favor and/ or commonly use?

- What evidence is currently collected and analyzed that informs the measurement of progress?

- Rate your department's level of engagement with instructional technology? With Moodle? $1=$ none; $5=$ high

- Are you aware of assessment tools that are built into Moodle? If so, which ones? To be answered after reviewing the Guidebook sections on balanced assessment, ensuring assessment quality and evidence, building communication systems, and strategies for providing professional development:

- Rate the level of assessment literacy within your department as a whole? $1=$ none; $5=$ high.

- What skills do you need to know more about in order to build your confidence with assessment literacy?

- Rate the importance of providing professional development to ensure a foundation of assessment literacy throughout your department? 
- Which statement best reflects your opinion of the role of the DC in providing this professional development within the department: The DC should:

1. Take a primary role in leading professional development in assessment literacy.

2. Take a secondary role in leading professional development in assessment literacy, and allow others to primarily lead this.

3. Not get involved and let faculty take the lead for themselves.

- Have you led departmental development in assessment literacy? If yes, what ideas and/or knowledge were important and useful to know?

- What gaps in assessment principles and practices do you perceive need to be addressed across the institution?

- What approaches for assessment reform do you believe could be successful with your faculty colleagues?

- How can the DL leadership help support your departmental efforts at assessment reform?

- What are the barriers to assessment reform at CCC?

To be answered after reviewing the Guidebook sections on Moodle assessment tools:

- Which Moodle assessment tools do think would be useful to you? By your faculty members?

- Does this set of training materials help you use Moodle more effectively? Would you use these materials for your own professional development? Do you think others in your department would find them useful? 
2) CCC Administrative Survey

Population: I plan to survey at least three college administrators (The Dean and Associate of the Arts and Sciences division, and the Dean of the Curriculum, Planning, and Research division.)

The survey protocol will consist of these questions:

- Would your division (the college) benefit from increased assessment leadership from DCs?

- What sorts of skills and knowledge should DCs leading faculty training about assessment prioritize in their instruction?

- What are the primary barriers to assessment reform at CCC?

- What are beliefs about assessment that you have heard expressed by your faculty?

- What positive comments about assessment have you heard? What negative comments?

- What sorts of assessment activities does faculty in the division commonly use?

- What approaches for assessment reform do you believe will be successful with your division faculty?

3) Faculty Survey

Population: I plan to survey at least three faculty colleagues.

- Rate the level that SLOs as articulated in the course outline impact your course design and assessment? 1=none; $5=$ high

- What sorts of "indicators of quality" do you use to measure course quality? 
- How do you assess whether the stated goals are being met? If yes, describe how this is done.

- What evidence is currently collected and analyzed that informs the measurement of student progress?

- What sorts of assessment activities do you commonly use in your classroom?

- What approaches for assessment reform do you believe cou;d be successful with your faculty colleagues?

- Rate your level of engagement with instructional technology? With Moodle? $1=$ none; $5=$ high

To be answered after reviewing the Guidebook sections on Moodle assessment tools:

- Which Moodle assessment tools do think would be useful to you?

- Does this set of training materials help you use Moodle more effectively? Would you use these materials for your own professional development? Do you think others in your department would find them useful? Why or why not?

7. Research that engages knowledgeable people from outside the institution Population: I plan to survey at least two people involved in faculty leadership/leading change processes or accreditation efforts at other colleges/universities (The Director of the Center for Online Learning and Director of Distance Education at Chemeketa CC.)

- What strategies have you found useful for engaging DCs in assessment literacy and leadership? 
- What are the most important elements of leadership required for leading faculty to adopt new practices?

- What approaches have you found to be successful in getting faculty to adopt new practices?

- What approaches have you found to not lead to success in getting faculty to adopt new practices?

The project will be conducted over the course of four terms (three terms for R\&D and project development and field testing, and one term to write up the results and to defend the completed dissertation.

\section{Step 3: Develop Preliminary Form of the Product (Guidebook Program Development):}

Based on Nicol and Draper (2009), the Guidebook should aim to provide support for 1) "a set of educational principles that if implemented would help realize the aspiration and address the problem domain: a model that can serve as an example here is the assessment and feedback principles guiding the REAP project (the REAP principles will be part of the prototype Guidebook). The Guidebook will provide 2) "a set of practical examples of the application of the principles across a range of disciplinary contexts; this shows that it can be done 'in my discipline'. This will be provided via exemplars of discipline-based SLOs that will be included in the Guidebook. Also, 3) "back-up educational research that validates the aspiration and that provides robust evidence that the application of the principles will result in real learning and/or efficiency benefits" (http://www.reap.ac.uk/TheoryandPractice/Policy.aspx) will be included in the 
form of "NOTEworthy" highlights that are showcased in the Guidebook margins. These will align with the college's professional development activities.

Based on results from the aforementioned survey cycle, the prototype Guidebook will be revised and used for the upcoming preliminary field test. First term: Spring 2012 Goal: Project authorization

I will defend the dissertation proposal and will finalize the project plans with my advisor, dissertation proposal review committee, and with my supervisor and others at CCC. A human subjects proposal will need to be reviewed at Portland State during this time.

Second term: Summer 2012 Goal: Conduct Preliminary Research

Goal: As described above, I will conduct further preliminary research to align institutional and project goals and establish methodology for faculty qualitative data collection during inservice sessions conducted before Fall 2012 term.

Methods used: Research and Development protocols (surveys, primary documents review, and participant observation) [Note to Committee: the timeline for steps 4 to 7 was adjusted back a term, but this information is not included in chapter 3; I have left the descriptions for Steps 4 to 7 below unedited and as originally proposed. The actual timeline that I used will be described in chapter 4$]$

\section{Step 4: Preliminary Field Testing}

Timeline: Second Term: Summer 2012/Inservice week (just prior to Fall Term). Tasks: Develop the three days sessions for faculty development wherein the prototype of 
the Guidebook and pertinent assessment theory/practice will be deeply explored with a group of DCs, principles and practices confirmed and refined . Exemplary practices described in the Guidebook will be introduced. Feedback will be solicited and data will be collected about prototype effectiveness.

The feedback system must be both proximal to the learning event, i.e., feedback should be given close in time to the event being evaluated, and also allow time for reflection to take place, i.e., allow time for the learner to process the event and its impact on his/her learning over time (Thorpe \& Godwin, 2006). Therefore, the instrument (feedback) will be provided immediately at the end of each substantive learning activity, after the daily event activities (after a complete module), and shortly after course completion. Ideally, DCs would be surveyed periodically after the course is over, but this activity would need to take place outside of the timeframe of this project. The interviews and document reviews conducted during spring and summer terms will inform a faculty development experience geared toward building DC understanding of 1) needs of accreditation, assessment reform program planning, and role of departmental leadership, 2) principles and practices of evidence-based assessment (review theory and practice sections of Guidebook) and 3) use of Moodle to conduct course-level and program-level assessment (review Moodle assessment tool sections of Guidebook). Survey (or interview) Questions to be asked of the Field Test Participants

- Has this experience helped build your understanding of accreditation needs related to assessment? 
- Does the methodology of collecting evidence make sense to you as a way to meet our accreditation goals?

- Which aspects of assessment theory covered in the Guidebook do you think will be useful to you as you practice and as you lead others?

- Were there gaps in the Guidebook between theories in use and the theories that are described? Which theories should be better elaborated?

- Do you think that the Guidebook adequately describes assessment theory in general? If not, how can this be improved?

- Do you think that the Guidebook adequately describes assessment theory pertinent to your discipline? If not, how can this be improved?

- Does the Guidebook adequately link assessment practices to Moodle assessment tools? Describe.

- Were the assessment tools described in the Guidebook ones that you will find useful? Should there be more information about any particular tool?

- Rate the quality of the Moodle training resources / materials? $1=$ poor; $5=$ excellent Are these materials usable by you? If not, how can they be improved? Will these resources / materials be effective with your faculty members?

- Do you feel your level of assessment literacy has improved? Do you feel more confident in your assessment practice?

\section{Step 5: Main Product Revision}

Timeline: Third Term: Fall 2012. Tasks: During the Fall 2012 term, I will produce a revised Guidebook (Principles and Practices of Assessment sections) and begin matching 
assessment tools to practices to develop the "showcases" of assessment practices (discipline-based practical examples of Moodle use to support assessment practice reform). I will look again at how the Guidebook and Moodle tools are introduced to DCs, how DCs are supposed to translate the learning materials from the Guidebook and Moodle tools into practice for departmentally led training sessions, if they are successful in doing this, and if the training is successfully improving the quality of evidence collected by faculty. This reflection and information will be used to refine the Guidebook.

"Although participant feedback is rarely a valid guide of program impact, it can be useful in revising program content, sequence, and materials" (Lorenz \& Pichert, 1989, p. 254). The results of the preliminary field test will be used to revise the individual components as well as review the entire process and products holistically. Each step within the entire process will be evaluated and refined if necessary. "Revision should result in a program ready for quantitative outcome assessment" (Lorenz \& Pichert, 1989, p. 254).

Using findings from the DC sessions on assessment - the guidebook will be developed along with first round related instructional materials and additional materials will be produced in preparation for main field-testing. Consistent with Lorenz and Pichert (1989), revisions may include changes in Guidebook content, presentation format, sequence of instruction, and feedback style.

\section{Step 6: Main Field Testing}


Timeline: Fourth term: Winter 2013 Goal: Introduce Guidebook and gather data from DCs in general and early-adopting DCs in specific operational aspects to determine if it achieves the performance objectives.

Early in Winter 2013 term, the Guidebook will be unveiled and distributed around campus and "showcases" held with all of the DCs at CCC. The showcases aimed at explaining the assessment program that $\mathrm{CCC}$ is planning to use to meet our accreditation goals of evidence-based assessment and methods for introducing these ideas to faculty. The Guidebook is central to the showcase presentations and provided models and examples for faculty buy-in to better assessment practices. A survey was distributed to showcase participants to gather their feedback about the Guidebook and the emergent procedures around assessment reform. Records were kept of the Showcases and resulting feedback. A feedback gathering process similar to that described in step 4, including using the same set of questions (albeit on a larger scale), will occur. However, because there was much more data to review as to the working of the product (as well as data about the quality of the course materials), more time will likely be needed to refine the materials. Since the data concerning the product components emerged early in the term, there is time during the winter term to complete the necessary revisions.

[Note to Committee: We agreed that I would not need to complete the steps described in this paragraph.] In addition, an operational field test will be conducted with a small set of early-adopting DCs to determine whether they (the DCs) can successfully train others (the faculty) in the theory and practices of evidence-based assessment and the processes and procedures of using Moodle tools to help them. I will attend these sessions 
and evaluate instructor and materials effectiveness as an independent observer. I will collect data about faculty questions and understanding to determine how to improve the operational aspects of the Guidebook.

\section{Step 7: Operational Product Revision}

Timeline: Fourth Term: Winter 2013. The scaled-up edition of the Guidebook will be unveiled in late winter term. I envision the Guidebook to be used independently by DCs to lead training with faculty in their areas. The use of the guidebook will be supported by the college's professional development office.

\section{Endgame: Completion of the Dissertation}

Fifth term: Spring 2013 - The endgame will involve final data collection, which may include surveys of faculty in attendance at showcases to ascertain if showcases have had any impact on assessment practice. I will write up the results of the dissertation. In late spring term, I hope to defend the Dissertation at PSU and complete the degree requirements.

\section{Conclusion and Beyond the Project (Steps 8 Through 10)}

Beyond the scope of the dissertation, but useful for the organization will be completion of steps 8 to 10 . Operational and final field testing of this project-based dissertation and further dissemination and implementation could be expanded to include a regional set of practitioners, perhaps at other Moodle-using Oregon Community Colleges (there are five OR Community Colleges that use Moodle), who will help explore, and potentially establish, a curriculum improvement process among a design community through a process of sharing a common set of assessment tools. When these evidence- 
based assessment practices are used regionally and analyzed collaboratively, new opportunities will emerge that might "open the doors" of online classroom assessment practices that facilitate faculty working together in an inter-college model. The completion of the written dissertation and subsequent defense will mark the end of the formal project, but it is likely that the Guidebook will continue to be adapted and used. The author has shared his preliminary project plan with DL leaders at other colleges, so there is already widespread interest among distance educators and practitioners within Oregon about the findings of this project. Guidebook and practical applications of the Moodle tools will be shared as open educational resources with anyone who is interested in using them. The guidebook may be made available online at a Moodle resources site for other colleges to use. 


\section{CHAPTER 4}

\section{ANALYSIS, FINDINGS, AND OUTCOMES}

\section{Introduction}

Chapter 4 connected the first three chapters together and extended the ideas presented in them. It showed how the problem statement, the literature review, and the proposed research methods, which were, out of necessity, adjusted during the process, led to this seven-step R\&D project. This chapter begins with descriptions of the numerous adjustments that were made as this project unfolded. It then turns to the step-by-step details of researching and creating the Guidebook for Student Learning Outcomes and Assessment Loop. It ends with outcome statements that set the stage for chapter 5.

\section{General Design of the Project and Review of Research Goals/Questions}

The project that was proposed in chapter 3 was explicitly designed to fit the circumstances of my work and meet the assessment needs of my institution, and while I hoped to follow my well-laid plans with fidelity, I made adjustments to most aspects of the proposal in order to complete the project. I aimed to produce a guidebook that moved my institution forward with assessment reform, and, while my preliminary research showed that building Department Chair (DC) capacity to lead faculty training aimed at using technology more effectively to support assessment work was likely to be useful, I ended up emphasizing direct, course-embedded assessment and fulfilled a more basic need. The proposed timeline, participants, research methods, product, and processes were adjusted, expanded and/or refocused as I worked to align my vision for the project with 
the needs of my organization. The data I collected and analysis that I completed (which was included below) show that this was the correct emphasis. As might be expected, the proposed outcomes were, in actuality, more or less attained, some with surprising results. Many other issues were uncovered which I discussed in chapter 5. The adjustments were described below. While I originally proposed a comprehensive training manual for Moodle assessment tools, I ended up more focused on direct, outcomes-based assessment. And rather than creating just one guidebook, fulfilling a timely request from the CCC curriculum committee led me to create two guidebooks. The process and products were described in great detail below.

Adjustments to Timeline. I needed to adjust the timeline. As proposed, I recruited the first round survey participants in July / August and received the entire first round survey responses (total of 11) by September 1. But some events proposed for Fall term did not happen. Fall term was a very busy time for the DL office and due to the added workload in serving as Faculty President this year, I got off to a slow start in Fall term with dissertation work. However, I completed a related project that greatly informed my dissertation work.

In June (about the time I defended my proposal), the curriculum committee chair at Clackamas Community College (CCC) approached me about creating a guidebook for a major project that began in September, 2012, to revise all 1800 of our course outlines to ensure they were complete, updated, and that our student learning outcomes (SLOs) were measurable. Since it fit closely to what I proposed for my dissertation project, I accepted the committee membership and, as principal author, completed a guidebook about how to 
use a computerized database system to revise course outlines and how to write measurable SLOs. The curriculum committee approved the final version in the Fall 2012 term. This work was a trial run of conducting a partial R\&D process and greatly impacted my dissertation project. I included the results of this preliminary research work below. This preliminary work delayed the draft version of my proposed guidebook until Winter break. Two rounds of R\&D were completed as proposed this winter term.

New Profile of the Participants. I worked with a slightly different population than I proposed. While my proposed methods for steps 1 through 4 followed my plan, steps 5 to 7 varied considerably from what I proposed. I intended to focus preliminary and main field test research on a set of DCs, in reality, due to workload of the DCs and their inability to fit in additional tasks, I ended up working more closely with the intended end-users of the Guidebooks, i.e., members of the CCC assessment committee, new fulltime, and adjunct faculty.

Re-Development of the Surveys. I adjusted my research methods. My proposed survey questions focused on accreditation, assessment theory, and Moodle use. After I discovered that my initial surveys were geared toward indirect outcomes of guidebook use, I revised my surveys. I refocused them on how well the Guidebook worked as a tool for teaching about direct, outcomes-based assessment. The revised survey questions were included in Appendix A.

A Refocused Product. I did not create the product that I had proposed, rather I created two different products, each of which have had more impact on my institution than the would-be proposed product. I described how and why I made this adjustment. 
In spring of 2012, to meet accreditation needs, the curriculum committee at my college decided that it needed a Guidebook for Course Outline Revision (also called Guidebook \#0), and appointed a subcommittee to develop one. This project emerged simultaneously to the defense of my proposal and was needed as soon as possible. I was asked to join the subcommittee and, in a demonstration of assessment leadership, I principally authored this Guidebook. I decided to tackle this project hoping the experience would help me to prepare more effectively for my dissertation project; it did. In completing this preliminary project, I learned that the DCs (and college) needed support at a more fundamental level. They needed a training and reference manual for writing and assessing measurable SLOs and that identifies practical methods/ tools for assessment instead of a guidebook on Moodle resources. To accommodate these institutional needs, I decided to focus my research and development on a book that guided more fundamental aspects of assessment; I drafted, studied, and developed a guidebook entitled Guidebook For Student Learning Outcomes and the Assessment Loop (also called Guidebook \#1).

Adjustments to Process. As I described above, the project involved creating two distinct, but, connected Guidebooks. Creating two guidebooks allowed me to go through certain steps of the $\mathrm{R} \& \mathrm{D}$ process more than once. By using this iterative process, I developed one product to the main product stage (through step five) and another fully researched and developed a high quality, operational product (through step seven). I practiced and refined my performance of critical process steps by performing them more than once. For example, the preliminary research portion of the project, where I created 
Guidebook \#0, afforded me opportunities to conduct important research and gather important information about guidebook components (Step 1- Research and information collecting); clarify and state specific learning objectives needed by my college and develop materials for a specific college need within a specific timeline (Step 2 - Planning objectives, learning activities, and small-scale testing); and develop and field test a preliminary form of the product (Steps 3 and 4). A final revision of the preliminary product brought the product through step five: main product revision. As I moved forward with development of Guidebook \#1, I used research and information collected during the preliminary research stage of Guidebook \#0 to partially develop the initial form of Guidebook \#1. I was able to adapt research already conducted to inform steps 1 and 2. I also was able to repeat the important process steps 3 and 4 twice as part of the project. Guidebook \#0 provided direction to the creation of the Guidebook \#1 in that it established the context for the project in terms of audience, purpose, and theoretical approaches; that is, I wrote a guidebook for DCs and faculty to purposefully extend their understanding of direct, outcomes-based, course-embedded assessment and measuring SLOs. It became clear that a second Guidebook, one that more thoroughly explained concepts presented in the first, could serve as a companion to Guidebook \#0.

\section{Steps of R\&D Process and Incremental Data Analysis}

\section{Finding Themes and Elements in the Data at Each R\&D Step and Discussion of Ongoing Field Testing Issues/Challenges}

To organize this section of the dissertation, I proceed step-by-step through the $\mathrm{R} \& \mathrm{D}$ process, described the questions asked, the research methods that were used, and findings and conclusions. I shared the analysis of the data that I collected at each step and 
what I learned that guided the next step of the project. When I encountered issues or challenges, I described them in the context of the step. Because I completed the first five steps of the R\&D process twice, I incorporated a third tier of information within these steps. The process and activities were interwoven and cumulative, leading to the emergent product.

\section{Research and Development Process}

In chapter 3, I described the research and development project-based dissertation format that was used for this project. To remind the reader, Bridges and Hallinger recommended an R\&D cycle developed initially by Borg and Gall (1989), and it consisted of ten steps (p. 120), the first seven of which were relevant to this dissertation research project (See Table 1). At each step, I conducted research that led to the next stage of development. The R\&D process was enacted through qualitative research involving data provided through surveys, institutional documentation, and observation.

\section{Research Methods and Data Analysis}

My study followed the commonly used research and development (R\&D) methodology to develop the guidebook. I conducted a literature review, review of local documentation, three rounds of surveying key informants, two rounds of field-testing, and made personal observations throughout. I used a qualitative analysis process of coding to discover themes and elements within the data. By finding patterns within and making connections between the respondent's answers, I was able to make sense of the data and use it to refine my Guidebook. A description of the qualitative data analysis process that I used follows: 
Creswell (2005) described coding as a "process of segmenting and labeling text to form descriptions and broad themes in the data" (p. 237). Through coding, common ideas are discovered and connections made among ideas so as to allow the ideas to merge together into themes. The themes that emerge from the data are derived from the elements in guidebook development or faculty/ institutional readiness about assessment reform. Therefore, themes represent a recurring, unifying pattern that "encompasses" a set of elements. Elements are the smallest piece of information about something that can stand by itself (Merriam, 2001). The elements that constituted the perspective of the respondents, e.g., the faculty members, DCs, or community college leaders who were active in building institutional capacity, were essential in determining how best to design instructional materials that taught this topic.

\section{Explanation of Reiterative R\&D Steps One through Five and Lessons Learned from Creating and Processing the Guidebook for Course Outline Revision (Guidebook \#0)}

As described above, as part of preliminary research, I completed R\&D Steps One through Five twice. Guidebook \#0 was conceived as a way to provide the necessary support materials for faculty to complete the task of revising course outlines and writing measurable student outcomes. It was intended as a time saver so that busy DCs would not need to repeatedly explain the task or procedures to complete with the various faculty members. It was hoped they would be able to refer people intending to complete the task to one comprehensive resource where the answers could be found.

I, with an incomplete understanding of the task, completed the initial draft, aiming to answer the most common questions of how to complete the revisions of course outlines. I ran into problems. I discovered that, without a larger context of potential 
guidebook users, the instructional design was incomplete. I needed to better understand others' unique approaches to how they would complete the task, and know what questions they would ask about the process. I needed their collaboration and advice. The R\&D process was the appropriate methodology to work through these problems. Through field-testing, I primed the pump of systems-, process-, and task-analysis and questionasking, which helped me to uncover the concerns and needs of end users. The result was a much more usable and effective product. This preliminary work informed my later work.

The sections below are organized sequentially following the steps of the R\&D process (again, steps one through five contain additional info about the preliminary work on Guidebook \#0). I describe the goals of each step, including the research questions I attempted to answer, and then I review the data analysis to show what I learned.

\section{Step One: Research and Information Collecting}

The initial step of research and information collecting defines the problem and educational need; methods used included review of the published literature, informal surveys of potential users, and field observations, with the result, in this case, being the conceptualization of and selection of subject matter for a prototype guidebook that will be fleshed out through "small-scale research" (Lorenz \& Pichert, 1989).

\subsection{Research Question(s)}

The problem and educational need that provided the impetus for this project emerged from and was informed through my doctoral studies, my work, and extensive participant observation in the activities and cultural norms of my institution. I found a 
provocative problem to study by simply paying attention to my surroundings at work and in my studies.

The problem and educational need that my product addressed, which were described and elaborated upon in chapter 1, related, mainly, to understanding important aspects of how my institution should, and needed to, respond as external forces impact us. There were three research questions I answered at step one.

Question 1. What are the most provocative issues facing my institution and that need attention within the timeframe of this study?

Question 2. What sort of tool should I research and develop that will help my institution move forward in addressing this provocative issue?

Question 3. What context and content should the tool include to be effective?

\subsection{Methods}

Consistent with Lorenz and Pichert (1989), my methods involved a review of the published literature, internal documentation, informal surveys of stakeholders and constituents, and field observations.

As a faculty leader, I accessed many historical and current institutional documents, participated in many committees and discussions with key administrative and faculty leaders and have learned their perspectives on many issues facing the college. From my graduate studies, I understood that higher education is in the midst of a paradigm shift, moving from a paradigm of instruction and inputs to a paradigm of learning and outcomes. As an instructional designer, I understood where I fit in the organization and the sources of power that I had available to implement change. These 
ideas formed the foundation from which I researched the formulation of a topic to study and conceptualization of a new tool useful to my institution and me.

\subsection{Findings / Analysis of the Data}

This section provides a summary of the research findings from which I draw conclusions about the problem and associated educational needs. The most frequently identified elements and variables that influence the author's perspective on guidebook development and institutional readiness for change were summarized in the next section.

\subsubsection{Themes and Elements}

My research into identifying an important education problem and meeting a need began by simply paying attention to my surroundings at work and in my studies. Through my doctoral studies, I developed an extensive knowledge about external change forces that were broadly impactful of higher education. Various elements were, and continue to be, readily apparent.

There were funding issues caused as a result of the great recession. Reduced state funding of approximately $20 \%$ over the previous ten years led to the diminishment of Full-Time Equivalency (FTE) reimbursements. The state of Oregon, through the Oregon Education Investment Board, enacted an overhaul of higher education funding structures, including an increased emphasis on outcomes/ completion and shifting to a performancebased funding model. This led to all of us doing more with less. At CCC, this meant employee reductions, restructuring of administration and staff, yearly tuition increases, and overhauls of work processes to increase productivity. All of this occurred while we 
also dealt with increased enrollments, larger seat loads, and taking steps to improve on our core mission: teaching and learning.

National and state policymakers were calling for increased accountability. At $\mathrm{CCC}$, this shaped up into increased student-centered teaching and learning, increased retention efforts especially among our first year students, calls to accelerate the time needed to complete degrees and programs, the awarding of credit for prior learning, and many others.

The themes that emerge were 'doing more with less' and 'increased accountability from the state'.

\subsubsection{What are the most provocative issues facing my institution, and that need attention within the timeframe of this study?}

Finding 1: The common connection to the themes is assessment. I realized that I needed to focus my tool on the institutional needs for assessment reform.

Out of this milieu of influences upon the organization mentioned above, a common element, which connected directly or indirectly to each of the themes and was high on the list of priorities for the college was assessment reform. The research questions helped me make the determination that my study and tool should address assessment reform.

Finding 2: Accreditation requires evidence of continuous improvement of assessment practice.

Our accreditation body was requiring that the college do a better job with courseand program-level assessment. The new process of accreditation moved this once- 
episodic process into the forefront of each year's strategic planning and institutional goal setting. We needed to show incremental progress was being made each year.

Finding 3: Our core mission of teaching and learning must improve.

Doing better assessment was the best way to understand the effectiveness of our teaching and learning.

Finding 4: We needed to do more with less.

Increasing productivity was important. Using technology and the Internet more effectively was the most direct way to increase productivity. It also leveraged the strategic investment in technology and infrastructure that the college has made.

\subsubsection{What sort of tool should I research and develop that will help my institution move forward in addressing this provocative issue?}

Finding 1: The tool should be a guidebook.

My work involved instructional design, so I was well trained to produce high quality instructional materials. Creating a guidebook fit within work I was already doing at the college. Guidebooks were useful in that they allowed an academic process of inquiry to emerge that connected colleagues to the mission of the college.

\subsubsection{What context and content should the tool include to be effective?}

Finding 1: Lack of professional capacity to use assessment to continuously improve hampered our assessment reform efforts. The guidebook should be used to build professional capacity of faculty and others.

One of the recognized problems in effectively utilizing outcomes assessment was "having the needed expertise and skills on campus" (Serban, 2004, p. 23). Black and Wiliam (1998) have found problems and shortcomings in everyday assessment practice; 
practitioner understanding of and the underutilization of assessment are among the shortcomings they mention. Faculty needed to better understand summative assessment and its connections to student production, educational evaluation, and grading. Faculty needed to better understand formative assessment, its connections to pedagogy, instructional and curriculum design, educational processes and in fostering student learning.

Finding 2: Many effective efforts for reform emerge at the department/discipline level, therefore supporting a guidebook that provided materials for DCs to work within their departments had a high likelihood of success.

DCs were well-placed to lead reform efforts, but since their capacity to lead was inconsistent (as described in chapter 1), the guidebook should help them improve.

Finding 3: The Guidebook should increase use of technology. Since our LMS provides support for assessment, connections to Moodle should be included.

Moodle was already in place at the college, it had been well-received by the faculty, and had a great set of built-in assessment tools. The upgrade of Moodle in September, 2012, introduced many new tools that faculty needed to know about. Producing a guidebook that connects assessment to Moodle could serve the college on many levels.

\subsection{Conclusions}

Conclusion 1: The tool should be a guidebook that focuses on assessment and Moodle.

Conclusion 2: The guidebook audience should be DCs and faculty. 


\subsection{Lessons Learned From Creating and Processing the Guidebook for Course Outline Revision (Guidebook \#0)}

The subject matter and target audience for Guidebook \#0 did not require research and analysis to define, rather it grew out of an expressed institutional need, i.e., to provide quality control for a faculty-led process that had, prior to then, been inconsistent and scatter-shot. The curriculum committee realized that this inconsistency derived from the lack of a common process, guidelines, or language that people used to complete the work of writing these important documents. The college had a set of instructional standards and policies, adopted between 2009 and 2012, that governed this work, but no one had taken the time to analyze and connect together the pieces, such as course outlines, general education outcomes and certifications, measurable SLOs, and course descriptions. Also, training had never been conducted and support materials had never existed.

\section{Step Two: Planning Objectives, Learning Activities, And Small-Scale Testing}

The second step of the R\&D process involved planning objectives, learning activities, and small-scale research and testing. This included stating specific learning objectives, defining the skills, developing a curriculum and timeline (Lorenz \& Pichert, 1989).

\subsection{Research Question(s)}

I proposed to better understand the instructional needs related specifically to assessment literacy and leadership practice of CCC DCs and more broadly, to understand how this group interacts with other constituent groups, i.e., administration and faculty, in 
order to establish what these groups value and need / wish to know regarding assessment practice.

In writing my proposal, I relied on, among other things, my observations as an instructional designer and faculty professional developer to form my assumptions about what the college needed to move forward with assessment reform. I observed my colleagues' approaches to assessment, listened to their critiques of attempts at academic reform, and worked to provide for their assessment needs within instructional design. There are three research questions I wanted to answer at step two.

Question 1. What does a cross-section of educators say an institution needs to improve assessment practice?

Question 2. How does this institutional need translate into the most appropriate components to include in a guidebook?

Question 3. Does the data affirm or contradict my assumptions about what the institution needs and what a guidebook should contain?

\subsection{Methods}

I gathered input from a cross-section of educators, who shared what they believed was needed to improve assessment practice. I recruited 11 participants, each representing one of the following four sub-group populations: of DCs, faculty, administrative personnel and assessment leaders from other institutions. I developed a different, but related, targeted survey for each of the four groups. I surveyed both internal and external colleagues, as I wanted to examine and verify whether the experiences of CCC constituents regarding the processes of accreditation-based reform were unique or typical. 


\subsection{Findings / Analysis of the Data}

This section provides a summary of findings that were teased from the perspectives of the 11 participants. The most frequently identified elements and variables that influenced the participants' perspective on guidebook development and institutional readiness were summarized in the next section. Conclusions follow the section on findings.

\subsubsection{Themes and Elements}

Five themes emerged from the survey results of DCs, faculty, administrative personnel and assessment leaders from other institutions. They were: "role of faculty," "role of administration," "motivators for assessment and getting started," "goals the guidebook should strive to meet," and "ways to meet the goals." Based on understanding gained via this analysis, I answered the proposed research questions. This section begins with a review of the research questions, and then the answers to each question. Following this, I incorporated other salient findings.

\subsubsection{What does a cross-section of educators say an institution needs to improve assessment practice?}

Finding 1: An institution should provide department-based professional development in assessment practices to the department faculty.

The DC respondents perceived that professional development for assessment reform was important. On average, the DC respondents rated the need for professional development for assessment literacy as 4.33 on a scale of 5 (where $1=$ not important and $5=$ high importance). However, when asked if they led professional development efforts in their departments, only one had done so (this person also was the only DC who felt 
that this was a primary role for the DC.) This indicates that DCs may not readily adopt the use of a Guidebook, even if one is provided. Since the field-testing of the Guidebook \#0 raised awareness of that resource, it was possible that this process would have a similar effect on subsequent materials. One respondent indicated that faculty buy in is essential for reform because without it, "they won’t gather meaningful data."

The data from all of the respondent groups reinforced the DC's comment; all constituents indicated that faculty engagement is key to successful assessment reform. The non-CCC respondents, who also said that the faculty efforts are central to success, confirmed this finding.

Finding 2: One role of administrative leadership is to support the faculty in acquiring the knowledge and skills necessary to reform

The CCC administrative and non-CCC respondents had valuable commentary about the role of college leaders in supporting assessment reform. One respondent stated that faculty members need to be supported by the top leadership in their efforts at reform. The administration at CCC was supportive of faculty-led efforts.

Finding 3: The role of DC and Administration is to motivate faculty and help them get started.

Commentary points to some perceptions about motivation and getting started in reform processes. One comment said that faculty must be intrinsically motivated to change or else it will not happen. One comment about creating "cognitive dissonance" between vision and reality could be helpful for motivating faculty to learn more about assessment reform. Another comment pointed to creating opportunities for faculty 
interaction and conversations as useful for motivation, especially if these opportunities allowed for the airing of "professional discord" to emerge. This discord can be useful for fostering debate that leads to the expression of assumptions and beliefs and for exploring differing viewpoints about assessment. While this may be a useful strategy for initiating and deepening discussions, it is not clear to me how this sort of dissonance can be enacted by the use of a Guidebook. This was a topic for related study.

\subsubsection{How does this institutional need translate into the most appropriate components to include in a guidebook?}

Finding 1: The guidebook should provide materials for instructing faculty in important elements of assessment reform; it should be a training manual.

The data show a high interest in assessment reform, but low capacity on the part of the DC and the faculty to engage in reform. This indicated that a solution that addressed both would be useful. The DC respondents rated the level of interest in learning more about their departmental assessment efforts, i.e., doing assessment auditing, was relatively high 4.33 (where $1=$ none (no interest) $5=$ high interest) and assessment literacy within their departments as relatively low; on average, they rated departmental levels at 2.33 (where $1=$ none; 5 = high). Since the data indicated that most DCs have not provided professional development in assessment practices $(66 \%$ of respondents report not engaging in professional development for assessment), the Guidebook should provide adequate content and context to enable them to successfully use the materials. When asked what would help support them, the DC respondents reported wanting help with building a culture of assessment within their departments and help providing training during department meetings instead of special sessions. It should 
be noted that such training would have a residual effect of building a college-wide culture. Also, the widespread use of Guidebook \#0 and the process of field-testing subsequent guidebooks could engage many people in discussions and activity around a common topic, and thus, could be looked upon as building an institutional culture for assessment reform.

Finding 2: The Guidebook should address gaps in knowledge and skills.

Each DC respondent had a different answer for addressing gaps in knowledge and skills. One DC thought that addressing assessment via revisions of the course outline and ensuring quality of measurable SLOs would fill a gap. Other gaps included a lack of faculty buy into assessment, cultural awareness, and lack of foundational awareness of the need for and ways to accomplish assessment reform. It was reiterated that any materials should be practical, and address face-to-face, blended, and online delivery modes.

Finding 3: The Guidebook should build consistent language about "grading," "assessment," and "assessment methods" being used by the department or college.

The answers provided showed the administrators were clearly distinguishing between grading and assessment, while the DC and faculty respondents tended to blur the distinctions, listing course-embedded activities they used to create the conditions for students to demonstrate their learning. The DCs and faculty respondents listed mostly summative and gradable assessments, meaning that the active instructor respondents view assessment and grading as similar tasks. The Guidebook should describe the differences, 
but lean toward the conceptual understanding of the practitioners; i.e., it should be focused on direct, outcomes-based course-embedded assessment.

\subsubsection{Does the data affirm or contradict my assumptions about what the institution needs and what a guidebook should contain?}

In the proposal, I made many assumptions about what the institution needs and what a guidebook should contain. The findings affirm some assumptions and contradict others.

Finding 1: A guidebook on assessment would be highly valued, and useful, by the institution.

In conducting preliminary research, I learned that many faculty members did not understand how to enact a grading system, much less an assessment system in their courses, and that many spoke of assessment without an understanding of what the basic terms mean. I assumed that assessment reform was hap-hazard. This led me to assume that an assessment guidebook would be useful. The findings affirm that this assumption was correct. The DCs indicated a high level of interest in assessment auditing (4.66 on a 5 point scale), and a low level of activity is this area. One of the three reported systemic evaluation of assessment practices had occurred in their department. This finding was supported by the three administrative respondents who reported that CCC's assessment practices were in need of improvement, with one of them calling current efforts "piecemeal."

Finding 2: Inasmuch as the guidebook supports DCs and faculty, it should not state that assessment work is done to meet accreditation goals; rather the focus should be on improvements to teaching and learning. 
I assumed that accreditation should be a driving motivator for assessment reform. The findings show that this assumption was incorrect. While the data show that 3 out of 3 $(100 \%)$ of administrators at CCC are conscious of accreditation (or institutional accountability) and that this motivates their interest in assessment reform, none of the DCs or faculty members mentioned accreditation in their responses. Three out of five $(60 \%)$ of the administrators responding specifically mentioned accreditation as a motivator for assessment; one of the three acknowledges that "saying we need it for accreditation doesn't move mountains" i.e.. it has limited impact in motivating faculty. This finding was affirmed by both of the non-CCC participants, who clarified that focusing on external forces as a motivator has limited impact. This finding was summed up most succinctly in this comment: "Telling faculty is generally not successful. If there is a federal or state mandate, then telling faculty that they must implement a new process can be efficient, but it is rarely effective. The less engaged the faculty members are in the development of the new process, the less effective the adoption."

Finding 3: The guidebook should not focus on assessment theory, rather it should focus on assessment practice; the guidebook should provide practical examples of methods/ tools.

I had assumed that connecting principles and theories of learning to instructional practice should be central to guidebook content. The findings show that, while content of the Guidebook should be theoretically sound, it should not focus on theory. The administrators and practitioners were clear that discussing theory was not the best approach for engaging faculty to improve practice, rather "concrete" and "practical" 
examples, preferably from a "variety of disciplines" should be used. Another faculty respondent wrote: [we need] "practical models of innovative assessment practices and their positive results, from real teachers. That's what gets instructors excited."

Finding 4: The Guidebook should focus on helping faculty to be clear and consistent in their expectations for student performance; it should focus on measurable SLOs.

The findings affirmed that my assumption about focusing the guidebook content on clarity and consistency of student assessment was correct. One DC stated it very clearly: a faculty knowledge gap that needs to be addressed is "development of more clearly measurable SLOs and better measurement methodologies."

Finding 5: It is important, but premature, to produce f guidebook focused on Moodle as an evidence repository or programmatic assessment tool; training materials should be provided once practice is more consistent.

While one faculty member stated: "workshops on assessment tools in Moodle" would support departmental efforts at assessment reform, the findings that show inconsistent knowledge about the assessment loop, a resistant institutional culture, and "piecemeal" approaches to assessment reform needed to be addressed first. Once that foundation was laid, then we could work on using technology to improve practice.

Finding 6: The findings show that DCs need training to feel confident in teaching other faculty about assessment theory and practice at the program level; these materials are the next deliverable. 
I assumed that the guidebook should address programmatic- and institutionallevel assessment practices, and the findings affirmed that this assumption was correct. However, working toward meeting this goal would have greatly expanded the scope of my work and been impossible to complete in the timeframe given for this project. I scaled back on meeting this goal, but it remains an item for further study and will be produced within the six months following completion of this dissertation.

Finding 7: The guidebook should establish a common language and culture around assessment.

I had assumed that a guidebook would be useful to build a common culture around assessment. The findings affirm that this assumption was correct. There was confusion present among administrative and faculty members about the language of assessment. Even commonly used terms like, "term paper" "essay test" and "reading" were interpreted differently by different respondents and this had connotations for students that needed to be clarified.

One administrator believed that faculty used "an incredible variety of assessments", but the DC and faculty respondents listed a relatively narrow list of 14 distinct assessment methods/tools, with all six of the practitioners listing "multiple choice quizzes," "tests," and/or "exams," four listing "essays," and three listing “projects." This finding indicates that confusion over the names of certain assessment tools/methods was present. There was inconsistency in the use of the terms: "quiz", "exam", "test." While the literature groups these together as being the same assessment tool/method, various respondents listed "quizzes and tests" or "quizzes and exams" in lists of assessment 
methods that are used. This would indicate that these are somehow different (there may be variation relating to the time of the term they are given, weighting within grading systems, or whether used formatively or summatively.) The meaning of "essay" included short answer quiz or writing assignments of various length. "Project" seemed to have various interpretations, which may or may not include a writing component. "Projects" seemed to be multi-day, more highly weighted activities that can be completed collaboratively or individually. This might include the concept "term paper"

\subsection{Conclusions}

Conclusion 1: The optimal components of a guidebook should be research-based, but unique to and based on stated need of the users; "pre-packaged" guidebooks will not suffice.

The use of Guidebooks for assessment is widespread; many colleges have such guidebooks. This is a common approach and such artifacts can be found all over the Internet. In creating my Guidebooks, I knew of these resources and, since I initially did not want to "reinvent the wheel" I dove into these artifacts, looking for pertinent examples to use. I discovered that most other colleges do not reinvent the wheel, either; they duplicate the documents that have already been created and optimized by others; in short, they simply copy, with varying levels of criticality and analysis of quality, what is already out there. As I reviewed the various assessment handbooks online, I found that many of them have the same content. For example, in my research, I discovered the following are commonly copied verbatim: lists of active verbs that accompany Bloom's 
and other taxonomies, the idea of SMART objectives, and definitions of common assessment terms.

Conclusion 2: To achieve a high level of usability and quality, the Guidebook should bring all of the pieces of the assessment loop together in one place.

The college had lots of resources that described aspects of assessment at course and program levels, across and within specific disciplines, and that covered all of the components of the assessment loop (see figure 1). However, I did not find an example where all of the content was refined and accumulated into a single place. Since a conceptual understanding of the entire loop was necessary to motivate people, this weakness led me to develop a guidebook that included and refined the entire assessment loop. 
Figure 1 Six steps of the assessment loop

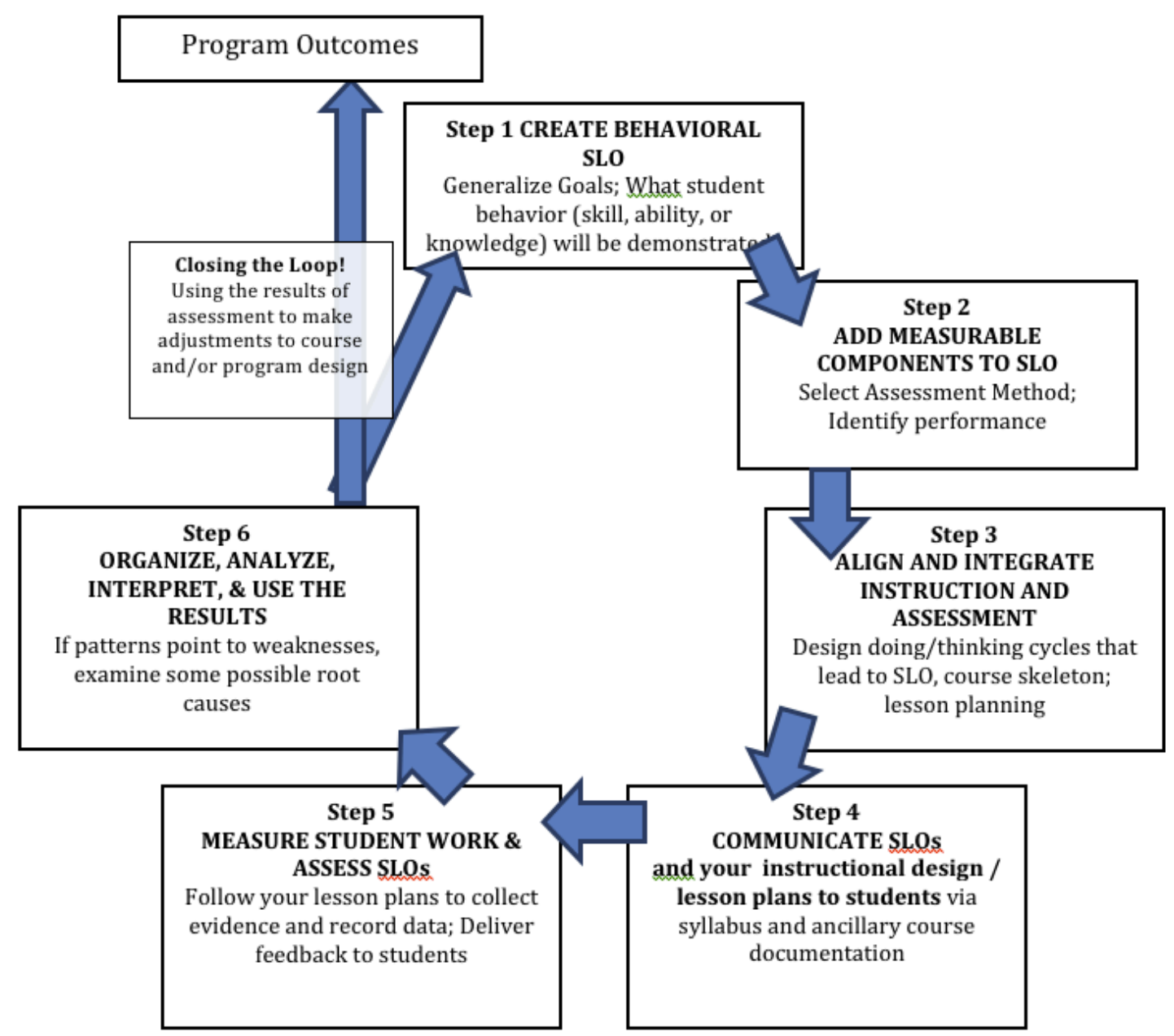

Conclusion 3: The guidebook should disambiguate the language and vernacular

of assessment.

One goal of the guidebook was to clarify inconsistent language. The guidebook more clearly and consistently defined differing assessment methods and provided a common name for similarly formatted assessments. The Guidebook provided common definitions of assessment types and the associated expectations for learning. Walvoord 
and Anderson (2010) described other inconsistencies in the naming of assignments that lead to confusion on the part of students.

Conclusion 4: The Guidebook should focus on direct, course-embedded, practical examples of assessment, preferably drawn from many disciplines, and refer to improvements in teaching and learning as a motivator for faculty engagement; the guidebook should avoid references to theory and external forces, such as accreditation, as a motivator.

\subsection{Lessons Learned From Creating and Processing the Guidebook for Course Outline Revision (Guidebook \#0)}

The sub-committee tasked with developing Guidebook \#0 made several assumptions. Since we were quite busy with other tasks, we believed that we should try to get this work done with a minimum of effort. We spoke of not reinventing the wheel with this project and thought that by simply re-purposing previously created content, we could produce the needed product. I was very familiar with policy that documented the required components of course outlines, thus providing some consistency of key components and terms as I had been a member of this policy development subcommittee. Under my leadership, the sub-committee initially discussed and interviewed others to establish our mission and needs, identified existing documents and flowcharts, worked to expand and more fully articulate these policies into the form of a guidebook. The subcommittee pulled together and reviewed many such documents.

\section{Step 3. Develop preliminary form of the product}

Step 3 included preparation of instructional materials, workbooks, and evaluation methods for the first presentation (Lorenz \& Pichert, 1989). 


\subsection{Research Question(s)}

In preparing the first draft of the Guidebook, I wanted to answer these questions:

Question 1. What is the appropriate scope, sequence, style, and tone of the Guidebook?

Question 2. What evaluation criteria will I use during the preliminary field-test?

\subsection{Methods}

In answering my research questions, I reviewed at least 14 assessment handbooks produced by other colleges and available online.

\subsection{Findings / Analysis of the Data}

Since I had done a comprehensive literature review of assessment and reviewed at least 14 assessment guidebooks, I had an understanding of what a quality guidebook should include. I found several themes and elements that described scope and sequence of assessment guidebooks.

\subsubsection{Themes and Elements}

I found that the quality of other colleges' handbooks varied considerably. Very few handbooks provide practical or comprehensive information about assessment. Many discussed aspects of summative assessment, but not formative assessment. Many described only program and institution level assessment, but not course-embedded assessment. The research was clear that course-level assessment is essential for programmatic assessment, but many guidebooks did not convey this information.

Very few handbooks that I found online were of high quality. Only a few explained measurability in terms of observable behaviors, performance levels, and 
criteria. Only a few mentioned activities that teach prerequisite knowledge and skills and how these are necessary to attain outcomes, but are separate from the outcomes. Only a few provided deep discourse about course-embedded, direct assessment methods and their relationship to teaching and learning. Only a few were field-tested to determine usability, applicability, or accessibility.

Some the themes that emerged from this step, i.e., from the review of assessment handbooks, were a bit paradoxical, as they include being both comprehensive and targeted. Being comprehensive was important to convey the big picture of the assessment loop, and being targeted was important because assessment reform should begin in the classroom ensuring consistent foundational practical assessment knowledge among all faculty.

\subsubsection{What is the appropriate scope, sequence and tone of the Guidebook?}

Finding 1: Be comprehensive.

Faculty members needed to understand the big picture of assessment and the big picture needed to be presented in a systemic way. The assessment loop provided a framework for understanding how all of the pieces of assessment fit together. The guidebook was designed to focus on the assessment loop.

Focusing on the assessment loop provided both a scope and sequence for the guidebook. The assessment loop allowed each piece of the process to be examined and learned in a logic order and independently, each within a loop of their own; thus, doubleloop learning was incorporated where needed.

Finding 2: Be targeted. 
I found the best guidebooks for practitioners were focused on direct, courseembedded assessment techniques, thus this became the orientation I took for the guidebook. All of the content (language used, definitions, scope of assessment work, etc) was geared to meet the needs of practitioners. Direct, course-embedded assessment tied closely to grading, thus I was able to say that this was work the user will do anyway.

The manual for "Testing and Evaluating Manuals" (Folmer et al., 1992) listed necessary components of guidebooks to increase their specificity. Based on Folmer, I learned that I should be explicit and emphasize the intended purpose, intended audience, and usability of the guidebook; I added the "introduction," "who should read this guidebook?" and "how to use the guidebook?" sections to subsequent guidebook editions.

Finding 3: Be collegial in tone

I found some guidebook authors approach assessment disdainfully and as only an administrative task that must be completed by faculty. It seemed unlikely that these colleges used the creation of their guidebooks as a way to foster deeper conversations about assessment. Many seemed geared to support dubious professional development sessions put on by administrators or non-faculty technologists. I found this tone to be offputting and de-motivating.

\subsubsection{What evaluation criteria will I use during the preliminary field-test?}

Finding 1: Focus evaluation on usability, applicability and accessibility of the manual for its intended audience and purpose. 
Part of step 3 is establishing evaluation procedures for field-testing. In researching and developing Guidebook \#0, I discovered a useful online resource that spoke to both content and evaluation of manuals.

The manual for "Testing and Evaluating Manuals" (Folmer et al., 1992) provided great advice on evaluation procedures for manuals. It stated why field-testing with intended users was important and provided a framework for field-testing based on usability, applicability and accessibility of the manual. I used an adapted version of this framework for subsequent field-testing of both guidebooks.

\subsection{Conclusions}

Conclusion 1: My college has a unique culture of assessment and needs effective and useful instructional materials that reflect that uniqueness.

While there were many examples of assessment guidebooks available for download and use for free on the Internet, my experience with Guidebook \#0 led me to approach the creation of Guidebook \#1 with a fresh and informed perspective. My experience with Guidebook \#0 convinced me to indeed "reinvent the wheel" and come up with the best possible guidebook based on the unique culture of assessment that was developing at CCC. I knew I could, and had to, do better.

Conclusion 2: Do not include assessment theory in the guidebook.

I did not include theoretical explanation within the first draft of the Guidebook. I was reluctant to remove theoretical constructs from the guidebook, but did so recognizing these concerns: Gunawardena and McIssac (2004) reminded us that "Theories are necessary because they help us to understand, communicate and predict the nature of a 
discipline or a field of practice, its purpose, goals, and methods" (p. 359). Removal of the theoretical connections from the practices they enact limits the practitioner's ability to deeply understand why a practice works and is effective. This, in turn, impedes one's ability to predict new uses for a practice and to generalize application of the practice to broader contexts. In removing the theoretical concepts, I also realized that one limitation of this approach was that the instructional materials became more job-specific, and thus less generalized; this could limit the size of the potential audience for the materials.

Conclusion 3: The tone of the Guidebook should be collegial and conversational Since the guidebook was written by colleagues for colleagues, I used a collegial tone. Clark (2010) affirmed that people attend to conversational tones better than procedural or authoritarian tones.

Conclusion 4: The style and formatting of Guidebook \#0 was professionally done. I maintained this style to ensure that the two guidebooks are companions.

\subsection{Lessons Learned From Creating and Processing the Guidebook for Course Outline Revision (Guidebook \#0)}

In addition to the ideas by Folmer (2010) that I learned, I adapted and incorporated existing policy and procedural documentation to create the preliminary Guidebook \#0. While it was easy to do, I learned during the next step that the subcommittee had made some assumptions that were not optimal.

\section{Step 4. Preliminary field-testing}

Step 4 emphasized a qualitative assessment of content rather than quantitative outcomes. Direct observations and participant feedback were the primary data obtained regarding issues such as clarity of instructions and materials, adequacy of time allotted 
for instruction, and maintenance of participant interest. Preliminary observations on achievement of learning objectives may also be made. Relatively small numbers of participants may be adequate (Lorenz \& Pichert, 1989).

\subsection{Research Question(s)}

Since this project would impact institutional culture, readiness, and accreditation efforts, I wanted to verify that the content, scope, sequence, tone, and style of the material within the guidebook would indeed be effective in meeting the outcomes the institution was aiming for. I needed to determine which subgroups of stakeholders would have valuable input about appropriateness of my guidebook at multiple levels and thus should be involved with the preliminary field-test. I wanted to find the right subgroup of stakeholders to make the determination that this was the right direction for the institution and the faculty would embrace the message. Due to the two-pronged nature of the outcomes, I used my past experience and insider status to determine an appropriate population to survey.

It was important that the guidebook took an appropriate approach that would lead to institutional reform. I determined that the administrators on the college's assessment committee would be the best stakeholder group to provide input on this question. It was also important that the guidebook appeal to faculty so as to serve their needs well. I determined that the faculty members who had served on the assessment committee would be the best stakeholder group to make this determination.

In preparing for the first field-test of the Guidebook, I wanted to answer these questions: 
Question 1) Is the conceptual approach used by the Guidebook one that will help the college optimally meet its assessment goals at all of the levels necessary?

Question 2) What are the strengths and weaknesses of the Guidebook?

Questions 3) Are all of the essential concepts and skills necessary to complete the task present and well explained?

\subsection{Methods}

After partially answering my research questions (more detail below), I recruited, via email, nine participants, who were all past administrative or faculty members of CCC's assessment committee and/or task force. I met with each individually face-to-face and, during this 10 to 15 minute meeting, each was given a hard copy of the Guidebook. I explained my project and survey protocol (including informed consent forms) and a brief

description of the guidebook. I then followed up this meeting with an email that provided links to an anonymous survey form, which they completed.

Due to their greater understanding of institutional assessment needs, the administrators were asked a couple of questions about conceptual approach that I did not ask the faculty participants. Otherwise, the surveys were similar. I recognized that the population of this sample was small. However, I considered their input to be reliable because of their extensive expertise with assessment. The respondents were college executives and deans.

\subsection{Findings / Analysis of the Data}

The preliminary product was developed during winter break and well after Guidebook \#0 had been produced. I was able to use this preliminary research to 
incorporate many aspects of Guidebook \#0 into the now-called "companion" guidebook. Since I had so closely linked my project to the college's institutional assessment initiatives, I wanted to verify that I had taken the right approach by emphasizing very specific, practical, direct, course-embedded, outcomes-based assessment methods. I wanted to know if the scope, sequence, and tone of the guidebook were appropriate and the content was usable and clear.

\subsubsection{Themes and Elements}

The questions focused on conceptual approach, strengths, weaknesses, content, scope, sequence, style, and tone; thus, these ideas form the themes of the responses.

\subsubsection{Is the conceptual approach used by the Guidebook one that will help the college optimally meet its assessment goals at all of the levels necessary?}

Finding 1: This is an appropriate conceptual approach for the guidebook to take that will lead to institutional level improvements.

All of the administrative participants (four out of four) confirmed that this was a useful component in the college's assessment toolkit. This affirmed that my assumption that taking a back-to-basics approach would benefit the college was correct. The data showed introducing the guidebook was, in the words of one respondent, "the right approach at the right time." Two affirmed that this approach successfully connected to the bigger picture of assessment and that more value could be attained by continuing to build connections to program-level assessment.

All of the administrative participants (four out of four) confirmed that this guidebook should be used with, and could help, faculty improve their practice. Two 
mentioned that some faculty would find it more useful than others and that faculty members currently resistant to change would likely not find the guidebook sufficiently motivating to adopt new practices.

\subsubsection{What are the strengths and weaknesses of the Guidebook?}

Finding 1: The Guidebook's intended audience and purpose are clearly stated. All nine respondents agreed that the intentions of the Guidebook were easily understood and spelled out for users. This was a strength of the guidebook and was retained in future editions.

Finding 2: The content that describes criteria and the setting of performance levels is weak.

Four (44\%) respondents gave excellent feedback about a discrepancy in the second step, i.e., the connections between setting criteria and performance levels was too tightly coupled and needed to be further analyzed and explained. One respondent suggested that more examples of how to elaborate the criteria by adding measurable components would help, another said that rubrics were not given adequate presence within the guidebook relative to other components, a third said that examples of performance levels were poor, and a fourth said that the worksheet provided to practice the identification of the three components of measurability (Factor, Criteria, and Conditions) was unclear because of a lack of performance levels being included in the SLO.

Finding 3: More emphasis should be given to the concept of the Assessment Loop and the big picture of assessment. 
Three $(33 \%)$ of respondents said they do not understand how the guidebook supports all aspects of the holistic assessment loop. They pointed out inconsistencies with the graphic entitled "Creating and Revising SLOs" and pointed out a lack of references back to the assessment loop. There were three comments that point to misunderstanding of how course- and program-level assessment efforts are connected.

\subsubsection{Are all of the essential concepts and skills present and well explained?}

Finding 1: Most of the essential concepts and skills are present and are well explained.

$75 \%$ of faculty respondents said that they could complete the intended tasks by using the guidebook and the overall usability rating of the materials is 4 (on a 5 point likert scale). There were exceptions in the introduction, the "who should read" and the "how to use" sections that did not accurately reflect current procedures.

Finding 2: The guidebook does not adequately emphasize the actual assessment of student work and collecting of evidence.

Two $(22 \%)$ respondents pointed out that there was a step missing between steps three and four that would focus faculty attention on the actual procedure of collecting evidence and assessing SLOs.

Finding 3: The graphic images that explain key concepts could be improved The overall clarity rating of the graphic images was relatively low 3.75 (on a 5 point likert scale). The importance of clarity within graphic images was reinforced by Clark (2010) who pointed out that many readers look first to graphic images to figure out procedures, and they often avoid reading textual descriptions. 


\subsection{Conclusions}

Conclusion 1: The small expert population doing field-testing was adequate.

The preliminary field-testing was conducted using four administrators and five faculty who had attended and had been active in the college's assessment committee. They were selected because I believed they had a critical eye towards assessment reform, strong knowledge and skills in assessment practice and a willingness to thoughtfully examine and adopt new practices. This population represented a broad sampling of disciplines. Faculty from the English, Math, History, Fine Arts, Automotive, and Business departments were selected for review of the guidebook. Lorenz and Pichert (1989) stated that a small population doing field-testing is adequate. This was the case here.

Conclusion 2: More work needs to be done to connect the guidebook to the assessment loop, to elaborate on the setting of performance levels and criteria, and to clarify where in the process assessment of SLOs is done.

While the feedback about the adequacy of the guidebook content and scope was positive, people who were familiar with assessment practices provided this feedback. Any negative feedback from this group of experts was given heightened consideration. Any confusion expressed by experts about guidebook components would be amplified for the intended audience of novice faculty.

\subsection{Lessons Learned From Creating and Processing the Guidebook for Course Outline Revision}

Based on Nicol and Draper (2009), the first draft of the Guidebook \#0 incorporated educational theory and principles, practical examples of the application of 
the principles across a range of disciplinary contexts, and back-up educational research. I learned that this approach needed to be rethought in several key ways, including revisiting task and procedures, audience considerations and user needs.

Field-testing played a key role in uncovering the need for better task and procedure analysis. Early in Fall term, I brought a group of DCs and directors together to field-test guidebook \#0. Based on Folmer et al., (2010), I focused the discussion of usability, applicability, and accessibility of the manual for the intended audience and purpose. The participants brought up three key questions /concerns about the manual; they were concerned with 1) audience considerations, 2) applicability to the immediate task of the course outline revisers, and 3) establishing common language and procedures around course outline revision. Field-testing helped to quickly uncover these key questions /concerns. By soliciting input up-front, we were able to uncover gaps in our language and procedures, and revamped the approach we used, moving toward more practical instructional design. In short, field-testing eliminated an all-too-common dynamic where unclear or incomplete directions for a process are presented as a finished product and then adjusted via public discussion as gaps are revealed.

Audience Considerations. DCs were clear that the guidebook should not have to be read in its entirety in order for faculty course outline revisers to use it. They asked for navigational aids and representational graphics (screenshots of the computer interface where faculty would complete course outline tasks) so that faculty could use the Guidebook as a reference manual rather than as a training manual. This spoke to Mehlenbacher's (2010) concept of “designing for two worlds" (p. 324) and reflects a 
design ethic for guidebooks that individuals can use for self-teaching. The DCs pointed out that the audience for this guidebook would use the materials to toggle between textual information and physical tasks in real time. The guidebook needed to help users easily find and use specific information when they got stopped. This field-test experience led to a major overhaul of the guidebook content.

Understanding Learner Needs. The field-testing experience brought into dispute Mehlenbacher's (2010) idea that thorough understanding of the "prior experiences, knowledge, problem-solving skills, attitudes, and expectations of learners" (p. 205) leads an instructor to design effective instruction. I learned that as an instructor designing materials for other instructors (or, in this case, a DC is designing for other DCs) that understanding is not enough. Despite commonalties of experience between the instructional designer and learner (all of them are DCs), the initial instructional designs were quite ineffective. The field-testing process provided opportunities for the instructional designer to become a learner, thus reversing the traditional instructor-asexpert model.

\section{Step 5: Main Product Revision}

Step 5 includes uses the evaluation of the preliminary field test to improve the program/product. Although participant feedback is rarely a valid gauge of program impact it can be useful in revising program content, sequence, and materials. Revision should result in a program ready for quantitative outcome assessment (Lorenz \& Pichert, 1989). 


\subsection{Research Question(s)}

In preparing the second draft of the Guidebook, I wanted to answer these questions:

Question 1. What is the appropriate scope, sequence, style, and tone of the Guidebook?

Question 2. What evaluation criteria will I use during the main field-test?

\subsection{Methods}

I used the first edition of the Guidebook and analysis of the feedback gathered during step four (as described above) to make several major revisions to prepare the main guidebook.

\subsection{Findings / Analysis of the Data}

More work needed to be done to:

a) connect the guidebook to the assessment loop,

b) to elaborate on the setting of performance levels and criteria, and

c) to clarify where in the process assessment of SLOs is done

\subsubsection{What is the appropriate scope, sequence, style, and tone of the Guidebook?}

Finding 1: The title and introduction should be revised to reflect instructional procedures related to course outline revision and to connect to program-level assessment (greater emphasis given to the assessment loop).

One example of the edits that were made here included changing the title from Guidebook for Writing and Assessing Measurable Student Learning Outcomes to Guidebook for Student Learning Outcomes and the Assessment Loop. Edits were made to 
the introduction and the "who should read" sections because they inaccurately reflected current procedures.

Finding 2: Incorporate a new step that emphasizes use of assessment methods/ tools to measure student behavior and assess SLOs.

Adding a new step required a major re-working of the guidebook organization. I

added a new step five to the "how to use" section, adjusted the other steps, and wrote up a new page of content to explicate this step. I used this as an opportunity to emphasize the use of Moodle assessment tools, which was not included in the first edition.

Finding 3: Enhance the explanations of criteria and performance levels.

The explanations of criteria and performance levels in step 2.2 of the preliminary edition were identified as weak. Based on this feedback, I completely revised this part of the Guidebook, fleshed out step 2.2, and added two examples of rubrics to further describe how performance levels are communicated to students. In addition, I streamlined the explanation of measurability: I changed the terms "factor," "conditions," and "criteria," to "behavioral outcome," "method/tool," and divided the concept "criteria" into two parts: "criteria" and "performance level." Based on findings 2 and 3, guidebook elements, such as graphics, captions, worksheets, and referencing elements were adjusted to reflect the new organizing structure.

Finding 4: Appendices are adequate.

I did not make significant changes to the Compendium of Assessment Methods/Tools or Glossary of Terms. I did change the title from "Compendium" to "Portfolio" 


\subsubsection{What evaluation criteria will I use during the main field-test?}

Finding 1: Intended users need to provide feedback as part of the next round of field-testing.

Since the field-testers of the preliminary materials were senior administrators and faculty, I realized that the next round of field-testers needed to be constituents of the audience for whom the guidebook is intended. I also needed to assess quantitatively if the guidebook was effective as a teaching tool by asking, "do people learn from these materials?"

\subsection{Conclusions}

Conclusion 1: the R\&D process of field-testing was enormously valuable in producing high quality instructional materials.

I saw benefit in both independently and collaboratively field-testing and revising these guidebooks because doing so has allowed an academic research and development process to unfold that has helped the faculty define, refine, understand, and improve its assessment practices and model useful instructional design techniques.

\subsection{Lessons Learned From Creating and Processing the Guidebook for Course Outline Revision (Guidebook \#0)}

Field-testing greatly impacted guidebook $\# 0$ design. The initial draft of the guidebook included theory, conceptual explanations, and practical examples pertinent to course outline revisions. The previewers pointed out that, since the guidebook was aimed at revising course outlines via a web-based application, it could be improved by providing definitions of key terms and step-by-step instructions of the processes involved. The theoretical and foundational concepts being applied were less important to 
their immediate needs and tended to make finding the practical information harder to find. Field-testers indicated that I should remove the conceptual content (theoretical constructs) and rather focus on the practical aspects of the instruction. I adopted these suggestions and continued this design specification into the creation of Guidebook \#1.

Guidebooks, like any instructional material, can be used to communicate declarative, conceptual, and procedural knowledge between an instructor and a learner (Mehlenbacher, 2010). During preliminary research, I learned that the design of the guidebook should be guided by the level of the task to be learned; i.e., completing a specific task with a computer. This is consistent with Mehlenbacher's (2010) contention that instruction in the operation of computer applications (a low-level cognitive task) was best conveyed through procedural instruction. The enhanced focus on declarative and procedural knowledge prompted me to incorporate shots of the pertinent computer screens upon which users would be working and call outs describing both declarative aspects (e.g., definitions of terms and facts about elements asked about on the screen) and procedural aspects (e.g., steps to take, things to include or not.)

The preliminary Guidebook was conceived as a way to avoid duplication of effort by each department and to centralize the versioning of the course outlines to ensure the most up-to-date versions were easily found. While the product went through one round of field-testing and revision, the subsequent adoption by the curriculum committee and departmental use of the guidebook affirmed that this process is effective and valuable. I have since become a strong advocate for field-testing of instructional materials and have 
developed feedback tools that can be embedded into online courseware to facilitate the collection of useful data.

\section{Step 6: Main Field Testing}

The Main field-test determines whether the program achieves the previously specified performance objectives. An experimental design with larger numbers of participants may be used. A secondary purpose is to collect additional data to guide further program revisions. Steps 5 and 6 may be repeated if performance objectives are not met (Lorenz \& Pichert, 1989).

\subsection{Research Questions}

I was able to get an exception from the HSRRB to complete the rest of my research. During the main field-test, I wanted to learn the answers to these questions:

Question 1. Which subgroup of stakeholders would have valuable input and should be involved with the main field-test?

Question 2. What are the strengths and weaknesses of the Main Guidebook?

Question 3. Are all of the essential concepts present and well explained?

Question 4. Did the end users indicate that they have learned anything from the Main Guidebook?

\subsection{Methods}

In the proposal, I planned to showcase the Guidebook with DCs at CCC. The showcases would explain evidence-based assessment and methods, the Guidebook would provide models and examples for faculty buy-in to better assessment practices. Afterwards, I planned to survey showcase participants to gather their feedback about the 
Guidebook and the emergent procedures around assessment reform. This plan was adjusted.

No showcases were held, rather I attempted, during the last four weeks of winter term, to individually recruit DCs, but as I described the procedures for the field-test (I wanted each of them to get a group of faculty together so they could teach them the concepts presented in the Guidebook); each declined. The DCs were engaged in other work and were not available to take on another task. Because of poor timing on my part, I rethought my approach and decided instead to work with the same population that the DCs would work with, i.e., newly hired full-time and adjunct faculty. I decided to recruit new and adjunct faculty to field-test the Guidebook as a self-study guide, hoping to still fulfill my goal of getting feedback from the intended audience.

I was able to recruit, via email, nine participants, all newly hired (within the past year) full-time or adjunct (with any number of years experience) faculty members. I met with each individually face-to-face and, during this 10 to 15 minute meeting, each was given a hard copy of the Guidebook. I explained my project and survey protocol (including informed consent forms) and a brief description of the guidebook. I then followed up this meeting with an email that provided links to a 10-question anonymous online survey form, which they completed. The questions focused on strengths, weaknesses, content, scope, sequence, style, and tone of the Guidebook.

To get the quantitative data on materials effectiveness, I asked respondents to self-report on their knowledge and abilities. I asked them to rate both before and after reading the guidebook, their knowledge of and/or ability to complete the following tasks: 
1) write measurable SLOs; 2) gather evidence and record assessment data; 3) analyze and interpret assessment data; 4) and use interpretation of records for curriculum improvement; with 1 indicting low knowledge and/or ability and 5 indicating high knowledge and/or ability.

\subsection{Findings / Analysis of the Data}

Similar to the first field-test, I again wanted to know if the scope, sequence, and tone of the guidebook were appropriate, that the guidebook is coherent, and the content was usable and clear. I also wanted to ascertain if this group of end-users would selfreport a positive learning experience.

\subsubsection{Themes and Elements}

I found three themes in the responses. "Connections," "usability/instructional issues" and "clarity" were themes that came up frequently and most of the responses connected to these ideas.

Elements that reflected "connections" came up frequently in the data; they included references to the big picture of assessment (comments made suggestions to improve the diagrams/graphics, such as assessment loop and holistic graphic on page 4, to better explain how the whole process connects to steps of the assessment loop, and to make better connections between each step) and the connections the respondent made to their own work (mention gaining a better understanding of how to go from concept to concrete example).

Elements that described "usability/instructional issues" were improvements to the materials to facilitate the teaching of these concepts (several mention that worksheet 
answer keys should be provided, additional worksheets at each step for training of others, reworking of descriptions of methods, a one-to-four page assessment-loop-at-a- glance booklet was proposed as a useful new tool and more overview-of- what-we-learned diagrams like the one on page 9.)

Elements that reflected "clarity" came up frequently in the data. They included more use of worked examples to clarify, a need for better formatting to ensure visual understanding, better organization of some steps, reference to taxonomy materials in Guidebook \#0 (and not the actual set of materials) were found to be weaknesses.

\subsubsection{Which subgroup of stakeholders would have valuable input and should be involved with the main field-test?}

Finding 1: Newly hired full-time and adjunct faculty display rich knowledge of assessment and instruction and are willing to ask good questions when they do not understand the materials.

Two of the guidebook's intended audiences were newly hired full-time and adjunct faculty and one of its purposes was to provide an option for them to self-study and learn the college's process for assessment. This group proved valuable as fieldtesters. This group of respondents affirmed that the revisions made as a result of the first field-test were effective, but also pointed out aspects related to guidebook clarity and formatting that more learned experts missed.

I realized afterward that this was an atypical group of new and adjunct faculty. I selected people who frequently attend professional development sessions on assessment, are recognized by peers to be excellent teachers in their disciplines, and have displayed an above average eagerness to learn new methods and tools. The quality of their feedback 
and specific comments may not reflect the viewpoints of the average new or adjunct faculty member.

\subsubsection{What are the strengths and weaknesses of the main guidebook?}

Finding 1: Organization of the guidebook has received high marks.

$55 \%$ stated that it was well organized and easy to follow. Still, there were several suggestions for improving organization even further.

Finding 2: Portfolio of Assessment Tools/Methods (Appendix A) was useful for providing useful solutions for assessment needs, exposing faculty to new methods and tools, and for reference.

$77 \%$ mentioned that appendix $\mathrm{A}$ as a whole or specific tools within appendix A as strengths of the guidebook. When asked to rate the effectiveness of the guidebook to provide exposure to new methods/tools, it received a very high rating of 4.66/5.

Finding 3: The guidebook does a good job of helping faculty to translate concepts into concrete examples.

$33 \%$ mentioned this as a strength.

Finding 4: The materials within the guidebook are clear (receive high clarity ratings).

Contextual information (who should do assessment work, why would someone do assessment, where and how does assessment fit into other aspects of one's work) received a rating of 4.5/5. Conceptual explanations (explains the key concepts and terms completely and in a clear way) received a rating of 4.65/5. Instructional materials (the 
sequence of materials make sense and are logically connected) received a rating of $4.625 / 5$.

\subsubsection{Are all of the essential concepts present and well explained?}

Finding 1: The guidebook needs to do a better job of coherence, i.e., connecting aspects of the guidebook to faculty work and other parts of the assessment process.

$44 \%$ offered suggestions to improve the diagrams/graphics, such as assessment loop and holistic graphic on page 4, 44\% wanted the guidebook to better explain how the whole process connects to steps of the assessment loop, $33 \%$ wanted the guidebook to make better connections between each step.

Finding 2: Bloom's and other taxonomies are not, but should be, included in each guidebook.

A comment made about not understanding Bloom was an indicator that this concept was essential to understanding SLOs and, anticipated a potential accessibility issue. If a user did not have access to both guidebooks $\# 0$ and \#1, i.e., if guidebook \#1 were to stand alone, then it should include the taxonomies.

\subsubsection{Did the end users indicate that they have learned anything from the main guidebook?}

Finding 1: Seven out of eight (88\%) of the respondents reported that they learned, via self-study, how to better complete at least one of the assessment tasks described in the guidebook: 1) write measurable SLOs; 2) gather evidence and record assessment data; 3) analyze and interpret assessment data; 4) and use interpretation of records for curriculum improvement. 
Finding 2: Four out of eight (50\%) of the respondents learned how to write measurable SLOs from self-study of the guidebook. While this skill was a major component of the guidebook, it resulted in the least improvement with an aggregate pre/post gain of .75 points.

The data show that the respondents had attained a high level of knowledge and skill in this area before reading the guidebook; the aggregate average before rating was 3.75/5. This area also had the highest aggregate after rating of 4.5/5.

Finding 3: Six out of eight (75\%) respondents learned how to gather evidence and record assessment data from self-study of the guidebook. The respondents had the second highest aggregate before score in this area (3.25/5) prior to reading the guidebook. This skill resulted in the second lowest improvement score with an aggregate pre/post gain of 1.0 points.

Finding 4: Seven out of eight (88\%) respondents learned how to analyze and interpret assessment data from self-study of the guidebook. The respondents had the third highest aggregate (a tie) before score in this area (2.88/5) prior to reading the guidebook. This skill resulted in the highest improvement score with an aggregate pre/post gain of 1.375 points.

Finding 5: Seven out of eight (88\%) respondents learned how to use interpretation of records for curriculum improvement from self-study of the guidebook. The respondents had the third highest aggregate (a tie) before score in this area $(2.88 / 5)$ prior to reading the guidebook. This skill resulted in the second highest improvement score with an aggregate pre/post gain of 1.125 points. 


\subsection{Conclusions}

Conclusion 1: The assessment loop graphic is not an accurate visual representation of the assessment process that is described in the guidebook.

The assessment loop graphic was adopted by the CCC assessment committee in 2009. Data point to the fact that while the graphic conveyed the concept of a cycle effectively, it was no longer effective in explaining the complexity of assessment work. A reworking of the assessment loop graphic was included in the operational product. It was hoped that this would solve issues related to providing a better overall picture of the holistic process and allow the guidebook to function more effectively as a reference manual.

Conclusion 2: More check-in/overview design work should be incorporated into the operational guidebook design.

More worked problems, examples, and answers for the worksheets were included. A condensed assessment-loop-at-a- glance booklet that was proposed could be useful in the operational product, as would more overviews-of-what-we-learned diagrams like the one on page 9.

Conclusion 3: Users of the Guidebook learned more from the guidebook when they had a lower level of knowledge about the topic before reading the guidebook, i.e., they made the greatest gains when they started with low knowledge and ability.

The users learned the most in the areas at the tail end of the assessment loop (analysis and interpretation of assessment data and use interpretation of records for 
improvement). This showed that these skills should be given special attention in followup training and materials production.

The eight respondents that self reported on their learning before and after reading the guidebook were above average in their attendance at professional development sessions on assessment, they were recognized by peers to be above-average teachers in their disciplines, and have displayed an above-average eagerness to learn new methods and tools. Concerns were generated about generalizing these results across a wider populations of new and adjunct faculty. A scientific study of a randomly selected population would have provided better results, but this level of rigor was not possible during this study. Their feedback and specific comments may not reflect the viewpoints of the average new or adjunct faculty member at CCC or elsewhere.

\section{Step 7. Operational Product Revision}

Uses data obtained in the main field test to prepare the program/product for use by others, independent of the developers (Lorenz \& Pichert, 1989).

\subsection{Research Question(s)}

In preparing the operational draft of the Guidebook, I wanted to answer this question:

Question 1. How can I improve the design of the Guidebook for a broader audience?

\subsection{Methods}


I used the second "Main product" edition of the Guidebook and analysis of the

feedback gathered during step six (as described above) to make several major revisions to prepare the operational guidebook.

\subsection{Findings / Analysis of the Data}

The data show more work needs to be done to:

a) connect the guidebook process steps to the assessment loop and increase the effectiveness of the guidebook as a general reference tool,

b) incorporate the essential components to allow the guidebook to stand alone, and,

c) improve readability, visual cuing, and clarify ambiguous language.

\subsubsection{How can i improve the design of the guidebook for a broader audience?}

Finding 1: Data suggested that a reworking of the Assessment Loop graphic would improve the guidebook by both explaining the big picture of assessment and to anchor the steps within a process.

This change worked to address user concerns that they found it difficult to use the manual as a reference tool. Also, focusing on the assessment loop provided a comprehensive approach that we needed. Not only did it lay the conceptual groundwork for faculty efforts, it was comprehensive in that it enables faculty to complete the loop.

Finding 2: Add the taxonomies for cognitive (Bloom's), affective and psychomotor domains, and associated lists of action verbs, to allow the guidebook to stand alone as an operational resource. I made room for this by removing the problematic holistic graphic on page 4 . 
Finding 3: Add a condensed assessment-process-steps-at-a-glance pull-out to assist those faculty who use graphics to learn new procedures.

\subsection{Conclusions}

Conclusion 1: the R\&D process of field-testing is enormously valuable in producing high quality instructional materials for a general audience.

I saw benefit in both independently and collaboratively field-testing and revising these guidebooks because doing so has allowed an academic research and development process to unfold that has helped the faculty define, refine, understand and improve its assessment practices and model useful instructional design techniques.

Conclusion 2: Guidebooks are useful as tools for moving forward organizations in solving intractable problems.

This project was directed at addressing haphazard DC capacity to lead assessment reform. While the Guidebooks do help to mitigate this, as I have worked to complete this project, I have learned that other organizational problems have, at least partially, been solved by the introduction of the Guidebooks and the process used to create them.

The Guidebooks provided common ground about assessment, that is, a set of definitions, clarity around necessary components, steps to follow to enact direct, courseembedded assessment within course design, and a framework for closing the assessment loop, including steps for gathering evidence, interpreting the results, and how to use the interpretations for continuous improvement. Teachers needed to be able to translate educational ideas into actual teaching and learning practices in their discipline if the educational aspiration was to have any meaning and if change was to transcend 
disciplinary boundaries. The instructional design support they received was invaluable to this translation process.

\section{Proposed and Actual Outcomes}

With this project, I proposed to meet the following goals and/or answer the following questions. I did not meet every goal in the way I had anticipated. I will describe how the project design fulfilled the listed goals and provided the answers I sought, and if the goal was not met, I will explain why and what I learned about that goal. I will also describe how the project helped me to uncover and address related, but unanticipated problems, which forms the groundwork for chapter 5.

Proposed Outcome 1. Address deficits in faculty understanding of outcomesbased assessment theory and practice and the role of evidence in program and course improvement. The Guidebooks will provide theory that underlies the principles that guide this work and related practical discipline-specific examples that will provide models for them to emulate.

Actual Outcome 1. I learned as part of the preliminary research that addressing deficits in faculty understanding of assessment practice was a useful goal, but that administrators and DCs, while interested in specific examples that support disciplinary work, were less interested with general theoretical foundations of practice and more concerned with practicality. This element was repeated several times by both groups of respondents. For example, the comment that captured this idea most succinctly was " the focus should be on very concrete specific plans for assessment in particular contexts that meet departmental and institutional needs." 
I learned that use of commonly accepted assessment theories or principles throughout departments is haphazard, and that theory of assessment was not readily of interest to certain departments. Only one of the DCs reported that faculty members within the department used commonly accepted theories or principles of assessment and, in this case, these were not departmentally developed, rather they were based on recommendations provided by a professional organization. (Four other chairs reported that assessment practices practiced within their department were not aligned or used in common.) Likewise, a career technical educator in my sample used highly authentic programmatic SLOs that were recommended by advisory groups that are comprised of local experts such as business owners, managers, and professionals. Assessment in these authentic workspaces was more of a connoisseur's effort of observing a high quality work ethic and functional approaches to work rather than measuring criteria through artificial academic exercises. Understanding assessment in career-technical and creative fields, such as the fine arts, was an area that required more study.

Proposed Outcome 2. Develop systems and methods to collect and store useful evidence, connect evidence to learning outcomes, extract and analyze assessment data, and to report the findings. The Guidebooks will provide practical examples that show effective methodology to complete needed tasks and that maximizes the functionality of the available tools.

Actual Outcome 2. I learned during preliminary research that there were no efforts underway to extract and analyze assessment data beyond the course level within the departments that responded. These efforts were geared toward using non-course 
embedded assessment methods to determine the effectiveness of our writing curriculum and writing program effectiveness.

Proposed Outcome 3. Address deficits in skill sets needed to use computer-based assessment tools more effectively and efficiently. The Guidebook will provide step-bystep training guides that DCs can use to show faculty how to implement the methods and tools that are available. Also, shifting to computer-based assessment tools also allows assessment work to be redistributed to the computer and can lessen the workload for faculty. When assessment entails less work, more assessments can be developed and used within courses.

Actual Outcome 3. The Guidebook provided some training for rubrics and completion tracking. Since reported use of Moodle was relatively high, some faculty members were figuring out on their own how the LMS can lessen workload. DCs may be ready to explore systems use for evidence collection and data reporting.

Providing step-by-step training guides for Moodle was not readily achievable, especially with paper-based Guidebooks. Frequent version changes in Moodle during Fall 2012 and Winter 2013 terms hampered efforts to create step-by-step training materials. These efforts are underway in electronic formats, but will not be completed as part of this project.

As described, the outcome of the faculty assessment committee was to improve assessment design, and use of technology within assessment work. In my role as faculty developer and assessment designer, I have taught others about our e-portfolio system, called "Mahara," which is being adopted by a grant-funded program. As I worked 
through the steps of the R\&D process, I incorporated, when appropriate, useful connections to Moodle, but I did not create the resource that I originally envisioned.

Proposed Outcome 4. Help faculty better understand and design curriculum in a way that promotes more effective use of formative assessment practices. Formative assessment tools, such as completion tracking, personalized learning designer, and notifications can act as cognitive tools that trigger metacognitive processing that empowers students. Use of formative assessment tools in Moodle and the increased feedback they enable can improve interaction and dialogue that engage students to achieve more.

Actual Outcome 4. During initial surveying, DCs and faculty members mentioned being interested in using formative assessment, and revealed that faculty in general misunderstand the nuances of formative assessment and feedback. DCs wanted more information about formative assessment and two faculty member reported using (use of clickers for scaffolded Q \& A were reported) or wanting to use formative assessment tools (develop rubrics) in Moodle. I know that these faculty members provide feedback on graded assignments, but did not mention this aspect of formative assessment.

Guidebook \#1 included information on completion tracking and rubrics, but I did not study student impacts of any assessment practice reform this project may have been instrumental in bringing about. This could be an area of further study.

Proposed Outcome 5. Showcase the function of specific tools and connect tools/functions to assessment practices unique to a discipline and across the curriculum. The guidebook will help improve communication of expectations by helping faculty 
better understand the value of clarity and to use formative assessment tools built into the LMS, such as the rubrics grading tool, that allow expectation to be communicated more comprehensively. Each department has assessment needs that can be better met by incorporating tools useful to the task; the Guidebook will examine these needs, identify and showcase appropriate tools.

Actual Outcome 5. The guidebook explained the role of criteria and performance levels thoroughly and encouraged faculty to communicate criteria via rubrics, checklists, syllabus, and ancillary course documents. Whether the Guidebook had an impact on this, however, was not part of the study and can only be ascertained via anecdotal evidence shared back by Guidebook users after the project was completed.

Proposed Outcome 6. Support institutional change / improvement in the face of increased accountability and meeting stakeholder / policy maker expectations for student achievement. As stated above, when enacted as part of a strategically planned improvement initiative, the Guidebooks could provide a focal point for articulating working principles, evidence, in the form of practical examples, of how these principles work in practice, and support persuasive arguments in favor of change. The intended outcome of improved assessment practice would benefit the institution by providing evidence that educational and teaching activities result in learning.

Actual Outcome 6. While I did not collect data about the impacts of the Guidebooks on institutional assessment practices, there was much evidence collected informally that indicates that the Guidebooks had this effect. 
Proposed Outcome 7. Model collaborative content identification, joint instructional design, use of research for making instructional design decisions, and prototyping and field-testing of materials to ensure their efficacy, for the faculty in support of their instructional design efforts. R\&D processes, by actively soliciting and incorporating the viewpoints of others to guide content selection and instructional design, provide new models that can improve curriculum. This project will model the use of these processes and encourage their adoption by others.

Actual Outcome 7. The design of the research, i.e., online surveys taken independently, did not allow as much modeling of instructional design processes as I had hoped to achieve during the actual R\&D for the dissertation. I learned many techniques that I incorporated into professional development activities that I have subsequently led for the college faculty. I will continue to do this. So, while the direct modeling of new design practices was not part of the dissertation project, there were indirect and future impacts. With my newfound expertise, I will model the instructional design strategies for the faculty and this will have increasing impact in the future.

\section{Conclusion}

I have shown in chapter 4 that by conducting a thorough research and development plan, I was able to successfully create and refine my product, a useful new tool. In addition to the product, the process has been as, or more, important than the product. $\mathrm{CCC}$ has a new tool that eliminates barriers to institution-wide transformational change. For example, many academics working in the disciplines are not knowledgeable about research on teaching and learning. This will help teach these teachers how to teach. 
The guidebook acts also as a reference manual that will help those who might read literature on teaching and learning generally or that which exists in their discipline (e.g. Journal of Chemical Engineering Education), to translate educational ideas into effective teaching and learning practices.

Assessment becomes institutionally sustainable when it is made meaningful and manageable for faculty, staff, and others who carry it out every day. Sustainable assessment is transformative because, when assessment becomes institutionalized, the campus culture of evidence is realized. A culture of institutional change is difficult to realize because most academics are focused on changes within their discipline, not the institution as a whole. Not all faculty view learning outcomes as the driver of instruction. The guidebook helped to show why they should be considered as drivers. 


\section{CHAPTER 5}

\section{CONCLUSIONS, SPECULATIONS AND RECOMMENDATIONS}

\section{Introduction}

Bridges et al., described the problem-based Ed.D dissertation as providing an opportunity for a student to demonstrate his "ability to apply knowledge in a professionally productive and academically sound manner [and as a] vehicle for building meaningful connections among research, theory, and practice in the classroom" (p. 113). As I completed this project, I affirmed that Bridges was correct; this project has been professionally productive, stretched me academically, and has led to a higher understanding of how to use research and theory to examine my own, and others', practice. This dissertation demonstrated that I have developed high-level expertise in instructional and assessment design. I have grown into a more thoughtful and resourceful leader. I have become more academic, a better researcher, and I've learned how to produce high quality and useful products to support the work of my institution. But more valuable than the products were the processes that I have learned. I find myself more capably applying useful approaches and theoretical frameworks to teaching and learning. I am more informed about and more capably discuss practice with colleagues. I feel more connected to other faculty and administrative leaders, better understand their goals, and how to effectively collaborate to accomplish them. I feel more confident in my abilities to support institutional change, especially in the area of assessment; I now consider myself a change agent and an assessment leader at my college. This chapter describes the details 
of experiences and my overall conclusions and assessment of the experience of completing this dissertation. I describe how I met my outcomes, what I learned, how I grew, and how my organization has benefited by my efforts.

\section{Overall Conclusions and Assessment of the Experience}

The results of the project have been more far-reaching than I expected. In chapter 1, I described problems relating to inconsistent levels of Department Chair (DC) assessment leadership. In the course of working to solve this problem, other issues and problems were uncovered and resolved. Through conducting the literature review in chapter 2, I have developed a broad and deep understanding of many areas of assessment and instructional design. This knowledge taught me to be a more critical observer of practice and to identify the aspects of assessment that are critical to moving the college forward. This also helped to uncover pockets of assessment expertise on campus; expertise that lies beyond direct, course-embedded assessment. I have learned much from my expert colleagues and have stretched my own understanding of assessment. I have learned that certain colleagues possess knowledge and expertise in all areas of assessment, some have as thorough an understanding as I have developed, only a few have a better understanding than me. Chapter 3 is about research methods and the R\&D process. By completing this project, I developed the skills to develop and harness a form of crowd-sourcing that helped make educational products more useful and effective. This experience impacted my work as an instructional designer and led to higher quality products being produced by my co-workers and me. It has provided new inquiry-based processes that were extremely useful and has given me more confidence. In chapter 4, I 
described how my project addressed inconsistent assessment knowledge and practices of my colleagues, the DCs at Clackamas Community College (CCC), but I learned that the inconsistencies in knowledge and practice existed at the faculty-level (which I expected) and at the administrative levels (which was surprising). DC awareness (and lack of awareness) of direct, course-embedded assessment was indicative of the awareness throughout the organization, including individuals within the management structure. In this chapter, I summed up all of these findings and make recommendations about them.

As I described, I was able to get excellent feedback on direct, course-embedded assessment from a few colleagues, but much of the data reveals a relatively low level of understanding of this form of assessment. I expected this from new and adjunct faculty members, but it was especially surprising when revealed in data collected from veteran faculty and administrators. While many of the administrators on campus have knowledge of program-level assessment, not enough of our leaders have a thorough understanding of assessment in all of its connotations. The guidebooks developed for this study helped to build their knowledge and expertise.

This inconsistent knowledge and expertise among our leadership, I believe, revealed itself in another problem area. While we made progress in implementing assessment reform, our approaches were scatter-shot. Different people have worked on different aspects of assessment reform, but no one person understood the complete picture. The college lacked a consistent, comprehensive, explicit, and strategic plan for assessment reform. The scale of earlier assessment reform efforts was too small to lead to widespread changes in practice. Achieving the high quality and iterative assessment 
practices that accreditation demands required a coordinated plan that combined communication, persuasion, and learning across a whole institution (Nicol, 2010). We are just now (Spring 2013) developing this groundwork. As described in chapter 4, the guidebooks provided some of the groundwork for faculty engagement with assessment, and I devoted attention to creating a similar guidebook that supported program-level assessment (more details about this were found below). A recently developed "assessment task force" worked on a conceptual groundwork and integrated structure that may lead to the sort of strategic plan that we need. I am taking a leadership role on this task force; my leadership will focus on faculty development as we change paradigms, moving from an instructional paradigm to a learning paradigm.

I plan to lead a variety of faculty-led initiatives that engage practitioners in understanding the changing role of faculty and that grapple with the questions that arise as the institution reforms its assessment practice. I want to get instructors involved with other instructors and further develop processes and practices that support improved practice.

Current efforts are more focused on collecting data than on adjusting assessment practice. The collection of assessment data occurs after grades are completed, so this process, unfortunately, has become associated with grade-keeping, records, and mark entry; we pay attention to this work after learning has occurred. Our strategies have reinforced episodic, summative assessment practices, to the detriment of continuous improvement and formative assessment. Our efforts at continuous improvement are inconsistent. Few instructors are keeping records of discrete assessment of outcomes, and 
even fewer do this longitudinally. We do not have effective information/ communications systems in place to support these efforts. The college-developed tool for collecting data is not capable of sharing data back to the faculty, so its use as a continuous improvement tool is hampered.

One role in task force leadership (and which will form an agenda for further research, as I'll explain later) is to encourage faculty to better understand the role of technology in teaching and learning. Technology can support the attainment of educational goals, assist in helping them complete the assessment loop and can help them do a better job of collecting, reporting, and analyzing assessment data leading to continuous improvement of teaching and learning. For example, I want to lead (and study) a series of faculty development efforts that build skills in the use of the assessment tools in Moodle. I also want to use new technology implementation as a springboard for faculty to examine their teaching methods.

Professional growth of myself and others Completing this project has led to increased professional expertise in all of the areas of my work: instructional design, faculty development and leadership, administration of learning management system (LMS) and staff. This process of professional development is iterative and mutually reinforcing. This outcome has been very satisfying to me.

I have always known that instructional and assessment design skills are essential for driving change at the course level, but I now realize that these skills can drive change at the institutional level as well. I am more effective at being a change agent. Campbell, 
Schwier, and Kenny (2009) described the role of the instructional designer as a change agent.

Instructional designers work directly with faculty and other clients to help them think more critically about the needs of all learners, about issues of access, about the social and cultural implications of the use of information technologies, about alternative learning environments, and about related policy development (Campbell et al., 2009, p. 646).

As such, they can play a critical role as change agents within colleges. Campbell et al., (2009) posited that the "actions [of instructional designers] may contribute strongly to changing the way colleges and universities realize their instructional missions" (p. 646). An outcome of the project is an increased sense of efficacy and confidence in using my instructional design expertise for change agency.

The effectiveness of a change agent can be enhanced when one combines professional expertise with other leadership activities that build professional community, connections, and credibility. I have enhanced my professional capacity and reputation among peers, the management and with peers outside my organization by serving as cocoordinator of CCC's faculty development unit, by serving a full-time faculty association President, by taking a lead role in faculty assessment reform via the newly established assessment task force, by creating useful assessment-focused resources for key instructional committees, and by serving as the chair of the Oregon Community College Distance Learning Association (the OCCDLA). All of these activities, combined with the experiences and knowledge gained via the dissertation have led me to become a skilled assessment leader. Assessment leadership has become my passion. I have learned that my 
college is desperate for assessment leadership, especially for leadership that arises out of the faculty ranks. CCC is a good place for me to be an assessment leader.

The knowledge and tools that I have developed as a result of the dissertation has elevated my confidence to lead. I feel very empowered to effect change at CCC. For example, I have cultivated strong working relationships with the assessment committee and with DCs. I was recently called, by a leader within our public affairs office, a college "thought leader" so it is clear that people listen to what I think and say. I have access to the right people, as I meet regularly with college executives and faculty leaders. I know the way to get things done and can easily get on the agendas of meetings of key departments and decision-making bodies at CCC. Campbell et al., (2009) found that a “designer's effectiveness is also related to the broader university community of practice, and the instructional designer's status in the institution" (p. 654) and, thus, affirmed that my professional effectiveness as a designer is enhanced by service as faculty president and by other roles. My design work at the institution is given credibility by the interpersonal relationships I have built over time and by the leadership positions I accept at the college. Over time, increased credibility affords more opportunities to successfully redesign structures and processes, thus building my capacity and portfolio as a professional designer. This process is iterative and mutually reinforcing.

Integrating my work as a faculty developer and as a designer with advocacy for reform of assessment practice is enabling me to play an important role in helping my college to move forward in a more systematic way and to get high levels of faculty to buy-in. It is allowing me to become a more effective faculty leader. Assessment reform is 
looked upon with suspicion among some faculty subgroups that possess a more traditional mindset about the work of the faculty. Some of the faculty view outcomesbased education as a right-wing conspiracy aimed at destroying public education. Some faculty are ignorant of assessment and do not understand its purpose or role in professional improvement. I aim to teach them new knowledge and skills. All behavior changes require new knowledge, but knowledge alone won't be sufficient to cause change. Being a faculty leader gives me the credibility to more effectively connect to other faculty, persuade them, and potentially teach and call them to action. Ultimately, effectiveness in my job requires me to persuade and convince my colleagues to talk about their practice, try new methods, and improve their instructional designs. Having an Ed.D credential will make me more credible.

The R\&D process of creating guidebooks for promoting change within the academy is well suited to academic organizations. The $\mathrm{R} \& \mathrm{D}$ process provides a framework for academic inquiry that connects research, theory and practice and leads to useful products that, in turn, make instructors' lives easier. Academics respond well to inquiry-based processes and to products that improve their productivity. Instruction is a process of communication, and the instructional designer studies how to communicate ideas and concepts more effectively. Academics want to be informed, they respond well to communication and they want to communicate better to their students. The R\&D process is a participatory design strategy. Professionals want to share in the redesign of their working environments. R\&D teaches its participants, to a high level of comprehension, about the elements that are being redesigned. $R \& D$ is a constructive act 
by the participants, in which a product emerges that the individuals working alone could not construct by themselves. The guidebook development process builds awareness of the salient processes that are being redesigned and acts as a touchstone for communication between the participants. Being part of a project to create change in itself helps to fortify the commitment to change. When people collaborate on the creation of a product, the completed product is sought out by the collaborators, who want to see their contribution to the work. They then share it with colleagues. In this way, the guidebook works as a way for colleagues to market the redesigned programs to peers. The guidebook allows a group of collaborators to redesign a problematic element and together they take a step forward to a new place. This soon encourages follow-through efforts that lead the organization to take the next step forward. Thus, guidebooks allow incremental changes to take place that lead to reform.

Role of assessment designer My professional title is "instructional designer", and I learned that the title of the role may lead both my colleagues and me to under-emphasize “assessment design”. While I have always connected instruction and assessment in my work, I realized through this project that I should emphasize assessment design as much as I do design of instruction. The two are inextricable and that idea should be consistently communicated. One outcome of creating the Guidebooks is that I developed the skills of an assessment designer.

My expertise as an assessment designer allows me to apply assessments concepts in other places, like strategic planning. For example, to address a new Oregon law, the college is trying to figure out how to award more credit for prior learning (CPL). In the 
past, a barrier to awarding CPL was the fact that certain departments refused to even consider CPL. We determined that these courses probably had unstated Student Learning Outcomes (SLOs) that the faculty member evaluated as part of grading. This led to a recommendation toward a policy requiring all SLOs to be stated in course outlines, or conversely, a policy that, if a student attains all SLOs stated on the course outline, then he or she will pass the course. Those in opposition to this idea pointed out this would eliminate student effort, participation, or growth as being considered as part of a course grade. A tension emerged between grading and assessment and led to a discussion that we should rethink the purpose of grades if we are to become an outcomes-based institution. The question arose: what purpose do grades play in an outcomes-based institution? This question is one that I will list as topic for additional study. We have not yet worked through the tensions created by this emerging dual system of determining the attainment of student learning. However, my enhanced understanding of assessment was of great benefit to the conversation. It allowed me to frame the questions and contexts so that people could see the tension and begin to grapple with these hard questions.

Writing and measuring SLOs will improve instruction, but also allow CCC to play a larger role in awarding credit for prior learning. Our lack of measurable SLOs for all courses is a barrier to CPL as it is often unclear what a student would need to do to earn the credit. Once faculty develop a rich assessment environment, including clear criteria and conditions for assessment, the creation of challenge assessments for courses will be easier. 
Once my expertise was known, I have been asked to complete similar projects. For example, the college is undertaking a project to develop a guidebook useful for writing and assessing program-level SLOs. I am taking the lead in this project and have begun system analysis work to uncover how such systems operate and how we can build such a system at CCC. This work is an area for further study and key questions will be developed below.

\section{Speculation about Future Research, Development, and Use of the Product}

Due to external pressures, CCC is transitioning from an instructional-focused institution into a learning-outcomes-based institution. I see the college grappling with the challenges of this transition. Transitioning away from an inputs-based (instructionalfocused) to outcomes-based (learning-focused) system will be difficult. There are numerous areas for further study that develop because of this transition. Chief among them is how CCC may come to more value outcomes- or competency-based education, in light of our traditional structure and use of grades to measure student progress. A goal of competency-based education is to gather evidence that a student has the knowledge, skills, and abilities to meet a performance standard established by the faculty. Institutions that have become competency-based, such as Western Governor's University (WGU), no longer use grades as a measure of student learning (Kinser, 2007) and assessment has taken on a new central role. One question that emerges is, what is the role of grades in such a system, and how will CCC and its constituencies (faculty, community, students, directors, governors, etc) adapt to the radical idea of no longer issuing grades to students. 
How will they accept not having such metrics as the grade point average (GPA), or student rankings?

WGU also outsources much of its instruction. If one accepts that instruction and assessment may be separated, then we need to study what it means to unbundle assessment. For example, Oregon HB 4059: Credit for Prior Learning will require community colleges to develop a transparent system for awarding CPL. I speculate that the spill-over from this law will force the community colleges to become more like WGU and further unbundle assessment from instruction. How this occurs and what is means for the Oregon community colleges and four-year institutions is an area for further study.

It leads also to reform of financial structures as we grapple with what "tuition" means in a competency-based system and leads to the question: how will students pay for credits and credentials?

\section{Understand how Technology can help the College meet Other Organizational Needs}

While I proposed some assessment/ technology-focused outcomes within my proposal, I discovered early in my research that the college needed more foundational materials. I therefore adjusted my study to better meet these needs and focused less on assessment technology. I have noted earlier that technology can be a major force for significant institutional change and its use, through tools like Moodle, should be harnessed to move our assessment efforts forward. Through such concerted efforts, we could more readily impact the mission, priorities and the very culture of the college. While I expanded and refocused my project to meet a more fundamental need, I still wish 
to understand how use of Moodle can help the college meet its assessment and accreditation needs.

More research needs to be conducted within the analytics and reporting tools of Moodle. The goal of analytics is to "improve student achievement, retention, and graduation rates and to demonstrate institutional accountability by offering students who may need additional help the information they need to obtain it" (Educause, 2010, p. 1). While there are direct benefits for students, faculty, departments, programs and management, Educause reminded us that the "effectiveness of any analytics tool depends heavily on the frequency and character of faculty and student use" (p. 2). I would like to study the usage patterns of analytical tools in Moodle and target professional development and student training in this area. While I have direct contact with the faculty and can coordinate such opportunities, I recognize that the college needs to do a better job of helping students use internet-connected computer systems for supporting their success at college. Moodle provides the individual student a dashboard apps and completion tracking to track personal progress empowering students to monitor their coursework and take greater responsibility for their learning. Our hosting company has committed to taking the global lead in developing a set of tools and reports that are designed specifically to generate meaningful analytics. I'd like to learn how to use these analytical tools at a high level and study how such use impacts achievement in the faceto-face and online classroom.

Longitudinal assessment efforts can be enhanced through use of an evidence repository. Moodle is an evidence repository. Students can upload their work (which 
becomes evidence) directly into the management system where it can be evaluated by faculty. The collected evidence is tied directly to the pertinent SLO and teacher evaluation of the evidence (in the form of a grade or performance indicator). This evidence and supporting data can be stored longitudinally. Once the evidence is in the system, it opens the door for many analytical processes to take place that can inform assessment efforts. I would like to build organizational capacity to use these tools and to study how such databases directly and indirectly impact achievement in courses and programs.

The Guidebooks that I have created would be useful, after some translation, to other community colleges in Oregon. I would like to share this resource throughout the state in support of the assessment efforts of small/ rural colleges who do not have adequate personnel to produce such materials themselves. As chair of the OCCDLA, I have made connections with most of the potential colleges already. It will be easy, once the guidebooks are approved, to share them online with CCC's sister institutions.

I also hope to share the guidebooks via OER repository sites through a Creative Commons BY license. This will allow my work to more broadly serve the world through an open resource that will be tied to $\mathrm{CCC}$. This will build name recognition and credibility for the college.

I plan to utilize $R \& D$ processes to better understand how program level assessment design challenges can be met. Our current program assessment methods and metrics are problematic. We have not developed student outcomes for many programs and those programs that have developed outcomes are focused on indirect measures, such 
as counting how many students get employment after completing the program or certificate. Our accrediting body has told CCC to improve its program-level outcomes and assessment. This work is ramping up quickly and will be my next project to complete. As I do preliminary research and system analysis, I am learning that there is considerable overlap between assessment practices at the course and program-levels. For example, techniques described in the Guidebooks for writing measurable SLOs are applicable for both. I plan to research our program outcomes development systems and implement an $\mathrm{R} \& \mathrm{D}$ process to develop materials to innovate in this area.

While I described in chapter 4 what I learned about peer review processes, and design community dynamics related to curriculum improvement at the course level, more needed to be learned about these aspects as they work at the program-level. Programlevel assessment is more complex than course level assessment and will require increased faculty interactions as they work collaboratively through the issues that arise. A question to be answered is how idiosyncratic personalities will react when faced with opposing viewpoints about the program-level curriculum. How can different emotional and professional reactions be anticipated and supported without causing undue conflict? These reactions may or may not be conducive to collegiality and peer mentorship.

More needs to be understood about assessment in career technical workplace settings and in highly creative spaces, such as in art classes. This is an area that I have identified for more study. The different disciplines may adapt and adjust these ideas to fit their needs, however, the authentic assessment practices of arts or career technical courses provide a challenge to direct, course-embedded assessment. For example, it is 
difficult to articulate performance levels for highly creative artwork. Since artistic and CTE courses make up a large minority of courses at CCC, I would like to further study techniques for articulating performance levels in these areas.

More needs to known about how assessment and continuous improvement processes focused on retention and completion intersect with academic freedom and faculty autonomy to control the curriculum. Assessment may reveal that content selections made by faculty are poor choices for supporting the learning of novice learners, yet the materials may be classics within the discipline and highly valued by the subject matter experts. How much autonomy over materials is a faculty member willing to forgo in order to ensure greater student understanding of the curriculum? Is a managed curriculum acceptable to faculty members if it is proven to increase attainment of student outcomes? Will those who want maximum understanding on the part of students on one level change the materials they choose if it means lessening the learning of another, perhaps higher order, outcome? What would be a good framework for faculty to understand how to balance these considerations? For example, will a faculty member change materials to increase understanding, if it also means giving up some level of sophistication of the materials? What trade offs would motivate faculty to do this? More needs to be known about this at CCC.

\section{Recommendations for Leadership}

The guidebooks are useful because they address a fundamental change that is occurring at $\mathrm{CCC}$ and at colleges around the country. $\mathrm{CCC}$ is transitioning from an instructional-focused institution into a learning-outcomes-based institution. I see the 
college grappling with the challenges of this transition. Transitioning away from an inputs-based (instructional-focused) to outcomes-based (learning-focused) system will be difficult. There are numerous recommendations that can be made to support these efforts.

Recommendation 1: Use guidebooks to introduce and sustain academic innovation.

It is necessary for high-level leaders to support an innovation in order for it to spread effectively (Smith, 2012). CCC is fortunate that it has top-level executives who support academic innovation. Even in these difficult financial times, sizable amounts are budgeted for innovation by the college leaders. Innovators are invited to submit proposals to tap into these innovation funds. These are best practices in innovation diffusion (Smith, 2012). "Innovations are more likely to be successfully adopted if they address context-specific problems or are relevant to what an institution or individual is being asked to use or do" (Smith, 2012, p. 176). R \& D based guidebook creation can be an ideal strategy that my institution should employ to better understand and eliminate the institutional barriers to change. They can be used to collaboratively develop, build awareness of, and disseminate new processes and products within the local context and are relevant for reference, training, and professional development, for new things that people are being asked to do.

Recommendation 2: Use guidebooks to establish new contexts that work to pull resisters (the late majority and laggards) toward new attractors.

$\mathrm{CCC}$ has realized success in its initial assessment efforts because the earlyadopters have been converted and buy-in to the innovations; the challenge it now faces is 
to move these ideas into the mainstream. We will need to accomplish this by bringing the late majority and laggards on board. This is not easy as the late majority and laggards actively resist change.

Morgan (2006) provided ideas on how leaders can foster organizational change to counteract personnel who actively resist change. Change is initiated by creating new contexts that provide alternatives for people that are heavily invested in the status quo.

Morgan (2006) wrote:

new contexts can be created by generating new understandings of a situation [...] New understandings [...] can be achieved by exposing the system to new information about itself or its environment [...] Through such means the system can begin to challenge and change its operating norms, paradigms, and assumptions, and free itself from the cognitive [...] traps that sustain its established attractor pattern (p. 259).

Rather than working to overcome resistance to new ideas, change agents, such as myself, can use these newly created contexts to introduce new attractors that are capable of pulling traditional educators toward a new paradigm (Morgan, 2006). "New contexts can also be created by engaging in new actions that help push the system into a new state more directly. Experiments, prototypes, changes in rewards [...], a fiscal crisis [etc,] can catalyze changes [...] in context" (p. 260). A key role that a guidebook can play in this shift in educational practice involves creating new contexts within the educational arena that establish the legitimacy of new practices wherein educators feel supported in integrating new practices into their work.

Consistent with Morgan (2006), new understandings and new actions can be introduced through production of new guidebooks and the establishment of new contexts around assessment and outcomes-based education could result. Guidebooks could 
provide new understanding of and promote advocacy for actions be taken in areas of educational practice that are connected to assessment practice, such as seat time, academic year, and teacher autonomy/isolation.

Guidebooks can be used to build a culture around a common understanding of institutionally important ideas or practices. Once a group of people coalesces around a common set of ideas, they, in turn, connect with others, in time building supportive networks of people (i.e., communities of practice) who understand and can promote innovations among those who are late adopters. These support networks are important to harness to power of collegiality (peers working to persuade each other) and peer pressure as a driver of improvements.

Recommendation 3: Use guidebooks as a resource for sustaining professional development for faculty

Teaching and learning must be a primary goal of the institution and be supported at every level and in every division and department in both words and action. Faculty members will improve if there is a good reason to, they are supported, and if there are available training resources, in terms of high quality materials and instructors. This project has helped the college to establish that supporting faculty development in direct, course-embedded assessment practices is the starting place for a robust assessment program that leads to numerous benefits: enhanced course design, instructional practice in multiple modes, course documentation and quality assurance, and ultimately, better policy and strategic planning, and practices that engage students to become self-regulated learners. Coupling reform of assessment practices with greater use of technology to 
support and complete assessment tasks will be a powerful combination that leads to sustained and sustainable reform. It is clear that professional development is key to building the organizational capacity to change. The college implemented a new program focused on faculty development. The Continuous Learning Collaborative (CLC) is CCC's professional development unit, and I co-coordinate the program for the college. This was a good move for the college and is necessary to achieve our goals. The college must sustain these efforts.

The college did not have a professional development group until 2010. Since short-term successes were important to building support for the program, the CLC immediately began offering the most requested and needed topics for faculty, i.e., technology- and distance learning-focused training and development activities topped the list. We invite all faculty to present on topics where they have expertise, so it has become a group effort. We have now moved into providing assessment and instructional design workshops that use materials that are being developed for the new guidebooks. The guidebooks ensure that we have effective materials that provide a high level of quality assurance and consistency to our assessment language and practices. Departments have begun asking for group sessions on the new materials, thus establishing the foundations for departmental-led assessment reform.

I recommend that leaders sustain the CLC group for the long term and incorporate as many faculty contributors as possible. Such efforts are essential to disseminating the knowledge and building the skills needed for the college to enact the sorts of changes in practice that are needed to meet our long-term accountability goals. 
Recommendation 4: Use guidebooks to ensure that high-level college administrators continue to grow and develop

Long-serving college administrators are faced with a new set of challenges. Oregon's higher education completion agenda is driving changes in how colleges are funded, moving them away from a paradigm of instruction to a paradigm of learning. Administrators are beginning to realize that FTE-focused models of funding driving colleges to focus on getting students in seats are no longer sufficient; they must also get students to complete the programs in which they enroll. Completion funding increases higher education's focus on assessment. Administrators who have backgrounds in discipline areas other then education must receive training and support to learn not only theory and practices of assessment at multiple levels, but must learn it well enough to lead others. The guidebook can, and the evidence shows this is likely, help DCs become better, but this must extend beyond the DC to all administrators. Some individuals in leadership roles are unprepared to lead innovative change and are not knowledgeable about the models that exist, the research on innovation and their own role in the process. Individuals in campus leadership roles, both formal and informal, must be informed about the issues, knowledgeable about the research on teaching and learning and on the change process and be both willing and able to lead.

Recommendation 5: Create guidebooks in other areas where change in needed Assessment reform is important, but we also need to be cognizant that assessment reform is interwoven with other aspects of reform that are mutually reinforcing; we must also support emerging best practices in design that supports student-centered instruction 
and curriculum reform. For example, the growing trend toward blended learning, and personalization or differentiation of curriculum is not well understood by many faculty as these represent a different, less familiar, paradigm of learning, i.e., a more personalized, student-centered, technology-focused paradigm as opposed to a traditional, standardized and instructor-centered paradigm. Yet student completion of courses, can be improved by incorporating differentiated instructional techniques, especially with blended learning techniques emerging from online courses. One of the strengths of blended learning is the ability to provide ancillary materials that enrich or remediate the curriculum. These advanced, blended learning techniques are being developed by some online courseware design researchers, such as the Open Learning Initiative at Carnegie Mellon University (Open Learning Initiative, 2013). The faculty has yet to invest in these new strategies that have the potential to reduce or eliminate failure in courses. A guidebook that teaches these strategies would be very useful.

Many faculty members have not been trained in how to personalize curriculum. Also, some faculty and disciplines are more performance-oriented and some are more mastery-oriented. New projects in guidebook development can help faculty understand how to balance these concerns and differences. It is hoped that faculty will learn how to both meet a common set of course outcomes while still providing more personalized learning opportunities for students within the same course. The R\&D process and guidebook creation can help the college innovate in many useful ways. As the college meets new milestones in its efforts to become outcomes-based, many opportunities will arise for new guidebooks to be created. I recommend that the college build on this 
capacity. One topic area for new CLC workshops will be in the area of prototyping and researching/developing instructional materials, so that the skills that I have learned can be shared with others.

Recommendation 6: Encourage use of assessment technology to decrease assessment workload

As financial woes continue, we have been asked to do more with less. Assessment technology makes assessment work easier, can increase faculty productivity, and improve quality of assessment. While I continuously advocate for increased use of Moodle through guidebooks, training, and cheerleading, the college leadership should try to do more. They do support Moodle and my work by speaking positively about it, but their advocacy could be improved. Senior staff needs to support innovative ideas (Smith, 2010); this would apply to include the Moodle system. The executives should find ways to disseminate info via Moodle. This sort of hands-on advocacy would encourage late adopters to try out the new tools.

Recommendation 7: Provide incentives for innovative lean instructional process improvements

CCC has a systems analyst on the faculty who has helped various departments examine their workflows and improve them by eliminating unnecessary steps or adding components that replace other more time-intensive components. We call this a "lean process" review. The college should develop similar lean practices for faculty and instruction. Faculty are extremely busy and their workloads are high. While direct, course embedded assessment is work faculty needs to do anyway, we must recognize that this 
new type of assessment work is not currently widely integrated into the work processes currently being used. Implementing direct, course-embedded assessment might require changing one's curriculum, developing new materials, or adopting new assessment methods/ tools. Some currently used designs for instruction and assessment may not be optimal. The college should develop a system, similar to its institutional innovation funding system, to support the cost-to-change instruction and curriculum. While instructional designers are available to help with this redesign work, additional support for system analysis may be needed to discover where instructional design can be improved and redesign instruction and assessment as needed to reduce workload. Guidebooks could be developed to assist with these tasks.

\section{Conclusion}

Chapter 5 described the overall conclusions, speculation and recommendations that emerged from the experience of completing this dissertation. I learned and practiced new processes that will lead to improved assessment practice at my institution as well as other connected outcomes. I hope this dissertation has successfully conveyed what I learned, how I grew, and how my organization has benefited by my efforts. 


\section{REFERENCES}

Angelo, T. A. (1995). Defining (and re-assessing) assessment: A second try. AAHE Bulletin, 48(3), 7

Allen, M. J. (n.d.). Choosing the right assessment tool. Retrieved December 17, 2012 from San Diego State CAS website http://www.sandiego.edu/cas/documents/assessment/ChoosingtheRightAssessmen tTool.pdf

Allen, M. J. (2005). Outcome-based approach to assessment: Experience from the U.S. Retrieved February 17, 2012 from http://edc.polyu.edu.hk/documents/OBE_7_Allen.PD

Arreola, R.A. (1998). Writing learning objectives. In R. A. Arreola \& L. M. Aleamoni (Eds.), Assessing student learning outcomes: A workshop resource document. University of Tennessee, Memphis.

Azevedo, R., \& Hadwin, A. (2005). Scaffolding self-regulated learning and metacognition: Implications for the design of computer-based scaffolds. Instructional Science, 33(5/6), 67-565. doi: 10.1007/s11251-005-1272-9

Bain, A., \& Swan, G. (2011). Technology enhanced feedback tools as a knowledge management mechanism for supporting professional growth and school reform. Education Tech Research Dev, 59, 673-685. doi:10.1007/s11423-011-9201-x

Baker, R. L. (2002). Evaluating quality and effectiveness: Regional accreditation principles and practices. Journal of Academic Librarianship, 28(1/2), 3 .

Bakersfield College. (n.d.). Assessment definitions webpage Retrieved March 21, 2013 at http://www2.bakersfieldcollege.edu/courseassessment/Definitions.htm

Ballantyne, C. (2003). Online evaluations of teaching: An examination of current practice and considerations for the future. New Directions for Teaching and Learning, 2003(96), 103-112.

Banta, T. W., Jones, E., \& Black, K. (2009). Designing effective assessment: Principles and profiles of good practice. San Francisco, CA: Jossey-Bass.

Banta, T. W., \& Blaich, C. (2011). Closing the Assessment Loop. Change, 43(1), 22-27. doi:10.1080/00091383.2011.538642. 
Bass, R., \& Bernstein, D. (2008). The middle of open spaces: Generating knowledge about learning through multiple layers of open teaching communities. In T. Iiyoshi \& M. S. Vijay Kumar (Eds.), Opening up education: The collective advancement of education through open technology, open content, and open knowledge. (pp. 303-317). Cambridge, MA: MITPress Retrieved February 13, 2011 from http://mitpress.mit.edu/catalog/item/default.asp?ttype $=2 \&$ tid $=11309 \&$ mode $=$ toc

Black, P., \& Wiliam, D. (1996). Meanings and consequences: A basis for distinguishing formative and summative functions of assessment. British Educational Research Journal, 22(5), 537-548.

Black, P., \& Wiliam, D. (1998). Assessment and classroom learning. Assessment in Education: Principles, Policy \& Practice, 5(1), 7-74. doi:10.1080/0969595980050102

Black, P., \& Wiliam, D. (2009). Developing the theory of formative assessment. Educ Asse Eval Acc, 21, 5-31. doi:10.1007/s11092-008-9068-5

Bloom, B. (1956). A taxonomy of educational objectives: The classification of educational goals (Handbook I Cognitive domain). New York, NY: McKay.

Borg, W., \& Gall, M. (1989). Educational Research: An Introduction (5th ed.). White Plains, NY: Longman.

Borko, H. (2004). Professional development and teacher learning: Mapping the terrain. Educational Researcher, 33(8), 3-15.

Bredin, A. (1993). Is self-study right for you?. Computerworld, 27(38), 143.

Bridges, E. M., Hallinger, P., \& ERIC Clearinghouse on Educational Management, E. R. (1995). Implementing Problem Based Learning in Leadership Development. Available from EBSCOhost.

Buller, J. (2011). The essential department chair: A comprehensive desk reference. San Francisco, CA: Jossey-Bass. Available from Ebook Library.

Campbell, K., Schwier, R., \& Kenny, R. (2009). The critical, relational practice of instructional design in higher education: An emerging model of change agency. Educational Technology Research \& Development, 57(5), 645-663.

Chappuis, S., Commodore, C, \& Stiggins, R. (2010). Assessment balance and quality: An action guide for school leaders (3rd ed.). Boston, MA: Pearson. 
Chism, N. V. N., (1999). Peer review of teaching: A sourcebook. Bolton, MA: Anker Publishing.

Clark, R. C., \& Mayer, R. E. (2011). E-learning and the science of instruction: Proven guidelines for consumers and designers of multimedia learning (3rd ed.). San Francisco, CA: Pfeiffer.

Clegg, K., \& Bryan, C. (2010). Reflections: Rationales and realities. In C. Bryan \& K. Clegg (Eds.), Innovative assessment in higher education. (pp. 216-225). London: Routledge

Creswell, J. W. (2005). Educational research: Planning, conducting, and evaluating quantitative and qualitative research ( $2^{\text {nd }}$ ed.). Upper Saddle River, NY: Pearson.

Dabbagh, N. (2003). Scaffolding: An important teacher competency in online learning. TechTrends, 47(2), 39-44.

Dabbagh, N., \& Kitsantas, A. (2005). Using web-based pedagogical tools as scaffolds for self-regulated learning. Instructional Science, 2005(33), 513-540. doi:10.1007/s11251-005-1278-3

Davies, S. (2010). Effective Assessment in a Digital Age, Retrieved December 29, 2011 at JISC website. http://www.jisc.ac.uk/media/documents/programmes/elearning/digiassass_eada.p $\mathrm{df}$

Delin, J., Bateman, J., and Allen, P. (2003). A model of genre in document layout. Information Design Journal, 11(1), 54-66.

Downing, K., Kwong, T., Chan, S., Lam, T., \& Downing, W. (2009). Problem-based learning and the development of metacognition. Higher Education, 57(5), 609621.

Dunlap, J. C., Sobel, D. M., \& Iceman-Sands, D. (2007). Supporting students' cognitive processing in online courses: Designing for deep and meaningful student-tocontent interactions. TechTrends, 51(4), 20-31.

Educause (2010). 7 Things You Should Know About Analytics, Retrieved March 9, 2013 at Educause website. http://net.educause.edu/ir/library/pdf/ELI7059.pdf

Elton, L. (2010). Academic professionalism: The need for change. In C. Bryan \& K. Clegg (Eds.), Innovative assessment in higher education (pp. 209-215). London: Routledge. 
Espasa, A., \& Meneses, J. (2009). Analysing feedback processes in an online teaching and learning environment: An exploratory study. Higher Education, 59(3), 277292.

Ferren, A. S., \& Mussell, K, (2000). Leading curriculum renewal. In A. F. Lucas \& Assoc. (Eds.), Leading academic change: Essential roles for department chairs. San Francisco, CA: Jossey-Bass.

Folmer, H.R., Moynihan, M.N., \& Schothorst, P. M, (1992). Testing and evaluating manuals: Making health learning materials more useful. Royal Tropical Institute, Amsterdam. Retrieved December 21, 2012 from Natural Resources Systems Programme website. http://www.nrsp.org.uk/pdfs/resources/CPG/17_Testing \& evaluating manuals.pdf

Gagne, R. (1985). The conditions of learning (4th ed.). New York, NY: Holt, Rinehart \& Winston.

Gagne, R., Briggs, L., \& Wager, W. (1992). Principles of instructional design (4th ed.). Fort Worth, TX: HBJ College Publishers.

Gibbs, G. (2006). Why assessment is changing. In C. Bryan \& K. Clegg (Eds.), Innovative assessment in higher education, (pp. 11 - 22). London: Routledge

Gibbs, G., \& Simpson, C. (2004). Conditions under which assessment supports students' learning. Learning and teaching in higher education 1(1), 3-31.

Graesser, A. C., McNamara, D. S., and VanLehn, K. (2005). Scaffolding deep comprehension strategies through point\&query, autotutor, and istart. Educational Psychologist, 40(4), 225-234.

Gunawardena, C. N., \& McIsaac, M. S. (2004). Distance Education. In D. H. Jonassen (Ed.), Handbook on research on educational communications and technology $\left(2^{\text {nd }}\right.$ ed.). (pp. 355-395). Mahwah, NJ: Lawrence Erlbaum.

Hatzipanagos, S., \& Warburton, S. (2009). Feedback as dialogue: Exploring the links between formative assessment and social software in distance learning. Learning, Media and Technology, 34(1), 45-59.

Heywood, J. (1989). Assessment in Higher Education (2 ${ }^{\text {nd }}$ ed.). New York, NY: John Wiley and Sons.

Huber, M. T., \& Hutchings, P. (2006). Building the teaching commons. Change, 38(3), 24-31 
Kim, N., Smith, M. J., \& Maeng, K. (2008). Assessment in online distance education: A comparison of three online programs at a university. Retrieved December 20, 2011 at University of West Georgia website. http://www.westga.edu/ distance/ojdla/spring111/kim111.html

Kinser, K. (2007). Innovation in higher education: A case study of the western governors university. New Directions For Higher Education, 2007(137), 15-25.

Lee, A. (2006). Learning and transfer in two web-based and distance applications. In H. F. O'Neil and R. S. Perez (Eds.), Web-based learning: Theory, research, and practice. Newark, NJ: Erlbaum Assoc. Publishing.

Lorenz. R. A., \& Pichert, J. (1989). Evaluation of education program developments: Illustration of the research and development cycle. The Diabetes Educator. 15(3), 253-6.

Lucas, A. F., \& Assoc. (2000). Leading academic change: Essential roles for department chairs. San Francisco, CA: Jossey-Bass.

MacDonald, J. (2001). Exploiting online interactivity to enhance assignment development and feedback in distance education. Open Learning, 16(2), 179-189.

MacDonald, R. J. (2008). Professional development for information communication technology integration: Identifying and supporting a community of practice through design-based research. Journal of Research on Technology in Education, 40(4), 429-445.

Marsh, H. W. (2007). Students' evaluations of university teaching: Dimensionality, reliability, validity, potential biases, and usefulness. In R. P. Perry \& J.C. Smart (Eds.), The scholarship of teaching and learning in higher education: An evidence based perspective (pp. 319-383). New York, NY: Springer Press.

Martin, F. (2011). Instructional design and the importance of instructional alignment. Community College Journal of Research and Practice, 35(12), 955-972.

Mehlenbacher, B. (2010). Instruction and technology: Designs for everyday learning. Cambridge, MA \& London: MIT Press.

Merriam, S. B. (2001). Qualitative research and case study applications in education. San Francisco, CA: Jossey-Bass. 
Miller, T. (2008). Formative computer-based assessment in higher education: the effectiveness of feedback in supporting student learning. Assessment \& Evaluation in Higher Education, 34(2), 181-192.

Millett, C. M., Payne, D., \& Dwyer, C. A. (2008). A culture of evidence: An evidencecentered approach to accountability for student learning outcomes. ETS Publication: [S.1.]: Available at ERIC Clearinghouse

Moore, M. G., \& Kearsley, G. (1996). Distance education. Belmont, CA: Wadsworth.

Moreno, R., \& Valdez, A. (2007). Immediate and delayed effects of using a classroom case exemplar in teacher education: The role of presentation format. Journal of Educational Psychology, 99, 194-206.

Morgan, G. (2006). Images of organizations. Thousand Oaks, CA: Sage

Murphy, R. (2006) Evaluating new priorities for assessment. In C. Bryan \& K. Clegg (Eds.), Innovative assessment in higher education (pp. 37 -47). London: Routledge.

Murray, H. G. (2007). Low-inference teaching behaviors and college teaching effectiveness: Recent developments and controversies. In R. P. Perry \& J. C. Smart (Eds.), The scholarship of teaching and learning in higher education: An evidence based perspective (pp. 145-183). New York, NY: Springer Press.

Nicol, D. F., \& Macfarlane-Dick, D. (2006). Formative assessment and self-regulated learning: A model and seven principles of good feedback. Studies in Higher Education. 31(2), 199-218.

Nicol, D. F., \& Draper, S. (2009). A blueprint for transformational organisational change in higher education: Reap as a case study. in T. Mayes (Ed.), Transforming Higher Education Through Technology-Enhanced Learning, Retrieved April 1, 2012 at REAP website. http://www.reap.ac.uk/Portals/101/Documents/Theory\%20and\%20Practice/NIcol _Draper_transforming_assessment_feedback.pdf

Nicol, D. F. (2010). REAP Home page. Retrieved April 1, 2012 at: http://www.reap.ac.uk/Home.aspx

Northrup, P. T. (2002). Online learner's preferences for interaction. Quarterly Review of Distance Education, 3(2), 219. 
OIT support. (2011). Moodle support webpage, Retrieved March 21, 2012 at http://www.oit.umass.edu/support/activities/checklist-activity-moodle

Open Learning Initiative. (2013). OLI homepage, Retrieved March 20, 2012 at http://oli.cmu.edu/

Pea, R. D. (2004). The social and technological dimensions of scaffolding and related theoretical concepts for learning, education, and human activity. Journal of the Learning Sciences, 13, 423-451.

Pintrich, P. R., \& Zusho, A. (2002). Student motivation and self-regulated learning in the college classroom, in: J. C. Smart \& W.G. Tierney (Eds.), Higher Education: Handbook of theory and research (vol. XVII). (pp. 55-128). New York, NY: Agathon Press.

Price, M., \& O’Donovan, B. (2010). Improving performance through enhancing student understanding of criteria and feedback. In C. Bryan \& K. Clegg (Eds.), Innovative assessment in higher education (pp. 100-109). London: Routledge

Puntambekar, S., \& Hübscher, R. (2005). Tools for scaffolding students in a complex learning environment: What have we gained and what have we missed? Educational Psychologist, 40(1), 1-12. doi:10.1207/s15326985ep4001_1

Quintana C., Zhang, M., \& Krajik, J. (2005), A framework for supporting metacognitive aspects of online inquiry through software-based scaffolding. Educational Psychologist, 40(4), 235-244.

Reddy, Y. M. (2007). Effect of rubrics on enhancement of student learning. Educate. 7(1), 3-17.

Sadler, D. R. (1989a). Formative assessment: Revisiting the territory. Assessment in Education: Principles, Policy \& Practice, 5(1), 77-85.

Sadler, D. R. (1989b). Formative assessment and the design of instructional systems, Instructional Science, 18, 119-144.

Serban, A. (2004). Assessment of student learning outcomes at the institutional level. New directions for community colleges, 126(2), 17-27.

Shute, V. (2008). Focus on formative feedback. Review of Educational Research, 78(1), 153-189. doi:10.3102/0034654307313795

Simonson, M. (2000). Myths and distance education: What the research says and does not say. Quarterly Review of Distance Education, 1(4), 277-279. 
Simonson, M., Schlosser, C., \& Orellana, A. (2011). Distance education research: a review of the literature. Journal of Computing in Higher Education, 23, 124-142. doi:10.1007/s12528-011-9045-8

Smith, K. (2012). Lessons learnt from literature on the diffusion of innovative learning and teaching practices in higher education. Innovations in Education \& Teaching International, 49(2), 173-182.

Stiggins, R. (2001). Student-involved classroom assessment (3rd ed.). Upper Saddle River, New Jersey: Merrill-Prentice Hall

Stiggins, R. (2005). From formative assessment to assessment for learning: a path to success in standards-based schools. Phi Delta Kappan, 87(4), 324-328.

Sweller, J., Van Merriënboer, J., \& Paas, F. (1998). Cognitive architecture and instructional design. Educational Psychology Review, 10(3), 251-296.

Taras, M. (2008). Summative and formative assessment: Perceptions and realities. Active Learning in Higher Education, 9(2), 172-192. doi:10.1177/1469787408091655

Thompson, N., \& McGill, T. J. (2008). Multimedia and cognition: Examining the effect of applying cognitive principles to the design of instructional materials. Journal of Educational Computing Research, 39(2), 143-159.

Thorpe, M., \& Godwin, S. (2006). Interaction and e-learning: The student experience. Studies in Continuing Education, 28(3), 203-221.

Tucker, B., Jones, S., Straker, L., \& Cole, J. (2003). Course evaluation on the web: Facilitating student and teacher reflection to improve learning. New Directions for Teaching and Learning, 2003(96), 81-93.

University Leadership Council. (2008). Assessing student learning outcomes: Best practices for engaging the faculty. Washington, DC: Education Advisory Board.

Walvoord, B. E., \& Anderson, V. J. (2010). Effective grading: A tool for learning and assessment in college ( $2^{\text {nd }}$ ed.). San Francisco. CA: Jossey-Bass

Weiner, W. (2009). Establishing a culture of assessment: Fifteen elements of assessment success - how many does your campus have? Retrieved December 19, 2012 at AAUP website. http://www.aaup.org/article/establishing-culture-assessment 
Wenger, E., McDermott, R., \& Snyder, W. (2002). Cultivating communities of practice: A guide to managing knowledge. Cambridge, MA: Harvard Business School Press.

Winters, F. I., Greene J., \& Costich, C. M. (2008). Self-regulation of learning within computer-based learning environments: a critical analysis. Educational Psychology Review, 20(4), 429-44. 
APPENDIX A

ADJUSTED SURVEY QUESTIONS 


\section{Adjusted Survey Questions}

Survey Questions for field-testers of Guidebook (Step 4)

Rate the following elements of the Guidebook in terms of its usability for teaching the seven steps of the assessment loop to others: 1 is "not usable"; 5 is "extremely usable." Contextual information (who should do this work, why would someone do this task, where and how does it fit into other aspects of one's work) Conceptual explanations (explains the key concepts and terms in a usable way)

Was additional information/ explanation needed to teach this material? If yes, what information did you add?

Rate the effectiveness of the Guidebook for teaching others about assessment practices? What are the strong points of the Guidebook as a teaching tool? What are the weak points of the Guidebook as a teaching tool? What are the strong points of the Guidebook as a reference tool? What are the weak points of the Guidebook as a reference tool? What suggestions can you make for improvement?

Survey Questions for Main Field-tests of Guidebook (Step 6) Are you willing to participate in this survey? Did you indicate your willingness to participate by reading and "signing" the informed consent waiver prior to entering this survey? If the answer to both of these questions is "yes," please click yes below and continue on to the survey. 
Yes No

Before reading the guidebook, rate your knowledge of and/or ability to complete the following tasks:

1 is low knowledge and/or ability; 5 is high knowledge and/or ability

Write measurable SLOs

Gather evidence and record assessment data

Analyze and interpret assessment data

Use interpretation of records for curriculum improvement

After reading the guidebook, rate your knowledge of and/or ability to complete the following tasks:

1 is low knowledge and/or ability; 5 is high knowledge and/or ability

Write measurable SLOs

Gather evidence and record assessment data

Analyze and interpret assessment data 
Use interpretation of records for curriculum improvement

Rate the following elements of the Guidebook in terms of clarity

["clarity" refers to the quality of coherence (connects to other parts logically and consistently) and intelligibility (it is easily understood)]:

1 is "not clear"; 5 is "extremely clear."

Contextual information (who should do assessment work, why would someone do assessment, where and how does assessment fit into other aspects of one's work.)

Conceptual explanations (explains the key concepts and terms completely and in a clear way) Instructional materials (the sequence of materials make sense and are logically connected.)

Muddiest point - What one idea or concept in the guidebook was hardest to understand?

Rate the effectiveness of the Guidebook in introducing you to new assessment methods/ tools that you have not tried, but want to learn more about?

1 is not effective; 5 is highly effective

When used as a self-study tool, what are the one or two strongest points of the Guidebook? 
When used as a self-study tool, what are the one or two weakest points of the

\section{Guidebook?}

When used as a reference manual for pertinent assessment practices, what are the one or two strongest points of the Guidebook?

When used as a reference manual for pertinent assessment practices, what are the one or two weakest points of the Guidebook?

What suggestions can you make for improvement? 
APPENDIX B

GUIDEBOOK FOR STUDENT LEARNING OUTCOMES \& ASSESSMENT LOOP 


\title{
GUIDEBOOK FOR STUDENT LEARNING OUTCOMES \& ASSESSMENT LOOP
}

\begin{abstract}
We define assessment as follows:
An ongoing process aimed at understanding and improving student learning. It involves making our expectations explicit and public; setting appropriate criteria and standards for learning quality; systematically gathering, analyzing, and interpreting evidence to determine how well performance matches those expectations and standards; and using the resulting information to document, explain, and improve performance.
\end{abstract}

\section{Introduction}

CCC initiated a new course approval and course outline revision (COR) process in Fall 2012. As proposed by the ISP and then adopted by the Curriculum Committee, each course outline will be revised every three years. This Guidebook has been developed to assist in aspects of outline revision and writing I assessing of measurable Student Learning Outcomes (SLOs). In addition, it provides a framework for gathering evidence, interpreting findings, and using them for improvement.

Course outlines include statements describing what students will learn in the course and be able to demonstrate upon successfully completing the course. This Guidebook will help instructors design conditions and criteria for measurement of the SLOs. An SLO is a starting point for teaching and measuring if students have learned the outcome. Outcomes as written for the course outline are usually focused on the discrete behaviors that demonstrate learning, but this aspect of the SLO, in and of itself, is insufficient for aligning curriculum and instruction with assessment. This Guidebook is intended to fill in the gaps between the SLO statement and classroom
Thomas Angelo, 1995

curriculum/instruction used to teach and assess the SLO.

The level of detail described in this Guidebook as it relates to writing and assessing SLOs does not lend itself to inclusion in an official course outline of record. The information will be too voluminous, will change too frequently, and is much too specific to the subject being taught. It is more appropriate for the course outline to relate the intent of the SLO, as is commonly done now, and then have an ancillary document present the detail of the student learning outcomes. This ancillary document could be a course syllabus, curriculum guide, and/or instructions for activities and assignments.

This guidebook encourages designing instruction and assessment together and in a way that allows the work that students complete as part of a course to be used for both grading purposes and for assessment of SLOs. Practitioners already grade student work as part of the course. If designed for both purposes, assessment becomes inextricable from instruction and grading; no additional work is needed. In addition, grading work ensures that students are motivated to produce their best efforts. 


\section{Who should read this guidebook?}

This Guidebook is the second in a series. It assumes that instructors have previous knowledge and experience designing instruction, grading, developing or revising course outlines, and writing SLOs. If terms such as "measurable SLO", "assessment loop" and "course outline" are unfamiliar to you, you should first read the Guidebook for New Course and Outline Revision Approval, which supports the Step 1 and 1.1 of the Assessment Loop (see Diagram 1.1) i.e., Setting Goals and Creating Behavioral SLOs about your course.

The glossary of assessment terms included in this guidebook in Appendix $\mathrm{C}$ defines pertinent terms from the point of view of a practitioner and should help in defining commonly used assessment language, understanding a larger picture of assessment processes and identifying why and what you may want to assess. If you are a beginner, you should be familiar with the terms in the glossary.

Faculty who are familiar with grading and writing SLOs.

This guidebook is intended to help you better understand measurability, assess measurable SLOs, close the assessment loop by providing information about gathering evidence, interpreting findings, and using the knowledge gained to improve your curriculum.

\section{Department Chairs (DCs)}

This guidebook is intended to help DCs lead the conversation with instructors about writing and measuring SLOs and connecting instruction to assessment, with the aim of supporting accountability and accreditation.

\section{Faculty}

The faculty will use it for more effectively writing and measuring SLOs. Enacting better measurement can lead to improved instruction and assessment practice. As the faculty create/revise course outlines and develop integrated instruction and assessment plans, they may find their SLOs or assessment methods /tools are incomplete or not effective in capturing the aspects of student learning they wish to measure. They may wish to incorporate untried, new, or a variety of assessment methods into their courses. This guidebook provides strategies for identifying, reviewing and evaluating commonly used assessment methods. It also provides ideas for their application. 


\section{How should the guidebook be used?}

The Guidebook for Student Learning Outcomes \& Assessment Loop presents the assessment loop in six steps. The guidebook provides instructional materials for each step of the process, and can be used as both a reference and training manual. These six steps of the assessment loop are shown below:

Step 1 (page 5): Create behavioral SLOs by:

\subsection{Generalizing course goals, and}

1.2 Convert goal(s) into a behavioral SLO by identifying the student behaviors, skills, or abilities and criteria that demonstrate learning has occurred. Use action verbs to describe these behaviors.

Step 2 (page 6): Make a behavioral SLO measurable by:

2.1 Selecting assessment methods /tools to match the behavior you wish to measure;

2.2 Identify and clarify performance levels that meet and do not meet your expectations.
Step 3 (page 12): Align and integrate SLOs, instruction, and assessment.

Step 4 (page 14): Provide clarity to students about what they will do in the course by communicating your instruction / assessment plan to students via ancillary course documentation.

Step 5 (page 15): Use the instruction / assessment plan; use the methods/tools selected in step 2.1 to measure student behavior and assess SLO.

Step 6 (page 16): Organize, analyze, interpret and use the results of classroom assessment to identify strong and weak areas of curriculum and instruction. Use this information for improvement.

The diagram 1.1 on page 4 shows how these components fit together.

Next Step (page 18): Correlate courseembedded assessments to program- and institution-level assessments. 
START HERE: What are the goals of the course?

Goals come from instructor or department expectations, program scope and sequence, advisory groups, professional associations, or other goal setting process. Have a list of goals handy before you start on step 1.

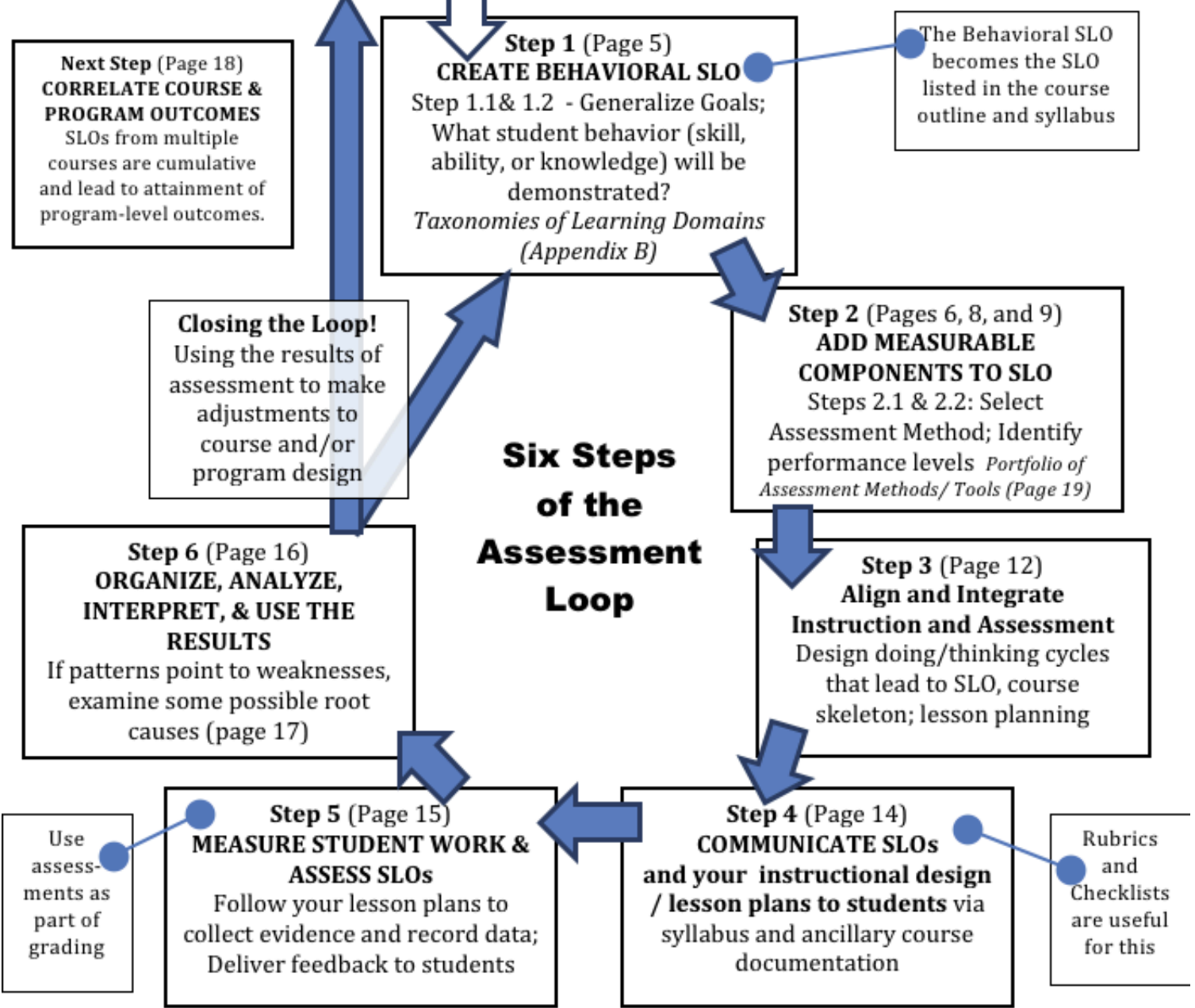

Diagram 1.1 - Six Steps of the Assessment Loop - This diagram depicts the six steps of the assessment loop that are described in this guidebook. Refer to the page numbers to learn more about each step. 


\section{Step 1 - Create behavior-focused student learning outcomes (SLOs) by:}

\section{Step 1.1 - Generalizing your course goals \& identifying the learning you want}

As the expert in your discipline and course, you are knowledgeable of your course goals; you may have dozens of goals for a course. These are likely already written down or otherwise available to you. Have the list handy.

Using a process of generalization and grouping of these goals, identify the most important things a successful student should know or being able to perform or do after taking your course; these represent the most wanted student behaviors.

\section{Identifying or Reviewing Goals}

If you are having trouble identifying course goals, try answering these questions:

- Examine how you use current assignments and activities. What do you want your students to learn and in what ways do you want them to grow while taking this course?

- What do your students usually learn and in what ways do they usually grow?

If revising goals, ask:

- Where do students have difficulty; what do they consistently not understand? (if you do not know the answer to this question, the practices in this guidebook will help you to determine this.)

- If you ran into a student who had taken your class the previous semester, what would you hope the student would say about what she took away from your course?

\section{Step 1.2 - Convert goal(s) into a behavioral SLO \& criteria}

The goals from the course are used to generate your SLOs. Using the lists of active verbs from the appropriate level and domain of the knowledge, skills, or affect tables found in Appendix B, find verbs that express behaviors that demonstrate what students should DO to meet your expectations. Students can and should meet multiple goals in the process of attaining an SLO. Five to eight SLOs is common for a four credit course.

Connect the behavior with your content by identifying criteria. If they should know something, how will they show you this? These behaviors are a starting point to create your SLOs.

Define the relevant terms of this subject...

Identify the concept that explains the processes we use to...

List the steps in the procedures for... Compare and contrast the two ideas... Compute the correct answers to the problems...

Describe the difference between...

Differentiate among ...

Design a product...

Example 1 - behaviors with criteria: 
Ultimately, these outcomes will be articulated in two ways; 1) as a more general behavioral outcome to be used within a course outline, and 2) as a measurable outcome from which you can enact instruction and assessment.

\section{Step 2 - Make a behavioral SLO measureable}

\section{Three components of measurable SLOs}

1) Behavioral outcome (skill, ability, or knowledge expressed with active verb),

2) Assessment method /tool that matches the behavior you wish to measure, and

3) Performance levels that are used to compare the behavior to performance expectations.

\section{Step 2.1 Select the assessment method /tool to match the behavior you wish to measure.}

Once the instructor has identified the behaviors he/she wants students to demonstrate, a method /tool to measure the outcome must be identified.

Take this multiple choice quiz...

Write an essay...

In the minute paper...

Present in written or oral form...

With a powerpoint presentation...

In a discussion forum...

Through a journal, self-report...

By role-playing...

Build a widget...

Produce a term project...

With a group project...

Within a portfolio...

Example 2 - Assessment method//tools:

Remember these guidelines about methods/tools:
- Some methods/tools lend themselves to certain behaviors and criteria.

- Some methods/tools lend themselves to certain disciplines.

- Different methods/ tools can and should be used to measure different types of behaviors and levels of thinking reflected in the outcome.

- It is important to choose tools based on the behavior you are trying to assess, not on what tool is most appealing to you.

- The method/ tool should match the type of learning expected and be as authentic as possible.

"What is authentic assessment?"

Assessments that closely match the expected behavior are authentic. For example, if the expected behavior is to demonstrate the procedures for diagnosing problems within a small engine, then a more authentic assessment would be to have the 
student diagnose a broken engine; a less authentic assessment would be to have the student write a paper about fixing an engine or taking a quiz with questions about diagnostic procedures.

- Consider what sort of evidence will provide you with adequate information to make informed decisions about attainment and then select a tool that provides that kind of evidence.

- Be able to justify your choice of tool and method.
For help, use the Portfolio of commonly used SLO Assessment Methods/ Tools in Appendix A. Details of each tool are shown on the pages listed. They are organized into four functional areas: 1) formative assessment of task performance, 2) cooperative, 3) objective assessment, and 4) authentic performance. Note: assessment tools used for communicating criteria and performance levels, such as rubrics and checklists are included in Step 2.2.

\section{Portfolio of commonly used SLO Assessment Methods /Tools}

1) Formative Assessment of Task Performance

Question and Answer

Polls

Clickers

Discussion (Forum)

Classroom Assessment Techniques (CATs)

Pre-Post Assessment or Survey

2) Cooperative

Team Project__ 24

3) Objective Assessment _ 25

Multiple Choice and other objective quiz types _ 25

Licensing Examination _ 26

Standardized Test

4) Authentic Performance 27

Writing Assignments, including essays and essay tests, and

reflective self-assessment essay / journal writing

Case Studies

Live presentations, including oral speech or examination, debate, and performance /simulation

Individual projects, including capstone project, thesis/research/term project, product creation and special reports 
Process Analysis, including flowcharts, diagrams, and

worked problem-solving 30

Portfolios 31

Step 2.2 Identify and clarify performance levels that meet your expectations

An SLO provides assessment criteria in a general sense, but the SLO does not usually provide enough detail for students to know what to do. Students need to understand how and to what degree you expect them to meet the criteria. In order to provide students with this information, the instructor should describe performances that do meet or do not meet their expectations.

Three tools that are useful for communicating criteria and expectations are 1) grade descriptions, 2) checklists (or check sheets) and 3 ) rubrics.

\section{Grade descriptions}

One way to clarify criteria for students is to "describe the requirements for each grade" (Walvoord, 2010). If the criteria are closely tied to the SLO, then the assignment grade can be a valid measure of the outcome. One way to do this is to use rating scales, which are subjective assessments made on predetermined criteria in the form of a scale. Rating scales can include numerical scales or descriptive scales. If you expect an individual to demonstrate more of one trait than another, then list that criteria for both and assign a higher grade to the one you expect to measure.

\section{Checklists (or check sheets)}

Walvoord (2010) advocates for the use of checklists which convey criteria via "a list of items that the teacher will use in grading the paper and that the student or peers can self-check beforehand." Students put a checkmark next to each item to show they have done it to the best of their ability and submit the checklist with their assignment.

\section{Rubrics (see example 3)}

This technique asks the instructor to link specific goals and objectives outlined for a particular course assignment to varying levels of achievement (e.g., excellent, good, fair, poor). These levels are based on the expectations of the instructor for student mastery of the SLO for the assignment. A commonly-used form of rubric is called the primary trait analysis (PTA). 
1. Identify the skill/knowledge you are assessing.

2. Break down the skill/knowledge into its characteristic parts (e.g., if you are assessing the ability to problem solve, determine the ideal steps a student would take to successfully demonstrate their ability to solve a problem).

3. Develop a scale that would describe low, intermediate and high levels of performance for each characteristic of the skill/knowledge you are assessing (e.g., Beginning, Developing, Competent, Accomplished, or Poor, Average, Outstanding, Exemplary etc.).

4. If possible, pilot the rubric on student work with several reviewers and students and obtain feedback.

\section{Review of Steps 1 \& 2 - Example of how a goal becomes a measurable SLO}

Course Goal

\author{
Behavioral Outcome... \\ Format of SLO included in \\ the course outline and \\ syllabus-Focused on \\ intent and behavior(s)
}

Is made measurable by: Selection of Assessment method /tool that allows the student to demonstrate the behaviors, skills and abilities

Criteria for measurement and assessment
Understand the five major approaches to conflict resolution: withdrawal, smoothing, forcing, compromising, and problem solving.

Upon successful completion of the course, students should be able to determine the most appropriate conflict resolution approach to use when presented with a specific scenario.

\section{Through completing a written essay exam, students will explain how the determination was made.}

To attain the outcome, students will identify the optimal approach and be able to explain the merits and demerits of the determination.
Performance Levels used to compare behavior to performance expectations e.g., to attain the outcome, students must meet the high aualitv critoria

\begin{tabular}{|l|l|l|}
\hline $\begin{array}{l}\text { High } \\
\text { Quality }\end{array}$ & $\begin{array}{l}\text { Correctly } \\
\text { identifies the } \\
\text { optimal approach }\end{array}$ & $\begin{array}{l}\text { Able to explain at } \\
\text { least two merits and } \\
\text { two demerits }\end{array}$ \\
\hline $\begin{array}{l}\text { Med } \\
\text { Quality }\end{array}$ & $\begin{array}{l}\text { Identifies a sub- } \\
\text { optimal approach }\end{array}$ & $\begin{array}{l}\text { Able to explain at } \\
\text { least one merit and } \\
\text { one demerit }\end{array}$ \\
\hline
\end{tabular}


quality criteria.

\begin{tabular}{|l|l|l|}
\hline $\begin{array}{l}\text { Poor } \\
\text { Quality }\end{array}$ & $\begin{array}{l}\text { Identifies an } \\
\text { incorrect approach }\end{array}$ & $\begin{array}{l}\text { Not able to explain } \\
\text { any merits or demerits }\end{array}$ \\
\hline
\end{tabular}

\section{Step 3 - Align and integrate SLOs, instruction, and assessment}

Behaviors reflect the active verbs selected from the taxonomies found on $\mathrm{p} 19-20$ in Guidebook for New Course and Outline Revision Approval. Certain instructional strategies /activities align with the levels described in the cognitive domain. This table can provide guidance about alignment. For example, if you want students to analyze a process, you might model how an expert does this, and then assess by having students create a flowchart of a process they have analyzed. Strategies for affective and psychomotor domains are not included here.

\section{Knowledge/Recall}

- Strategies/activities to teach: Lecture, modeling, guided practice, assigned reading, classroom discussion, team work, drill and practice activities, students recite

- Strategies/activities to measure: Multiple choice quiz, matching quiz, flash cards, games, essay, oral or clicker poll, survey, formative Q \& A

\section{Comprehension}

- Strategies/activities to teach: Lecture, modeling, guided practice, guided inquiry by mode, classroom discussion, team work, role-playing

- Strategies/activities to measure: Multiple choice quiz, essay, oral or clicker poll, survey, formative opportunities to explain, summarize, and interpret

\section{Application}

- Strategies/activities to teach: Recall prior knowledge, coaching, problemsolving, laboratory work, forensics, prediction exercises, research and development, role-playing

- Strategies/activities to measure: Essay, case study, demonstration of problemsolving, debate, product creation, special reports, performance

\section{Analysis}

- Strategies/activities to teach: Recall prior knowledge, coaching, problem-solving, laboratory work, forensics, dialectics, research and development, modeling, hermeneutics, problem-solution/cause and effect simulations

- Strategies/activities to measure: Essay, case study, demonstration of problemsolving, debate, product creation, special reports, performance, flowchart, carefully constructed quiz

\section{Synthesis}

- Strategies/activities to teach: Recall prior knowledge, coaching, problemsolving, laboratory work, prediction exercises, research and development, modeling, assembling from parts, 
problem-solution/cause and effect simulations

- Strategies/activities to measure: Essay, case study, demonstration of problem-solving, debate, product creation, special reports, performance, carefully constructed quiz

\section{Evaluation}

- Strategies/activities to teach: Recall prior knowledge, coaching, problemsolving, prediction exercises, research and development, modeling, planning, problem-solution/cause and effect simulations

- Strategies/activities to measure: Essay, case study, demonstration of problem-solving, debate, product creation, special reports, performance, carefully constructed quiz

Notice that SLOs do not include a description of the instruction that precedes the initiation of the behavior. While this aspect is not stated, this aspect of teaching and learning is essential for student success and should be approached thoughtfully. Effective instruction involves clear communication, purposeful activity, and getting students to do things that help them learn the outcomes you wish to impart. Richards (2006) describes this process as doing/thinking cycles.

Instructional strategies or prerequisite knowledge that leads students to accomplishing an outcome is important to consider when writing SLOs, but not included in the SLO. This can be planned using a course skeleton, like the one shown in Example 4, and/or organized in and communicated to students through your syllabus or activity schedule.

Guidelines to consider about selection of activities and assessments:

- A sequence should begin with activities that activate prior knowledge.

- Sequence the learning activities using less complex activities initially and more complex activities later.

- Activities should be of a sufficient size and duration to teach the content and skills. For example, learning a new concept requires at minimum (1) a presentation of the essential defining characteristics of the target concept, (2) presentation of examples and also nonexamples of the concept, and (3) opportunities to practice classifying examples and non-examples as instances of a concept. Another example is learning a new skill. Skill development requires modeling, guided practice, and independent practice that includes coaching and feedback. Students need to practice new skills in order to master them. Make practice part of your plan.

- Student centered teaching is cumulative and iterative.

- An assignment /activity should connect to both the one that immediately preceded and the one that will immediately follow it. Students should understand the connections.

- Activity grades should be proportionately weighted relative to all of the activities in the course

- All knowledge and skills needed to successfully attain course SLOs should be identified as either prerequisite or taught within the instructional sequence

- Look for gaps in instruction

- Avoid activities that do not lead to SLOs 
- Not all activities need to be graded or

assessed

Course Skeleton for SLO - Useful for aligning SLO, activity, and assessment

Identifying prerequisites and class activities that lead to assessment of SLO, but are not included in SLO: Upon successful completion of the course, students should be able to determine the most appropriate conflict resolution approach to use when presented with a specific scenario.

\begin{tabular}{|c|c|c|c|c|}
\hline $\begin{array}{l}\text { Prerequisite } \\
\text { Knowledge } \\
\text { Writing at college } \\
\text { level } \\
\text { Ability to recall, } \\
\text { role-play, assess, } \\
\text { and analyze }\end{array}$ & $\begin{array}{l}\text { Define \& discuss } \\
\text { examples of with- } \\
\text { drawal/ smooth- } \\
\text { ing/ forcing; } \\
\text { comprehension } \\
\text { quiz } \\
\text { Class } 2\end{array}$ & $\begin{array}{l}\text { Define \& discuss } \\
\text { examples of } \\
\text { compromising/ } \\
\text { problem solving; } \\
\text { comprehension } \\
\text { quiz }\end{array}$ & $\begin{array}{l}\text { Class } 3 \\
\text { Apply five } \\
\text { approaches to } \\
\text { conflict resolution } \\
\text { through role- } \\
\text { playing in teams. } \\
\text { Compare them. }\end{array}$ & $\begin{array}{l}\text { Class } 4 \\
\text { Assessment } \\
\text { of SLO } \\
\text { via shown } \\
\text { examples } \\
\text { and written } \\
\text { exam }\end{array}$ \\
\hline
\end{tabular}

Class 1

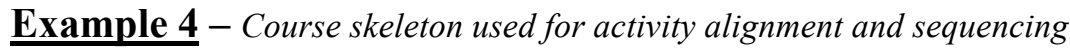

Create a doing/thinking cycle:

Instructions: Work backward to create sequence of learning activities that lead to an outcome:

1

2.

3.

SLO:

Step 4 - Provide clarity to students about what they will do in the course by communicating your plans to students via ancillary course documentation;

The purpose of step four is to help students succeed in the course and on assessment tasks. Students will fare best in assessment activities when you make your instructional design clear, expectations explicit, provide detailed instructions, and offer samples or models of successful performance.

Students should not have to guess at what they should be doing and what you are expecting of them to attain the SLO.
To ensure that this clarification helps to improve student performance, communicate the criteria, preferably in writing, before the student begins the assignment (Walvoord, 2010).

The Syllabus - communicate your instructional design

The syllabus should include the SLOs and how the assignments and graded work help students develop and demonstrate each SLO. Students will 
better understand the progression of their learning if they know how activities, such as reading, discussing, reflecting, etc. fit together and lead to an outcome. Among other things, the syllabus should communicate the alignment of activities, assignments and outcomes and make explicit the connections among outcomes, assignments and grades. If you created a course skeleton as a design aid for your curriculum, this sort of organizer can also be used to share the sequence of course activities and the learning that occurs at each step toward the attainment of an SLO.

\section{Creating ancillary course documentation}

The syllabus provides an overview of the instructional design but cannot communicate every detail of every activity; so ancillary course documentation should be used to make your expectations for specific performances explicit. The documents should show how the assignments and graded work fit together and into larger course goals, and what your criteria are for a successful performance within that portion. If possible, include examples of well done and poorly done work samples. This documentation could include an assignment or curriculum guide, rubrics, grade descriptions, and checklists (see step 2.2 for more information.)

\section{Guidelines for effective communication}

- Students benefit when opportunities to practice the demonstration of learning are provided prior to assessment. Provide independent practice and feedback opportunities within your instructional design.

- Use Moodle to help you communicate your expectations. The Rubrics Grading and Completion Tracking tools are useful for communicating your expectations.

\section{Moodle}

Moodle is a learning management system that supports instructors at all levels of instruction and assessment. It is particularly useful for concurrently completing assessment and grading. It helps you to collect evidence, store it in a repository, and link it to recorded data about attainment and grades. These functions will prove useful as you move toward step 7 and the college moves toward program-level outcomes and assessment.

Rubrics Grading Tool - Moodle provides a tool that lets instructors combine the tasks of assessment and grading through its rubric grading tool. This tool is also useful to communicate expectations to students. Rubrics use a marking guide, which is an advanced grading method where an instructor may enter points earned and a comment per criterion; the points will automatically tally up to the maximum allowed score.

Checklists can be managed using Moodle's Completion Tracking tools. This tool is designed to allow course activities to be marked as completed in the system based on one or more criteria. Completion tracking can be based on any of the following: 
- The student completing one or many activities in a course. Tracking can be managed by the student or instructor.

- A specific date

- A certain number of days after the student was enrolled in the course

- The student achieving a final grade in the course above a certain percentage
How to enable Completion Tracking.

1. Enter your course and under the Settings Block $>$ Course Administration $>$ Edit Settings

2. Find "Student Progress" field and select to "Enable, control via completion and activity settings".

You may also choose to enable "completion tracking begins on enrollment" $\sim$ this will allow completion tracking to start when a student enrolls.

\section{Step 5 - Use the instruction / assessment plan; use the methods/ tools selected in step 2.1 to measure student behavior and assess SLOs.}

A well-developed and integrated instruction and assessment plan provides the organizational and measurement components needed to do a great job of both assessing and grading your students' work. Follow your plan to collect evidence and record data of student performance.

\section{Guidelines for Assessing and Grading}

- Students benefit when given detailed feedback about the quality of their performance, so provide timely feedback to student work, including planning for opportunities for sharing feedback during classroom time.

- Technology can help. Use the learning management system and productivity tools, such as Microsoft Office, to streamline your assessment tasks.

\section{Outcomes Recording in the Moodle Gradebook}

Moodle's outcomes recording tool is built into the gradebook, which is useful to keep data for both purposes. Outcomes are specific descriptions of what a student has demonstrated and understood at the completion of an activity or course. Each outcome is rated by some sort of scale. Outcomes assess specific levels of knowledge through a series of statements that may be coded with numbers or letters. Thus, an overall grade can be given for a course, along with statements about specific competencies in the form of outcomes.

Our Moodle system already contains the general education outcomes that we use (GEOs are described in the Guidebook for New Course and Outline Revision 
Approval.) Outcomes may also be set at the site and/or course level. To choose outcomes for use in your course:

1. View available standard outcomes in Settings $>$ Course administration $>$ Outcomes or via the gradebook Outcomes tab

2. Add outcomes from the standard available list (right side), and use the left-facing arrow button to add them to outcomes used list (left side). Multiple outcomes may be selected by holding down the Apple or Ctrl key whilst clicking on the individual outcomes.

Microsoft Office provides tools that can allow you to organize and store information useful for assessment.

- Excel - Keep a database of frequently-used feedback/ comments in a spreadsheet that will save you time as you assess.

- Word - Annotation tools, such as comments and track changes can help you to quickly provide feedback within the documents that students are submitting.

\section{Step 6 - Organize, analyze, interpret, and use the results of classroom assessment to evaluate course design and instruction}

Using the results of your assessment data to improve teaching and learning in your course (and ultimately in your department or programs) is essential to the assessment process. A result of completing the assessment loop is to learn about the effectiveness of your instruction and course design. After completing step 6, you may identify strong and weak areas of your course. You may discover areas you want to improve.

We learned in step 5 that evidence is collected when students turn in assignments and assessment data is created when you enter scores and outcomes ratings in your outcomesenabled gradebook or rubrics scoring sheets. Now you'll want to organize the data so that you can make sense of it. The key task here is to look for patterns that reveal what the data says and to learn what to do with that information once you have it.

\section{Organizing the results}

Using an electronic grade book, such as the one found in Moodle, can increase the ease of producing spreadsheets or tables for analysis. Electronic spreadsheets can facilitate easy averaging or aggregation of scores, for keeping longitudinal data, or for comparing two sets of students. Another tool for collecting and reporting assessment data is the assessment tab in the MyClackamas portal that faculty fill out each term.

The first step is organizing the information you have collected. Table 6.1 suggests one possible way to organize data.

\begin{tabular}{|l|l|l|}
\hline SLO Assessed & $\%$ Attainment? & $\begin{array}{l}\% \text { Near } \\
\text { Attainment }\end{array}$ \\
\hline SLO \#1 & & \\
\hline SLO \#2 & & \\
\hline
\end{tabular}


SLO \#N

Table 6.1 - Organizing assessment data

This format will allow you to determine the percentage of students that attain SLOs. Does student performance match your expectations? Does student performance match your departmental expectations?

Currently, faculty report this data for general education outcomes in the assessment tab that is filled out after grading. This is a good starting place for data on your GEOs. This guidebook goes further in that it asks you to collect similar data for all SLOs in your course.

\section{Analyze the results}

Analysis is breaking larger things into smaller ones. If the percentage of students meeting an SLO is below your expectations, then break down the factors that comprise the SLO to identify possibilities where there might be weaknesses that lead to non-attainment of your SLOs. Look to the design of the course and the activities that lead to attainment.

Look for patterns at the assignment level. Do students do poorly on a particular assignment that prevents them from otherwise attaining an outcome?

Look for patterns over time and through multiple sections. Look for poor performance on a specific outcome across every section or term. Keeping a section-by-section and term-by-term record of student performance on SLOs in your courses can make longitudinal comparisons easier.

\section{If patterns point to weaknesses, examine these things as possible root causes}

- Gaps in instruction - Do students have adequate opportunities to learn and practice, and/or are you teaching all of the items that you are assessing? Could additional activities, or more time with them, help improve student attainment?

- Sequence of activities is out of alignment - Are there ineffective or unnecessary activities in the sequence? Could activities be changed? Could reorganizing the sequence of activities enhance the learning of the outcomes? If you created one, your course skeleton may help with analysis.

- Criteria for success are not clear Have you shared the criteria with students? Do students understand what you are expecting them to do? Are good and poor examples included?

- The assessment does not align with the criteria - Does the assessment method you are using validly assess the criteria? Are you assessing the stated criteria you are expecting or something else?

- Student characteristics - Are students enrolling in your course without the prerequisite knowledge and skills? Are some students passing your assignments, but others do not? Can this group of failing students be targeted for an intervention of some sort?

- Program-level or Institution-level characteristics - While beyond the scope of this Guidebook and the ability of a single instructor to address, students may be ill-prepared 
by programmatic weaknesses, such as poor attainment of SLOs in courses that precede your course, or by institutional weaknesses, such as inaccurate placement testing or poor advising. We will learn more about these aspects, and how they fit into student attainment of our SLOs as we build a stronger culture of assessment.

\section{Improvement of Design or Instruction} If you have found a root cause for a weakness in need of improvement, decide what you will do. Here are some ideas:

- Adjust your Course - What adjustments can be made in the course -- goals, curriculum, instruction, and assessment -- so that more students attain your SLOs? Get support if you need it; peers or CLC can help.
- Attend CLC activities that focus on assessment and curriculum.

- Conduct scholarship of teaching and learning in order to learn more about root causes of weaknesses.

- Replace underperforming curriculum with new materials and activities. Materials effectiveness can be increased by prototyping or fieldtesting before use.

- Design new materials with peer consultation or jointly - many instructors have solved problems similar to the ones you face and love to share solutions. Ask your department chair or other colleagues to share what works for them.

\section{Continuous Improvement}

When course evaluations are used to adjust the course goals, curriculum, instruction, and assessment and this activity is repeated each term, a continuous improvement loop is created.

\section{Next Steps - Correlate how course-embedded assessments link to program-level assessment}

\begin{abstract}
Department-based review
This guidebook attempts to teach the processes and practices of direct, outcomes-based, course-embedded assessment. These practices form the foundation for excellent classroom assessment, which in turn, forms the foundation for improved programmatic and institution level assessment. While this latter activity is beyond the scope of this guidebook, it is an aspect of assessment that CCC is moving toward and should be considered in any departmental efforts to improve assessment practice.
\end{abstract}

Angelo (1995) defines "assessment" on this broader scale as "an ongoing process aimed at understanding and improving student learning. It involves making our expectations explicit and public; setting appropriate criteria and high standards for learning quality; systematically gathering, analyzing, and interpreting evidence to determine how well performance matches those expectations and standards; and using the resulting information to document, explain, and improve performance. When it is embedded effectively within larger institutional systems, assessment can help us focus our collective attention, examine our assumptions, and create a 
shared academic culture dedicated to assuring and improving the quality of higher education."

Without accurate and consistent SLO data from the courses that make up the program, program-level assessment is hampered. Once a departmental faculty reach efficacy with outcomes-based assessment, departments can begin to take a bigger picture look at their programs. They can begin to align their curriculum both horizontally, making sure that gaps in curriculum that occurs within the program sequence are eliminated; and vertically, making sure that students within multiple section courses consistently reach SLOs.

\title{
APPENDIX A- PORTFOLIO OF COMMONLY USED ASSESSMENT METHODS /TOOLS
}

Legend of Categories

Following each method /tool, look for codes that help you to apply them most appropriately.

These code are described here:

Domain

$\mathrm{C}=$ Cognitive

$\mathrm{P}=$ Psychomotor

$\mathrm{A}=$ Affective

Usage Type

$\mathrm{F}=$ Formative

$\mathrm{S}=$ Summative

\author{
Bloom's level \\ $\mathrm{K}=$ Knowledge \\ $\mathrm{C}=$ Comprehension \\ $\mathrm{A}=$ Application \\ $\mathrm{ASE}=$ Analysis or Synthesis or \\ Evaluation \\ Moodle \\ Yes $=$ This method /tool is \\ available in Moodle \\ No $=$ This method /tool is not \\ available in Moodle
}

Courtesy to MJ Allen (2004)

\section{METHODS /TOOLS USEFUL FOR FORMATIVE ASSESSMENT OF TASK PERFORMANCE}

"Formative assessment of task performance" means that the instructor, through dialogue and interaction with the student, dynamically assesses learner ability to successfully complete tasks, actively provides support to the student when he/she struggles, and adjusts instruction to meet the needs of learners. These methods /tools are used to foster opportunities for interaction where student understanding and ability can be demonstrated for instructors to formatively assess. These learning-support techniques may use both direct oral communication and body language to assess understanding.

\section{Question and Answer (Q\&A)}

The easiest way to determine if someone has learned something is to ask him/her. Q\&A is the basic format of a variety of formative and summative assessment methods; polls, surveys, quizzes, exams, essays, all use some form of Q\&A. The Q\&A methods 
described in this section are used formatively and consist of answering instructor- or student-generated questions as a way for faculty to check for student understanding of the salient points of a learning task. Q\&A strategies are also used to encourage instructor-tostudent and student-to-student interaction and provide channels for feedback.

Wiggins and McTighe (2004) offer at least eight variations of the Q\&A technique to check for understanding in face-to-face environments. They include index card summaries and questions, hand signals, question box or board, analogy prompt, visual representation (web or concept map), oral questioning, follow-up, and the misconception check.

Domain: C P A | Usage Type: F | Bloom's Level: K C A ASE | Moodle: Yes (through polls, quizzes, and other tools)

\section{Polls}

Polls are a distributed Q\&A technique where students share their understanding of a fact, concept, or process, emotional response, or belief/opinion, through a voting process. Answers may be displayed in aggregate form to show a sampling of responses useful for instruction.

Domain: C P A I Usage Type: F I Bloom's Level: K C A ASE I Moodle: Yes (Choice tool)

\section{Clickers}

Clickers are remote-control devices that allow a distributed form of Q\&A (using polling technique) to take place within a large group. Answers are actively recorded and displayed using an electronic slideshow presentation. They are used to transmit and record student feedback to interactive questions. Registered to a student, clickers allow instructors to track involvement and retention, understand attitudes and preconceptions, facilitate discussion and instruction and provide meaningful feedback and clarification.

Domain: C P A I Usage Type: F I Bloom's Level: K C A ASE I Moodle: No

\section{Discussion (Forum)}

This method /tool allows an expanded version of Q\&A to occur through an oral dialogue where students, with or without instructor intervention, share their knowledge / experiences related to the discussion prompt. The Moodle version of this method is called a "forum" and the dialogue takes place through writing.

\section{Domain: C P A | Usage Type: F | Bloom's Level: K C A ASE | Moodle: Yes}

\section{Classroom Assessment Techniques (CATs)}

A collection of classroom-based formative assessment techniques produced by Angelo, Thomas A. and K. Patricia Cross, in their 1993 Classroom Assessment Techniques: A Handbook for College Teachers, Second Edition (San Francisco: Jossey-Bass Publishers). 
Advantages: CATs are useful for assessing:

- Course-related knowledge and skills (including prior knowledge, recall and understanding; analysis and critical thinking skills; synthesis and creative thinking skills; problem solving skills; and application and performance skills)

- Student attitudes, values, and self-awareness (including students' awareness of their own values and attitudes; students' awareness of their own learning processes; and course-related learning and study skills awareness), and

- Reactions to instruction methods (including student and peer reactions to teachers and teaching, class activities, assignments, and materials)

When CATS are used frequently, they can have the following impacts:

For faculty, CATs can:

- provide instant feedback that can be applied immediately;

- provide useful information about what students have learned without the amount of time required for preparing tests, reading papers, etc.;

- allow you to address student misconceptions or lack of understanding in a timely way; and

- help to foster good working relationships with students and encourage them to understand that teaching and learning are on-going processes that require full participation.

For students, CATs can:

- help develop self-assessment and learning management skills;

- reduce feelings of isolation and impotence, especially in large classes;

- increase understanding and ability to think critically about the course content;

- foster an attitude that values understanding and long-term retention; and

- show your interest and caring about their success in your classroom.

Disadvantages: CATs do not provide a complete assessment picture and should be combined with other methods for a fuller picture of student learning. Faculty and students may criticize CATs if they perceive them as sacrificing content coverage time for time required to assess. However, careful context-setting will avoid or minimize students making unfavorable judgments that the activities are potentially time-wasting, particularly if faculty share the conclusions drawn from the assessment data with the students and make efforts to address concerns, where appropriate.

\section{Minute paper}

\begin{tabular}{|l||l|l|l|l|}
\hline $\begin{array}{l}\text { Kind of } \\
\text { Evaluation }\end{array}$ & Name & How It's Done & $\begin{array}{l}\text { Hime } \\
\text { Needs }\end{array}$ \\
\hline $\begin{array}{l}\text { Course Knowledge } \\
\text { and Skills }\end{array}$ & $\begin{array}{l}\text { Muddiest } \\
\text { Point }\end{array}$ & $\begin{array}{l}\text { Similar to One-Minute Paper but only } \\
\text { ask students to describe what they } \\
\text { didn't understand and what they think }\end{array}$ & $\begin{array}{l}\text { Same as One-Minute } \\
\text { Paper. If many had } \\
\text { the same problem, try }\end{array}$ & Low \\
\hline
\end{tabular}




\begin{tabular}{|c|c|c|c|c|}
\hline \multirow[t]{5}{*}{$\begin{array}{l}\text { Course Knowledge } \\
\text { and Skills }\end{array}$} & $\begin{array}{l}\text { Muddiest } \\
\text { Point }\end{array}$ & $\begin{array}{l}\text { Similar to One-Minute Paper but only } \\
\text { ask students to describe what they } \\
\text { didn't understand and what they think } \\
\text { might help. }\end{array}$ & $\begin{array}{l}\text { Same as One-Minute } \\
\text { Paper. If many had } \\
\text { the same problem, try } \\
\text { another approach. }\end{array}$ & Low \\
\hline & Chain Notes & $\begin{array}{l}\text { Pass around a large envelope with a } \\
\text { question about the class content. Each } \\
\text { student writes a short answer, puts it in } \\
\text { the envelope, and passes it on. }\end{array}$ & $\begin{array}{l}\text { Sort answers by type } \\
\text { of answer. At next } \\
\text { class meeting, use to } \\
\text { discuss ways of } \\
\text { understanding. }\end{array}$ & Low \\
\hline & $\begin{array}{l}\text { Application } \\
\text { Article }\end{array}$ & $\begin{array}{l}\text { During last } 15 \text { minutes of class, ask } \\
\text { students to write a short news article } \\
\text { about how a major point applies to a } \\
\text { real-world situation. An alternative is } \\
\text { to have students write a short article } \\
\text { about how the point applies to their } \\
\text { major. }\end{array}$ & $\begin{array}{l}\text { Sort articles and pick } \\
\text { several to read at } \\
\text { next class, illustrating } \\
\text { range of applications, } \\
\text { depth of } \\
\text { understanding, and } \\
\text { creativity. }\end{array}$ & Medium \\
\hline & $\begin{array}{l}\text { Student- } \\
\text { generated test } \\
\text { questions }\end{array}$ & $\begin{array}{l}\text { Divide the class into groups and assign } \\
\text { each group a topic on which they are } \\
\text { each to write a question and answer for } \\
\text { the next test. Each student should be } \\
\text { assured of getting at least one question } \\
\text { right on the test. }\end{array}$ & $\begin{array}{l}\text { Use as many of the } \\
\text { questions as possible, } \\
\text { combining those that } \\
\text { are similar. }\end{array}$ & Medium \\
\hline & Journals & $\begin{array}{l}\text { Ask students to keep journals that } \\
\text { detail their thoughts about the class. } \\
\text { May ask them to be specific, recording } \\
\text { only attitudes, values, or self- } \\
\text { awareness. }\end{array}$ & $\begin{array}{l}\text { Have students turn in } \\
\text { the journals several } \\
\text { times during the } \\
\text { semester so you can } \\
\text { chart changes and } \\
\text { development. }\end{array}$ & Medium \\
\hline $\begin{array}{l}\text { Attitudes, Values, } \\
\text { and Self- } \\
\text { Awareness }\end{array}$ & 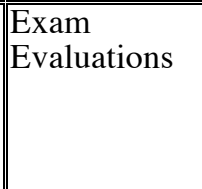 & $\begin{array}{l}\text { Select a test that you use regularly and } \\
\text { add a few questions at the end which } \\
\text { ask students to evaluate how well the } \\
\text { test measures their knowledge or skills. }\end{array}$ & $\begin{array}{l}\text { Make changes to the } \\
\text { test that are } \\
\text { reasonable. Track } \\
\text { student responses } \\
\text { over time. }\end{array}$ & Medium \\
\hline \multirow[t]{4}{*}{$\begin{array}{l}\text { Reactions to } \\
\text { Instruction } \\
\text { Methods }\end{array}$} & $\begin{array}{l}\text { Student Rep } \\
\text { Group }\end{array}$ & $\begin{array}{l}\text { Ask students to volunteer to meet as a } \\
\text { small group with you on a regular basis } \\
\text { to discuss how the course is } \\
\text { progressing, what they are learning, } \\
\text { and suggestions for improving the } \\
\text { course. }\end{array}$ & $\begin{array}{l}\text { Some issues will be } \\
\text { for your information, } \\
\text { some to be addressed } \\
\text { in class. }\end{array}$ & High \\
\hline & \begin{tabular}{|l} 
Suggestion \\
Box
\end{tabular} & $\begin{array}{l}\text { Put a box near the classroom door and } \\
\text { ask students to leave notes about any } \\
\text { class issue. }\end{array}$ & $\begin{array}{l}\text { Review and respond } \\
\text { at the next class } \\
\text { session. }\end{array}$ & $\begin{array}{l}\text { Low to } \\
\text { Medium }\end{array}$ \\
\hline & Peer Review & $\begin{array}{l}\text { Work with a willing colleague, pick a } \\
\text { representative class session to be } \\
\text { observed, and ask the colleague to take } \\
\text { notes about his/her impression of the } \\
\text { class, your interactions with students, } \\
\text { and your teaching methods. }\end{array}$ & $\begin{array}{l}\text { Decide method with } \\
\text { the colleague. } \\
\text { Discussion is best, } \\
\text { but a written report } \\
\text { may be more useful } \\
\text { in the long term. }\end{array}$ & High \\
\hline & $\begin{array}{l}\text { Small Group } \\
\text { Instructional } \\
\text { Diagnosis }\end{array}$ & $\begin{array}{l}\text { Trained facilitators, such as CLC staff, } \\
\text { spend a class session eliciting } \\
\text { responses from your students about }\end{array}$ & $\begin{array}{l}\text { Facilitators meet with } \\
\text { you to explain the } \\
\text { data they have }\end{array}$ & High \\
\hline
\end{tabular}

The minute paper is the most widely used CAT. This method offers a quick and easy way to assess student learning at a particular point in time Several minutes before the end of class, you might stop your lecture or end the discussion to ask students to take one or two minutes to answer, in writing, several questions about the day's work. These questions might include "What is the most important thing you learned in today's class?" or "Do 
you still have questions about the material we covered today?" Students respond on a sheet of paper and hand them in before leaving.

You can use the minute paper to assess:

- Student recall and understanding

- Student evaluation of what they recall

- Student ability to self-assess their learning and understanding

Other commonly used CATs are listed in Table G1.

$\underline{\text { Table A1 }}$ - Examples of CATs [courtesy to http://www.celt.iastate.edu/teaching/cat.html]

Domain: C P A | Usage Type: F | Bloom's Level: K C A ASE | Moodle: Yes (though polls, online text/feedback comments, forum, feedback, and other tools)

\section{Pre-Post Assessment or Survey}

Pre- and post-assessments are another way to assess student learning from the start of the course until the end. A pre-assessment can be used at the beginning of the semester to capture the extent of student knowledge and understanding about key course concepts they will study that semester. It can also be used to measure students attitudes and values relevant to course concepts and predictive of their response and position on course materials. Using a follow-up post-assessment (either the same as the pre-assessment, or somewhat different) at the end of the semester and comparing results from the two can be an effective way to demonstrate student achievement over time.

A type of pre-assessment, called a "background knowledge probe" asks students not only basic questions about previous coursework and preparation but also focuses on identifying the extent to which the student may or may not be familiar with key concepts that will be discussed in the course. Use the background knowledge probe at the beginning of the semester, at the start of a new unit, or prior to introducing a new topic.

Data collected from the background knowledge probe can help you:

- understand the difference between student preparation and your expectations

- plan and prepare for upcoming topics or units to be covered in the course

- point out for students important areas in which they may lack basic knowledge and identify resources that they can access to improve their level of understanding

Domain: C P A | Usage Type: F | Bloom's Level: K C A ASE | Moodle: Yes (though polls, online text/feedback comments, questionnaire, survey, feedback, and other tools)

METHODS /TOOLS USEFUL FOR COOPERATIVE LEARNING /ASSESSMENT 
Cooperative learning is an approach to organizing classroom activities into academic and social learning experiences that are useful for creating conditions for students to demonstrate what they have learned. Outcomes can be both formatively and summatively assessed using cooperative learning methods /tools.

Hundreds of cooperative learning techniques have been created for use in any content area. Among the easy to implement techniques are Think-Pair-Share, Think-Pair-Write, variations of Round Robin, Jigsaw, Jigsaw II, Reverse Jigsaw and the Reciprocal Teaching technique. Complete explanations of these techniques and others can be found here:

http://www.fresno.k12.ca.us/divdept/sscience/siop/siop_docs/InstructionalStrategiesActiv ities.pdf

Researchers have found that cooperative learning, when compared with competitive and individualistic efforts, tends to result in higher achievement, greater long-term retention of what is learned, more frequent use of higher-level reasoning and meta-cognitive thought, more accurate and creative problem solving, more willingness to take on difficult tasks and persist in working toward goal accomplishment. It has been described as "structuring positive interdependence," and, thus, has many applications in the psychomotor domain. Moodle provides many tools to support cooperative learning. The tool set listed below team project provides a variety of online learning tools, sometimes referred to as "Social Media" tools, that are useful for team work and projects.

Cooperative learning activities can be difficult to design and manage. There are so many methods/ tools that there is a possibility that instructors or students, especially novices, may become overwhelmed. Teachers implementing cooperative learning may also be challenged with resistance and hostility from students who believe that they are being held back by their slower teammates or by students who are less confident and feel that they are being ignored or demeaned by their team. Peer review and evaluations may be controversial among students due to perceived competition among peers. A confidential evaluation process may be needed to help to increase peer evaluation effectiveness, thus increasing instructor work load.

\section{Team Project}

The many assessment methods /tools described in individual projects below can be adapted to team projects. What sets the team project apart from the others is that it is a method that is designed to assess the three domains of learning and interpersonal skills. The way to make the team project work involves using the techniques of cooperative learning.

One of the defining features of this method is individual accountability - holding each team member accountable for the entire project and not just the part that he or she may have focused on. References on cooperative learning offer suggestions for achieving individual accountability, including giving individual exams covering the full range of knowledge and skills required to complete the project and assigning individual grades based in part on how well the students met their responsibilities to their team. 
Moodle has a variety of cooperative learning tools that can be used for activities and assessments. These tools pair nicely with CATs as well as many authentic performance tasks

\begin{tabular}{|c|c|c|}
\hline $\begin{array}{l}\text { Moodle Tools for } \\
\text { Cooperative Learning }\end{array}$ & Tool Description & Some e-Learning Applications \\
\hline $\mathrm{B} \log \mathrm{s}$ & $\begin{array}{l}\text { A non-course page where individuals } \\
\text { write commentaries on an ongoing } \\
\text { basis. Classmates can comment or link } \\
\text { to another student's blog. }\end{array}$ & $\begin{array}{l}\text { Learning journals } \\
\text { Pre-class intros } \\
\text { Post-class reflections } \\
\text { Informal updates on course skills } \\
\text { and related topics } \\
\text { Evaluation of course effectiveness, } \\
\text { Organize individual thoughts and } \\
\text { course notes }\end{array}$ \\
\hline Chats & $\begin{array}{l}\text { Two or more participants } \\
\text { communicating at the same time by } \\
\text { text }\end{array}$ & $\begin{array}{l}\text { Role-play practice } \\
\text { Group decision making } \\
\text { Group project work } \\
\text { Pair collaborative study } \\
\text { Questions or comments during a } \\
\text { virtual presentation }\end{array}$ \\
\hline $\begin{array}{l}\text { E-mail / Instant } \\
\text { Messaging }\end{array}$ & $\begin{array}{l}\text { Two or more participants } \\
\text { communicating at different times. } \\
\text { Messages received and managed at } \\
\text { the individual's mail site }\end{array}$ & $\begin{array}{l}\text { Group project work } \\
\text { Instructor-student exchanges } \\
\text { Pair collaborative activities } \\
\text { Case-study work } \\
\text { Short post-class updates with links } \\
\text { Post-class commentaries } \\
\text { Intersession multimedia work and } \\
\text { discussions }\end{array}$ \\
\hline Groups/Groupings & $\begin{array}{l}\text { A tool that allows instructors to } \\
\text { coordinate groups and groupings of } \\
\text { students. Groups can be created to } \\
\text { work separately on activities or } \\
\text { allowed to view other group's work }\end{array}$ & $\begin{array}{l}\text { Allows any activity in Moodle to } \\
\text { become a cooperative learning } \\
\text { activity }\end{array}$ \\
\hline $\begin{array}{l}\text { Online Conferencing } \\
\text { with BB Collaborate }\end{array}$ & $\begin{array}{l}\text { A number of participants online at } \\
\text { once with access to audio, whiteboard, } \\
\text { polling, media displays, and chat }\end{array}$ & $\begin{array}{l}\text { Guest speakers } \\
\text { Virtual classes } \\
\text { Group project work } \\
\text { Synchronous team work during a } \\
\text { virtual classroom session } \\
\text { Small group meetings }\end{array}$ \\
\hline Wikis & $\begin{array}{l}\text { A course page that allows students to } \\
\text { edit its contents. Can be controlled for } \\
\text { editing/viewing by a small group or } \\
\text { by all. }\end{array}$ & $\begin{array}{l}\text { Collaborative work on a project } \\
\text { document } \\
\text { Ongoing updated repository of } \\
\text { course information } \\
\text { Collaborative course material } \\
\text { construction }\end{array}$ \\
\hline
\end{tabular}

Table A.2 - Moodle tools that can be used for group activities and assessments

Domain: C P A | Usage Type: F, S | Bloom's Level: K C A ASE | Moodle: Yes (See table A.2 for examples) 


\section{METHODS /TOOLS USEFUL FOR OBJECTIVE ASSESSMENT}

Objective assessment is a form of questioning which has a single correct answer. Objective question types include true/false answers, multiple choice, multiple-response and matching questions. Objective assessment is well suited to the increasingly popular computerized or online assessment format. Moodle provides many options for objective testing that can be used for assessment of SLO.

\section{Multiple Choice and other objective quiz types}

Multiple choice is a form of assessment in which respondents are asked to select the best possible answer (or answers) out of the choices from a list. Multiple choice quizzes (MCQs) are widely popular with faculty because they are often bundled with course packs from textbook publishers, easy to administer, are time effective because they are computer- or machine-marked.

Disadvantages: MCQs have limitations as assessment tools. They are most effective for measuring outcomes only at lower levels and, thus, orient students to take a rote approach to their studies and to believe that learning involves cramming. They are perceived to be easy to cheat at and encourage cheating. They provide few opportunities for useful feedback. Publisher-provided question banks may be of poor quality.

While MCQs can be administered via paper-based formats and with fill-in-the-answer scanable sheets, they are most efficiently administered electronically via a learning management system; the LMS allows students to take the quiz outside of class, the scores are computed automatically and are transferred directly to the gradebook.

It is possible to increase the reliability of MCQs when assessing higher order SLOs. They are able to measure learning at higher levels if care is taken to ensure they validly measure higher order thinking skills. However, problem-solving and higher-order reasoning skills are better assessed through subjective measures, such as shortanswer and essay tests.

Good multiple choice items result when these guidelines are followed:

- Stem should present single, clearly formulated problem.

- Stem should be in simple, understood language; delete extraneous words.

- Avoid "all of the above"--can answer based on partial knowledge (if one is incorrect or two are correct, but unsure of the third...).

- Avoid "none of the above."

- Make all distractors plausible/homogeneous.

- Don't overlap response alternatives (decreases discrimination between students who know the material and those who don't).

- Don't use double negatives.

- Present alternatives in logical or numerical order. 
- Place correct answer at random (A answer is most often).

- Make each item independent of others on test.

- Way to judge a good stem: students who know the content should be able to answer before reading the alternatives

- List alternatives on separate lines, indent, separate by blank line, use letters vs. numbers for alternative answers.

- Need more than 3 alternatives, 4 is best.

\begin{tabular}{|c|c|}
\hline True/False & $\begin{array}{l}\text { A simple form of multiple choice question with just the two choices 'True' and } \\
\text { 'False' }\end{array}$ \\
\hline Short Answer & $\begin{array}{l}\text { Allows a response of one or a few words that is graded by comparing against } \\
\text { various model answers, which may contain wildcards. May require manual } \\
\text { scoring }\end{array}$ \\
\hline Numerical & $\begin{array}{l}\text { Allows a numerical response, possibly with units, that is graded by comparing } \\
\text { against various model answers, possibly with tolerances. }\end{array}$ \\
\hline Calculated & $\begin{array}{l}\text { Calculated questions are like numerical questions but with the numbers used } \\
\text { selected randomly from a set when the quiz is taken. }\end{array}$ \\
\hline Matching & $\begin{array}{l}\text { The answer to each of a number of sub-question must be selected from a list of } \\
\text { possibilities. }\end{array}$ \\
\hline $\begin{array}{l}\text { Random Short } \\
\text { answer matching }\end{array}$ & $\begin{array}{l}\text { Like a Matching question, but created randomly from the short answer questions } \\
\text { in a particular category. }\end{array}$ \\
\hline $\begin{array}{l}\text { Embedded } \\
\text { Answers (Cloze) }\end{array}$ & $\begin{array}{l}\text { Questions of this type are very flexible, but can only be created by entering text } \\
\text { containing special codes that create embedded multiple-choice, short answers and } \\
\text { numerical questions. }\end{array}$ \\
\hline $\begin{array}{l}\text { Calculated } \\
\text { multichoice }\end{array}$ & $\begin{array}{l}\text { Calculated multichoice questions are like multichoice questions which choice } \\
\text { elements can include formula results from numeric values that are selected } \\
\text { randomly from a set when the quiz is taken. }\end{array}$ \\
\hline Calculated Simple & $\begin{array}{l}\text { A simpler version of calculated questions which are like numerical questions but } \\
\text { with the numbers used selected randomly from a set when the quiz is taken. }\end{array}$ \\
\hline $\begin{array}{l}\text { Drag and Drop } \\
\text { Matching }\end{array}$ & $\begin{array}{l}\text { An extension of the matching question that allows the user to drag and drop items } \\
\text { to match answers to subquestions. }\end{array}$ \\
\hline
\end{tabular}

Table A-3 Other objective question types that Moodle supports:

Moodle provides item analysis for objective computer-scored questions that allows easy review of individual attainment of SLOs and aggregated scores to determine class averages. Note: subjective question formats (essay questions) require manual grading (see authentic assessment method/ tools).

Moodle supports adaptive mode quizzing which allows MCQs to be used formatively.

Domain: C A | Usage Type: F, S | Bloom's Level: K C A (if carefully constructed ASE) | Moodle: Yes (See table G.2 for examples)

\section{Licensing Examinations}

Licensing examinations, usually administered through objective testing formats, are required by the state to perform professional services in nursing and other fields. 
Domain: C P | Usage Type: S | Bloom's Level: K C A (if carefully constructed ASE) | Moodle: No Standardized Cognitive Test

Commercial, Norm-Referenced, Standardized Exams - are group administered, mostly or entirely multiple-choice, objective tests in one or more curricular areas. Scores are based on comparison with a reference or norm group. Typically must be obtained (purchased) from a private vendor.

Traditional standardized tests, by requiring specified administration protocols (i.e., complete secrecy) for their validity, make it difficult for teachers and students to rehearse and gain the confidence that comes from knowing the expectations for performance.

Domain: C | Usage Type: S | Bloom's Level: K C A (if carefully constructed ASE) Moodle: No

\section{METHODS /TOOLS USEFUL FOR AUTHENTIC PERFORMANCE}

Authentic assessment is a form of assessment in which students are asked to perform real-world tasks that demonstrate meaningful application of essential knowledge and skills. Also called "performance assessment," it calls upon the examinee to demonstrate specific skills and competencies, that is, to apply the skills and knowledge they have mastered in an assessment that matches the context where they will use the skills. For example, if the expected behavior is to demonstrate the procedures for diagnosing problems within a small engine, then a more authentic assessment would be to have the student diagnose a broken engine; a less authentic assessment would be to have the student write a paper about fixing an engine or taking a quiz with questions about procedures

Authentic assessments offer more direct evidence of application and construction of knowledge. Having a student demonstrate a skill provides much more direct evidence of proficiency than giving the student an objective test. If your SLO states that a student will effectively critique the arguments someone else has presented (an important skill often required in the real world), having the student write a critique should provide more direct evidence of that skill than asking the student a series of multiple-choice questions about a passage. If used together to measure different levels of cognition, both assessments may be useful for thorough, multi-pronged assessment.

Disadvantages:

Authentic assessments take more time to do than objective assessments. Creating real world contexts for assessments are not always practical in classrooms or online.

\section{Writing Assignments, including essays and essay tests, creative writing, and reflective self-assessment essay / journal writing}


Writing is an essential real world skill that can be used across the curriculum and at all domains/levels to measure SLOs. Writing excels as a condition for demonstration of higher level thinking in all domains. Writing is a comprehensive assessment method /tool that requires transfer of skills from other areas and integration of learning from other sources and that can include applications of problem-based learning. Writing is ideal to assess self-reflection and creative, imaginative thinking. Writing assessments are easy to administer and faster to construct than objective tests.

Disadvantages: Writing assessment takes longer to grade and provide feedback and thus is more time consuming than objective measures. Writing assessment can be made less time-consuming if criteria are well articulated and communicated. Ensuring consistency of attainment across multi-section courses can be problematic, unless efforts are made to ensure inter-rater reliability. Writing may disadvantage ESL and novice students with poor writing or thinking skills.

Online courses rely heavily on writing skills. As such, Moodle provides numerous tools for writing activities and assessments. In addition to managing documents and rubricbased grading, Moodle offers forums, chats, wikis, journals, commentary, and other tools that support writing performances.

\section{Domain: C P A | Usage Type: F, S | Bloom's Level: C A ASE | Moodle: Yes}

\section{Case Studies and Simulations}

Case studies are stories that are used as a teaching tool to show the application of a theory or concept to real situations. Various disciplines have employed case studies, including humanities, social sciences, sciences, engineering, and business. Good cases /simulations generally have the following features: they tell a good story, are current, create empathy with the main characters, are relevant to the reader, serve a teaching function, require a dilemma to be solved, and can be broadly applied. In online environments, cases and simulations may be presented in a multimedia format to increase their effectiveness. The cases and simulations used should correspond closely to the learning conditions to promote the best transfer of knowledge.

Case studies/ simulations are useful for the demonstration of SLOs that require comprehension, application, analysis, and/or evaluation. Case studies /simulations that are fact-driven and where there are a narrow-range of possibilities for answers can address comprehension and application-level thinking and skills. Case studies /simulations that are context-driven, where multiple solutions are possible, and require interdisciplinary and complex thinking and skills by connecting other knowledge to the topic to be assessed can address analysis and evaluation-level thinking and skills.

Disadvantages: Creating cases for study and simulation activities is time consuming, especially if they involve multimedia production. Evaluating performance is difficult, but can be facilitated by clearly developed criteria. If used for multi-section courses, the quality of the rubric and the training of the evaluators will influence reliability. Rubrics will sometimes not provide for unexpected, creative responses. Locating already- 
designed materials is challenging. students may rely on common sense under pressure rather than their knowledge from the course.

Online courses may incorporate case studies and simulations as materials. As a content management tool, Moodle does a good job of supporting the organization and presentation of multimedia-based cases and simulations, but does not provide specialized tools for assessments. Moodle will manage documents and rubric-based grading, and allow case studies and simulations to be done/assessed via forums, chats, wikis, journals, commentary, and other tools that support writing performances.

Domain: C A | Usage Type: F, S | Bloom's Level: C A ASE | Moodle: Yes (limited to content management)

\section{Live presentations, including oral speech or examination, debate, and performance /simulation}

A live presentation is an assessment practice where students show a skill and/or explain the content of a topic to an audience, usually consisting of instructor(s) and students. Live presentations can come in many forms and contexts, including demonstrations of skills or procedures, a lecture, a speech, a play or recital, an academic, athletic, artistic, or other creative performance; they may be done independently or with a group. Live presentations may include visuals, such as slideshows, multimedia, handouts, or a poster.

There are many benefits to the use of live presentations, including being highly authentic and providing the best-possible conditions for the display of SLOs. Presentations allow other students to see and learn what each student learned, and thus, provide excellent opportunities for peer review. They promote interdisciplinarity and connect general education goals with discipline-specific content. Assessments of presentations can be completed as the performance occurs, thus eliminating after-the-fact instructor tasks, but are difficult to provide feedback for, unless assessments are improved with use of rubrics.

Disadvantages: Presentations can increase stress for students and difficulty for ESL students. Presentations take course time away from other activities. The level and style of delivery may confound assessment of content knowledge, thus instructors must fairly grade content criteria independently of delivery criteria. Some students may take the evaluation very hard - evaluative statements must be carefully framed; this can be helped with use of a good rubric and having more than one evaluator.

By definition, they must be completed face-to-face, but new tools like video and audio recording are allowing recorded presentations to be used for assessment and feedback in online courses.

Domain: C P A | Usage Type: F, S | Bloom's Level: K C A ASE | Moodle: Yes (limited to content management) 
Individual projects, including capstone, thesis/research project, term projects, product creation and special reports

Multiple or high-level, complex SLOs in a course can be demonstrated through completion of a complex, usually cumulative, multi-dimensional individual project. Individual projects provide students the opportunity to apply their learning in activities that make optimal use of their potential intrinsic interest in the subject matter. Projects allow students to deeply study a topic of interest, usually outside of class time, and express their learning through critical and creative thinking. Projects are aimed at the creation of some sort of real world product useful to an authentic audience.

Projects can take many varied forms and time-frames. Projects that take longer, e.g. capstone or term projects that extend over several weeks or an entire term, usually require more work and incorporate higher levels of complexity. Projects may include writing, speaking, applied research and library use, technical, artistic, and academic production, technology use, and problem solving. Projects are versatile methods /tools for demonstrating learning and can be adapted to all domains and levels of SLOs, but excel at measuring application, analysis, synthesis, and evaluation. Projects that are done in stages allow instructors to incorporate formative assessment and feedback into production.

The types of projects faculty choose as assessment vehicles will depend, in part, on the expertise the faculty have in evaluating works in various modes. The clear articulation of expectations will be critical to success. Specifying student creativity as a criterion will facilitate efforts that stretch students to go beyond minimum expectations. Some products may involve decisions about storage and laboratory space, access to equipment, and cost of materials/supplies.

Disadvantages of projects include:

- time consuming and labor intensive to design and execute both for instructor and students, including the production of clearly defined criteria and evaluative measures; "the look" should not over- ride the content

- may use materials wastefully (e.g., making transparencies for one speech or making a model using expensive materials)

- students may select a narrow content range in which to work, thus full breadth of understanding of content may not be demonstrated

- student variability (ability, motivation) challenges reliability and value of performance

- labor intensive for student

- cost may be prohibitive

Domain: C P A | Usage Type: F, S | Bloom's Level: K C A ASE | Moodle: Yes (limited to content management)

Process Analysis, including flowcharts, diagrams, and worked problem-solving 
Process analysis assessment methods/ tools provide a means for students to demonstrate they understand how a system works, how a certain series of events occur, how complex things are organized, or can perform the steps of an operation or procedure themselves. It requires students to think both holistically, analytically, and logically as they break large steps or methods into smaller ones. Process analysis methods excel at measuring application, analysis and synthesis level SLOs.

A flowchart or diagram is a visual or graphic illustration of a process or system used to solve a problem or produce a product. Flowcharts are excellent ways to communicate the logic involved in a system; students must recall the appropriate information and associated content but must also analyze how the components fit with the entire system or process. Flow charts and diagrams allow students the opportunity to gain confidence in their ability to describe the entire system or process. Follow-up case study questions concerning the system or process, involving potential problems or adaptations, allow the students to use the flowchart to evaluate system changes.

Advantages:

- These strategies appeal to visual learners who may be able to encode and remember more course content by adopting this strategy.

- provides experience in applying and organizing course concepts

- assists in thinking through organization of information

- additional grappling with the material enhances recall

Disadvantages:

- students may have limited practice with displaying graphic skills

- students may not have sufficient experience in interpreting graphics

- technological sophistication will influence production quality

Domain: C P A | Usage Type: F, S | Bloom's Level: A ASE | Moodle: Yes (limited to content management)

\section{Portfolios}

Portfolios are a systematic and organized collection of a student's work that exhibits to others the direct evidence of a student's efforts, achievements, and progress over a period of time. The student is involved in selection of its contents. Contents should include information about the performance criteria, the rubric or criteria for judging merit, and evidence of student self-reflection or evaluation. Portfolios may include a variety of demonstrations of learning and have been gathered in the form of a physical collection of materials, videos, CD-ROMs, reflective journals, etc.

Portfolios are becoming an increasingly popular method of assessment, especially at the program level. Portfolios look at student work at specified periods of time and measures the extent of learning based on the progression of the work from the first assignment until the last to determine if mastery of SLOs is attained. At the classroom level, this might include a series of writing assignments of increasing difficulty or all work that the student 
has produced for a particular course. At the program level, it might include all key pieces of work for each SLOs that the student has attained.

The advantages of the portfolio include:

- A visual representation of student learning from beginning to end

- A concrete way to track and document student progress over a period of time

- Evidence of learning can be retained by the student for future reference and use

- A systematic progression of tasks that can be linked to course goals and objectives and interpreted in the context of whether each was accomplished

- An opportunity for students to reflect on their own progress as they review their completed work

- A key piece in portfolio work is getting students to self-analyze and reflect on their portfolio - what can they see that they've learned, what doesn't it tell them about what they've learned, and how can they document the progression of their ideas and work from the beginning of the semester until the end.

Disadvantages include:

- Time consuming to grade;

- Different content in portfolio makes evaluating difficult and may require training;

- Bulky to manage depending on size, however electronic portfolios eliminate this concern.

Moodle has a built-in electronic portfolio tool, called Mahara, that faculty can use with students to build portfolios. Mahara allows a variety of formats and can include criteria used to assess the contents.

Domain: C P | Usage Type: S | Bloom's Level: K C A ASE | Moodle: Yes 
APPENDIX B - Learning Domains \& Taxonomies

In the 1950's the American educational psychologist Benjamin Bloom and a set of colleagues identified three "domains" of learning—the "cognitive, "psychomotor", and "affective"; shown below.

The columns within each domain refer to levels of complexity. The level of cognitive, psychomotor, or affective complexity described increases as one moves from left to right. In the cognitive domain, for example, knowing something requires less thinking and is therefore a less complex action, than evaluating something based on knowledge previously acquired.

In each column, directly below the term which designates the complexity level is a description of behavior typical of students who have achieved that level. Beneath that is a list of verbs that can be used to expand that description and thereby to tailor it to a given course.

As a means of applying this research to your student learning outcomes, we suggest that you proceed in something like the following manner:

- Read through the descriptions in all three domains until you find the one that comes closest to the behavior you have in mind for students successfully completing your course. Generally speaking, the more advanced the course, the further to the right within a given table will be found the description that best fits that course.

- Use that description, or a version that you tailor to your course, to generate one or more student learning outcomes.

For Course Outlines (behavioral SLOs)

- Starting each student learning outcome with a verb, written with all lower-case letters, "grammatically completes the sentence". Use the list of verbs further down that same column, or verbs similar to them, for starting off each student learning outcome that you write for that domain and level.

\section{Cognitive Domain}

\section{Learning outcomes related to knowledge}

\begin{tabular}{|c|c|c|c|c|c|}
\hline Knowledge & Comprehension & Application & Analysis & Synthesis & Evaluation \\
\hline $\begin{array}{l}\text { Student } \\
\text { remembers } \\
\text { or } \\
\text { recognizes } \\
\text { informatio } \\
\text { n or } \\
\text { specifics as } \\
\text { communica } \\
\text { ted with } \\
\text { little } \\
\text { personal } \\
\text { assimilatio } \\
\text { n. }\end{array}$ & $\begin{array}{l}\text { Student grasps } \\
\text { the meaning } \\
\text { behind the } \\
\text { information } \\
\text { and interprets, } \\
\text { translates, } \\
\text { or } \\
\text { comprehends } \\
\text { the } \\
\text { information. }\end{array}$ & $\begin{array}{l}\text { Student uses } \\
\text { information to } \\
\text { relate and } \\
\text { apply it to a } \\
\text { new situation } \\
\text { with minimal } \\
\text { instructor } \\
\text { input. }\end{array}$ & $\begin{array}{l}\text { Student } \\
\text { discriminates, } \\
\text { organizes, and } \\
\text { scrutinizes } \\
\text { assumptions in an } \\
\text { attempt to identify } \\
\text { evidence for a } \\
\text { conclusion. }\end{array}$ & $\begin{array}{l}\text { Student } \\
\text { creatively } \\
\text { applies } \\
\text { knowledge } \\
\text { and analysis } \\
\text { to integrate } \\
\text { concepts or } \\
\text { construct an } \\
\text { overall } \\
\text { theory. }\end{array}$ & $\begin{array}{l}\text { Student } \\
\text { judges or } \\
\text { evaluates } \\
\text { informatio } \\
\text { n based } \\
\text { upon } \\
\text { standards } \\
\text { and } \\
\text { criteria, } \\
\text { values and } \\
\text { opinions. }\end{array}$ \\
\hline
\end{tabular}




\begin{tabular}{|c|c|c|c|c|c|}
\hline $\begin{array}{l}\text { cite } \\
\text { label } \\
\text { list } \\
\text { enumerate } \\
\text { identify } \\
\text { imitate } \\
\text { match } \\
\text { name } \\
\text { quote } \\
\text { recall } \\
\text { reproduce } \\
\text { state } \\
\text { write }\end{array}$ & $\begin{array}{l}\text { convert } \\
\text { define } \\
\text { describe } \\
\text { discuss } \\
\text { estimate } \\
\text { explain } \\
\text { generalize } \\
\text { identify } \\
\text { illustrate } \\
\text { locate } \\
\text { paraphrase } \\
\text { restate } \\
\text { summarize }\end{array}$ & $\begin{array}{l}\text { apply } \\
\text { chart } \\
\text { compute } \\
\text { demonstrate } \\
\text { determine } \\
\text { dramatize } \\
\text { establish } \\
\text { make } \\
\text { manipulate } \\
\text { prepare } \\
\text { project } \\
\text { solve } \\
\text { use }\end{array}$ & $\begin{array}{l}\text { analyze } \\
\text { compare } \\
\text { contrast } \\
\text { correlate } \\
\text { diagram } \\
\text { dissect } \\
\text { differentiate } \\
\text { distinguish } \\
\text { infer } \\
\text { investigate } \\
\text { limit } \\
\text { outline } \\
\text { separate }\end{array}$ & $\begin{array}{l}\text { assemble } \\
\text { create } \\
\text { construct } \\
\text { design } \\
\text { develop } \\
\text { formulate } \\
\text { generate } \\
\text { hypothesize } \\
\text { initiate } \\
\text { invent } \\
\text { modify } \\
\text { reframe } \\
\text { synthesize }\end{array}$ & $\begin{array}{l}\text { access } \\
\text { appraise } \\
\text { conclude } \\
\text { critique } \\
\text { decide } \\
\text { defend } \\
\text { diagnose } \\
\text { evaluate } \\
\text { judge } \\
\text { justify } \\
\text { rank } \\
\text { recommen } \\
\text { d } \\
\text { support }\end{array}$ \\
\hline
\end{tabular}

Psychomotor Domain

Learning outcomes related to skills

\begin{tabular}{|c|c|c|c|c|c|}
\hline Observe & Model & $\begin{array}{l}\text { Recognize } \\
\text { Standards }\end{array}$ & Correct & Apply & Coach \\
\hline $\begin{array}{l}\text { Students } \\
\text { translate } \\
\text { sensory } \\
\text { input into } \\
\text { physical } \\
\text { tasks or } \\
\text { activities. }\end{array}$ & $\begin{array}{l}\text { Students are } \\
\text { able to replicate } \\
\text { a fundamental } \\
\text { skill or task. }\end{array}$ & $\begin{array}{l}\text { Students recognize } \\
\text { standards or criteria } \\
\text { important to } \\
\text { perform a skill or } \\
\text { task correctly. }\end{array}$ & $\begin{array}{l}\text { Students use } \\
\text { standards to } \\
\text { evaluate their own } \\
\text { performances and } \\
\text { make corrections. }\end{array}$ & $\begin{array}{l}\text { Students } \\
\text { apply this } \\
\text { skill to real } \\
\text { life } \\
\text { situations. }\end{array}$ & $\begin{array}{l}\text { Students } \\
\text { are able } \\
\text { to } \\
\text { instruct } \\
\text { or train } \\
\text { others to } \\
\text { perform } \\
\text { this skill } \\
\text { in other } \\
\text { situation } \\
\text { s. } \\
\end{array}$ \\
\hline $\begin{array}{l}\text { hear } \\
\text { identify } \\
\text { observe } \\
\text { see } \\
\text { smell } \\
\text { taste } \\
\text { touch } \\
\text { watch } \\
\text { *Usually no } \\
\text { outcomes or } \\
\text { objectives } \\
\text { written at } \\
\text { this level. }\end{array}$ & $\begin{array}{l}\text { attempt } \\
\text { copy } \\
\text { follow } \\
\text { imitate } \\
\text { mimic } \\
\text { model } \\
\text { reenact } \\
\text { repeat } \\
\text { reproduce } \\
\text { show } \\
\text { try }\end{array}$ & $\begin{array}{l}\text { check } \\
\text { detect } \\
\text { discriminate } \\
\text { differentiate } \\
\text { distinguish } \\
\text { notice } \\
\text { perceive } \\
\text { recognize } \\
\text { select }\end{array}$ & $\begin{array}{l}\text { adapt } \\
\text { adjust } \\
\text { alter } \\
\text { change } \\
\text { correct } \\
\text { customize } \\
\text { develop } \\
\text { manipulate } \\
\text { modify } \\
\text { practice } \\
\text { revise }\end{array}$ & $\begin{array}{l}\text { build } \\
\text { compose } \\
\text { construct } \\
\text { create } \\
\text { design } \\
\text { originate } \\
\text { produce }\end{array}$ & $\begin{array}{l}\text { demonst } \\
\text { rate } \\
\text { exhibit } \\
\text { illustrate } \\
\text { instruct } \\
\text { teach } \\
\text { train }\end{array}$ \\
\hline
\end{tabular}


Affective Domain

Learning outcomes related to attitudes, behaviors, and value

\begin{tabular}{|c|c|c|c|c|}
\hline Receiving & Responding & Valuing & Organizing & Characterizing \\
\hline $\begin{array}{l}\text { Students } \\
\text { become } \\
\text { aware of an } \\
\text { attitude, } \\
\text { behavior, } \\
\text { or } \\
\text { value. }\end{array}$ & $\begin{array}{l}\text { Students exhibit } \\
\text { a reaction or } \\
\text { change as a } \\
\text { result of } \\
\text { exposure to an } \\
\text { attitude, behavior, or } \\
\text { value. }\end{array}$ & $\begin{array}{l}\text { Students } \\
\text { recognize } \\
\text { value and } \\
\text { display this } \\
\text { through } \\
\text { involvement or } \\
\text { commitment. }\end{array}$ & $\begin{array}{l}\text { Students } \\
\text { determine a } \\
\text { new value or } \\
\text { behavior as } \\
\text { important or } \\
\text { a } \\
\text { priority. }\end{array}$ & $\begin{array}{l}\text { Students integrate } \\
\text { consistent behavior as a } \\
\text { naturalized value in } \\
\text { spite of discomfort or } \\
\text { cost. } \\
\text { The value is recognized } \\
\text { as a part of the person's } \\
\text { character. }\end{array}$ \\
\hline $\begin{array}{l}\text { accept } \\
\text { attend } \\
\text { describe } \\
\text { explain } \\
\text { locate } \\
\text { observe } \\
\text { realize } \\
\text { receive } \\
\text { recognize }\end{array}$ & $\begin{array}{l}\text { behave } \\
\text { comply } \\
\text { cooperate } \\
\text { discuss } \\
\text { examine } \\
\text { follow } \\
\text { model } \\
\text { present } \\
\text { respond } \\
\text { show } \\
\text { studies }\end{array}$ & $\begin{array}{l}\text { accept } \\
\text { adapt } \\
\text { balance } \\
\text { choose } \\
\text { differentiate } \\
\text { defend } \\
\text { influence } \\
\text { prefer } \\
\text { recognize } \\
\text { seek } \\
\text { value }\end{array}$ & $\begin{array}{l}\text { adapt } \\
\text { adjust } \\
\text { alter } \\
\text { change } \\
\text { customize } \\
\text { develop } \\
\text { manipulate } \\
\text { modify } \\
\text { practice } \\
\text { revise }\end{array}$ & $\begin{array}{l}\text { authenticate } \\
\text { characterize } \\
\text { defend } \\
\text { display } \\
\text { embody } \\
\text { habituate } \\
\text { internalize } \\
\text { produce } \\
\text { represent } \\
\text { validate } \\
\text { verify }\end{array}$ \\
\hline
\end{tabular}

Adapted from

http://www.morningside.edu/academics/research/assessment/documents/Writingstudentlearningoutcomes.pdf Tables of verbs developed by Janet Fulks and Kate Pluta, Bakersfield College, CA 


\section{APPENDIX C: GLOSSARY OF ASSESSMENT TERMS}

The following definitions are written for the practitioner who is using direct, courseembedded, outcomes-based assessment practices.

\begin{tabular}{|c|c|}
\hline $\begin{array}{l}\text { Ancillary } \\
\text { Course } \\
\text { Documentation }\end{array}$ & $\begin{array}{l}\text { These are documents that describe the course, including what students will do, the } \\
\text { conditions and criteria of assessment, the scope, sequence, and schedule of } \\
\text { activities that lead to SLOs, etc. and includes, but is not limited to, the course } \\
\text { outline, syllabus, course schedule, assignment / grade descriptions, rubrics, and } \\
\text { check lists. }\end{array}$ \\
\hline Assessment & $\begin{array}{l}\text { An ongoing process aimed at understanding and improving student learning. It } \\
\text { involves making our expectations explicit and public; setting appropriate criteria } \\
\text { and standards for learning quality; systematically gathering, analyzing, and } \\
\text { interpreting evidence to determine how well performance matches those } \\
\text { expectations and standards; and using the resulting information to document, } \\
\text { explain, and improve performance. (Angelo, 1995) }\end{array}$ \\
\hline $\begin{array}{l}\text { Authentic } \\
\text { Assessment }\end{array}$ & $\begin{array}{l}\text { A form of assessment in which students are asked to perform real-world tasks that } \\
\text { demonstrate meaningful application of essential knowledge and skills }\end{array}$ \\
\hline Conditions & $\begin{array}{l}\text { The environment created by the curriculum, instruction, and assessment where } \\
\text { students are able to demonstrate learning }\end{array}$ \\
\hline $\begin{array}{l}\text { Continuous } \\
\text { Improvement }\end{array}$ & $\begin{array}{l}\text { A process where assessment information is regularly and periodically used to } \\
\text { improve SLO outcomes through curriculum adjustment and (re)design }\end{array}$ \\
\hline $\begin{array}{l}\text { Cooperative } \\
\text { Learning }\end{array}$ & $\begin{array}{l}\text { An approach to organizing classroom activities into academic and social learning } \\
\text { experience that emphasis group and interpersonal interaction }\end{array}$ \\
\hline $\begin{array}{l}\text { Course- } \\
\text { Embedded } \\
\text { Assessment }\end{array}$ & $\begin{array}{l}\text { A means of gathering information about student learning that is built into and a } \\
\text { natural part of the teaching-learning process. Often uses for assessment purposes } \\
\text { classroom assignments that are evaluated to assign students a grade. Can assess } \\
\text { individual student performance or aggregate the information to provide } \\
\text { information about the course or program; can be formative or summative, } \\
\text { quantitative or qualitative. Example: as part of a course, expecting each student to } \\
\text { complete a research paper that is graded for content and style, but is also assessed } \\
\text { for advanced ability to locate and evaluate Web-based information (as part of a } \\
\text { college-wide outcome to demonstrate information literacy). (Leskes, 2002) }\end{array}$ \\
\hline $\begin{array}{l}\text { Course } \\
\text { Evaluation }\end{array}$ & $\begin{array}{l}\text { Evaluation of one's curriculum conducted by the instructor using evidence } \\
\text { collected from SLO measurements }\end{array}$ \\
\hline Criteria & $\begin{array}{l}\text { Guidelines, rules, characteristics, or dimensions that are used to judge the quality } \\
\text { of student performance. Criteria indicate what we value in student responses, } \\
\text { products or performances. They may be holistic, analytic, general, or specific. } \\
\text { Scoring rubrics are based on criteria and define what the criteria mean and how } \\
\text { they are used. }\end{array}$ \\
\hline $\begin{array}{l}\text { Direct } \\
\text { Assessment }\end{array}$ & $\begin{array}{l}\text { Gathers evidence about student learning based on student performance that } \\
\text { demonstrates the learning itself. Can be value added, related to standards, }\end{array}$ \\
\hline
\end{tabular}




\begin{tabular}{|c|c|}
\hline & $\begin{array}{l}\text { qualitative or quantitative, embedded or not, using local or external criteria. } \\
\text { Examples are written assignments, classroom assignments, presentations, test } \\
\text { results, projects, logs, portfolios, and direct observations. (Leskes, 2002) }\end{array}$ \\
\hline $\begin{array}{l}\text { Doing-Thinking } \\
\text { Cycles }\end{array}$ & $\begin{array}{l}\text { A process that involves sequentially exposing students to the content, activities, } \\
\text { and practice that lead to learning of a SLO. Cycles may include time for } \\
\text { metacognitive activity, including reflection and self-evaluation }\end{array}$ \\
\hline Evaluation & $\begin{array}{l}\text { When used for most educational settings, evaluation means to measure, compare, } \\
\text { and judge the quality of student work, schools, or a specific educational program. }\end{array}$ \\
\hline $\begin{array}{l}\text { Formative } \\
\text { assessment }\end{array}$ & $\begin{array}{l}\text { Assessment that provides feedback to the teacher for the purpose of improving } \\
\text { instruction. Also called "assessment FOR learning" }\end{array}$ \\
\hline $\begin{array}{l}\text { Inter-rater } \\
\text { reliability }\end{array}$ & $\begin{array}{l}\text { The consistency with which two or more judges rate the work or performance of } \\
\text { students. }\end{array}$ \\
\hline $\begin{array}{l}\text { Measurable } \\
\text { SLO }\end{array}$ & $\begin{array}{l}\text { A statement describing what students will learn in a course that includes an } \\
\text { observable student behavior, conditions for demonstration, and criteria that will be } \\
\text { used to measure performance. }\end{array}$ \\
\hline Metacognition & $\begin{array}{l}\text { Refers to an individual's ability to think about his/her own thinking and to monitor } \\
\text { his/her own learning. Metacognition is integral to a learner's ability to actively } \\
\text { partner in his or her own learning and facilitates transfer of learning to other } \\
\text { contexts. }\end{array}$ \\
\hline $\begin{array}{l}\text { Primary Trait } \\
\text { Analysis }\end{array}$ & See Rubrics \\
\hline $\begin{array}{l}\text { Program- and } \\
\text { Institutional- } \\
\text { Level } \\
\text { Assessment }\end{array}$ & $\begin{array}{l}\text { Assessment process that takes place on a scale larger than the course-level and is } \\
\text { analogous to that of course-level assessment-identifying program learning goals, } \\
\text { aligning goals with the curriculum, gathering evidence of student learning, } \\
\text { interpreting the evidence, and using the evidence for improvement. A key } \\
\text { distinction between the two processes is that program-level assessment requires } \\
\text { the collective engagement of faculty during all steps in the process. }\end{array}$ \\
\hline Reliability & $\begin{array}{l}\text { How accurately a score will be reproduced if an individual is measured again. The } \\
\text { degree to which the results of an assessment are dependable and consistently } \\
\text { measure particular student knowledge and/or skills. Reliability is an indication of } \\
\text { the consistency of scores across raters, over time, or across different tasks or items } \\
\text { that measure the same thing. }\end{array}$ \\
\hline Rubrics & $\begin{array}{l}\text { Specific sets of criteria that clearly define for both student and teacher what a } \\
\text { range of acceptable and unacceptable performance looks like. Criteria define } \\
\text { descriptors of ability at each level of performance and assign values to each level. } \\
\text { Levels referred to are proficiency levels which describe a continuum from } \\
\text { excellent to unacceptable product. A commonly used format for rubrics is the } \\
\text { Primary Trait Analysis }\end{array}$ \\
\hline $\begin{array}{l}\text { Student } \\
\text { Learning }\end{array}$ & $\begin{array}{l}\text { Learning outcomes describe the learning mastered in behavioral terms at specific } \\
\text { levels. In other words, what the learner will be able to do. }\end{array}$ \\
\hline
\end{tabular}




\begin{tabular}{||l||l||}
\hline $\begin{array}{l}\text { Outcomes } \\
\text { (SLOs) }\end{array}$ & \\
\hline \hline $\begin{array}{l}\text { Summative } \\
\text { assessment }\end{array}$ & $\begin{array}{l}\text { Summative assessment involves gathering and interpreting evidence of student } \\
\text { learning at the end of a unit of study or course. Also called "assessment of } \\
\text { learning" }\end{array}$ \\
\hline \hline Validity & $\begin{array}{l}\text { The extent to which an assessment measures what it is supposed to measure and } \\
\text { the extent to which inferences and actions made on the basis of test scores are } \\
\text { appropriate and accurate. For example, if a student performs well on a } \\
\text { mathematics test, how confident are we that that student is a good mathematician? } \\
\text { An assessment cannot be valid if it is not reliable. }\end{array}$ \\
\hline \hline
\end{tabular}




\section{Appendix D - SLO Components Identification Worksheet}

Instructions: Using the discipline-specific examples of measurable SLOs, identify the Behaviors, Assessment Method /Tool, and Criteria found in the following SLOs. If components are missing, identify them.

\section{Worked Example for English:}

Measurable SLO: Upon successful completion of the course, students should be able to: analyze the relationship between the language of satire to literary form in eighteenth-century literature by correctly identifying and differentiating these elements when conducting a close examination of selected texts in a written essay.

SLO with Behavior, Assessment Method/Tool, and Criteria: Upon successful completion of this course, students should be able to (Behavior) [analyze the relationship between the language of satire to literary form in eighteenth-century literature]

(Criteria) [by correctly identifying and differentiating these elements when conducting a close examination of selected texts]

(Assessment Method /Tool) [in a written essay.]

Speech: Upon successful completion of the course, students should be able to: in an oral presentation, the student will identify persuasive appeals used by Dr. Martin Luther King in his I Have a Dream address. Examples of logos, pathos, and ethos should be identified and explained.

Behavior:

Criteria:

Assessment Method /Tool:

Mathematics: Upon successful completion of the course, students should be able to: correctly plot a quadratic equation using a graphing calculator.

Behavior:

Criteria:

Assessment Method /Tool:

Engineering: Upon successful completion of the course, students should be able to: functioning as a member of a team, students will design and present a detailed diagram for a concrete structure that complies with engineering standards.

Behavior:

Criteria:

Assessment Method /Tool: 
Philosophy: Upon successful completion of the course, students should be able to: fairly examine both sides of an argument without elements of bias by writing an argumentative composition.

Behavior:

Criteria:

Assessment Method /Tool:

English as a Second Language: Upon successful completion of the course, students should be able to: demonstrate English reading and writing competence by writing a well organized, grammatically correct paragraph in response to a reading selection.

Behavior:

Criteria:

Assessment Method /Tool:

Psychology: Upon successful completion of the course, students should be able to: through the written term paper, compare and contrast the foundational assumptions, central ideas, and dominant criticisms of the psychoanalytic, Gestalt, behaviorist, humanistic and cognitive approaches to psychology.

Behavior:

Criteria:

Assessment Method /Tool:

Engineering: Upon successful completion of the course, students should be able to: through a multi-part examination, apply the most appropriate solutions for noise and vibrations in a helicopter chassis.

Behavior:

Criteria:

Assessment Method /Tool:

Biology: Upon successful completion of the course, students should be able to: interpret and discuss research methods in biological sciences research/ design and present, in both written and oral form, a report that critiques the methodology used in a specific research study in biology.

Behavior:

Criteria:

Assessment Method /Tool: 


\section{Assessment documents / handbooks reviewed and utilized to produce this document}

Assessment cyberguide for learning goals and outcomes retrieved Dec 2012 from http://www.apa.org/ed/governance/bea/assessment-cyberguide-v2.pdf

Assessment Primer: Goals, Objectives and Outcomes Retreived Dec 2012 from http://assessment.uconn.edu/primer/goals1.html

The Assessment Tool Kit for Faculty Bresciani, M (No Date) retrieved Dec 2012 from www.ncsu.edu/assessment/old/.../assess process/assess tookit_faculty.pdf

Guidebook for New Course and Outline Revision Approval CCC Curriculum Committee 2012

How to Write Learning Objectives that Meet Demanding Behavioral Criteria Kizlik, B. Retrieved Dec 2012 from http://www.adprima.com/objectives.htm

Writing Assessable Student Learning Outcomes for Course Syllabi and the CCR Process by Stanny C. J., (2005) Retrieved Dec 2012 from http://uwf.edu/cutla/Assessres.cfm 